\title{
6. ENGINEERED SAFETY FEATURES
}

Engineered safety features are provided to witigate the consequence of postulated accidents in spite of the fact that these accidents are very unlikely. This chapter of the SAR should present information on the engineered safety features provided in the plant in sufficient detail to permit an adequate evaluation of the performance capability of these features. The information should include:

1. Descriptions of the experience, tests at simulated accident conditions, or conservative extrapolations from existing knowledge that supports the concept selection upon which the operation of the feature is based;

2. Considerations of component reliability, system interdependency, redundancy, diversity, and separation of components or portions of systems, etc., associated with ensuring that the feature will accomplish its intended purpose and will function for the period required;

3. Provisions for test, inspection, and survejllance to ensure that the feature will be dependable and effective upon demand;

4. Evidence that the material used will withstand the postulated accident environment, including radiation levels, and that radiclytic decomposition products that may occur will not interfere with it or other
engineered safety features.

The engineered safety features included in plant designs vary. The engineered safety features explicitly discussed in the sections of this chapter are those that are commonly used to limit the consequences of postulated accidents in light-water-cooled power reactors. They should be treated as illustrative of the engineered safety features that should be treated in this chapter of the SAR and of the kind of informative material that is needed. Where additional or different types of engineered safety features are used, they should be covered in a similar manner in separate added sections (see Section 6.X).

This section should identify and provide a brief summary of the types of engineered safety features provided in the plant. List each system of the plant that is considered to be an engineered safety feature.

\subsection{Engineered Safety Feature Materials}

This section should provide a discussion of the materials used in engineered safety feature (ESF) components and the material interactions that potentially could impair operation of ESF. 


\subsubsection{Metalic Materials}

6.1.1.1 Materials Selection and Fabrication. Information on the selection and fabrication of the materials in the engineered safety features (ESF) of the plant, such as the emergency core cooling system, the containment heat removal systems, and the containment air purification and cleanup systems should be provided. Include materials treated to enhance corrosion resistance, strength, hardness, etc. Materials for use in ESF should be selected for their compatibility with core and containment spray solutions as described in Section III of the ASME Boiler and Pressure Vessel Code, Articles NC-2160 and NC-3120.

1. List the specifications for the principal pressure-retaining ferritic materials, austenitic stainless steels, and nonferrous metals, including bolting and welding materials, in each component (e.g., vessels, piping, pumps, and valves) that is part of the ESF.

2. List the ESF construction materials that would be exposed to the core cooling water and containment sprays in the event of a lossof-coolant accident. Show that the construction materials are compatible with the cooling and spray solutions.

3. Provide the following information to demonstrate that the integrity of the safety-related components of the ESF will be maintained during a) stages of component manufacture and reactor construction:

a. Enough details on means for avoiding significant sensitization during fabrication and assembly of austenitic stainless steel components of the ESF to demonstrate that the degree of freedon from sensitization will be comparable to that obtainable by following the recommendations of Regulatory Guide 1.44, "Control of the Use of Sensitized Stainless Stee 1."

b. Enough details on process controls for limiting exposure of austenitic stainless steel components of the ESF to contaminants capable of causing stress-corrosion cracking to show that the degree of surface cleanliness during ail stages of component manufacture and reactor construction will be comparable to that obtainable by fol lowing the recommendations of Regulatory Guide 1.44 and Regulatory Guide 1.37. "Quaitty Assurarce Requirements for Cleaning of Fluid Systens and Associated Components of Water-Cooled Nuclear Power Plants."

c. Details on the use of cold-worked austenitic stainless steels. If such steels have yield strengths greater than 00,000 psi, provide assurance that they will be compatiole with the core cooling water and the containment sprays in the event of a loss-of-coolant accident.

d. Enough information cn the selection, procliremert, testing, storage, and installation of normetallic thermal insulation to demonstrate 
that the leachable concentrations of chloride, fluoride, sodium, and silicate are comparable to the recommendations of Regulatory Guide ?.36, "Nonmetallic Thermal Insulation for Austenitic Stainless Steel."

4. Provide enough information concerning avoidance of hot cracking (fissuring) during weld fabrication and assembly of austenitic stainless steel components of the ESF to show that the degree of weld integrity and quality will be comparable to that resulting from following the recommendations of Regulatory Guide 1.31, "Control of Ferrite Content in Stainless Steel Weld Metal." Describe plant requirements for weiding procedures and amount and method of determination of delta ferrite in weld filler metals and in production welds, etc.

6.1.1.2 Composition, Compatibility, and Stability of Containment and Core Spray Coolants. The following information relative to the composition, compatibility, and stability of the core cocling water and the containment sprays of the ESF should be provided:

1. A description of the method used for establishing and controlling the $\mathrm{pH}$ of the cooiants of the ESF during a loss-of-coolant accident to avoid stress-corrosion cracking of the austenitic stainless steel components and to avoid excessive generation of hydrogen by corrosion of containment metals. For all posiulated design basis accidents involving release of water into the containment building, estimate the time-history of the $\mathrm{pH}$ of the aqueous phase in each drainage area of the building. Identify and quantify all soluble acids and bases within the containment.

2. A description of the methods used for storing ESF coolants. Derionstrate that the coolants can be stored for extended periods without significant corrosive attack on the storage vessel.

\section{1 .2 Organic Materials}

Ident ify and quantify all organic materials that exist within the containment building in significani amounts. Such organic materials include wood, plastics, lubricants, paint or coatings, insulation, and asphalt. Plastics should be classified by ANSI Standard N4.1-1973, "Classification System for Polymeric Materiais for Services in Ionizing Radiation" (a)so designated ASTM D2953-71) and paints and other coatings by Regulatory Guide 1.54, "Quality Assurance Reouirements for Protective Coating Apjied to Water-Cooled Nuclear Power Plants." Coatings not intended for 40 -year service without overcoating should include total coating tricknesses expected to be accumulated over the ser:ice life of the substrate surface.

\subsection{Containment Systems}

\subsubsection{Containment Functiona? Design}

\subsubsection{Containment Structure}

1. Design Bases. This section shouid discuss the design bases for the containment, including tha following information:

$$
6-3
$$


a. The postulated accident conditions and the extent of simultaneous occurrences (e.g., seismic event, loss of offsite power, and single active failures) that determine the containment design pressure requirements (including both internal and external design pressure requirements) should be discussed. The maximum calculated accident pressure should be stated, and the bases for establishing the margin between this pressure and the design pressure should be discussed.

b. The postulated accident conditions and the extent of simultaneous occurrences (e.g., seismic event, loss of offsite power, and single active failures) that determine the design pressure requirements for the containment internal structures (i.e., containment subcompartments with reference to the design evaluation in Section 6.2.1.2) should be discussed. The maximum calculated accident pressures should be stated, and the bases for establishing the margin between this pressure and the design pressure should be discussed.

c. The postulated accident conditions and the extent of simultaneous occurrences (e.g., seismic event, loss of offsite power, and single active failures) that determine the design pressure requirements for the internal structures of pressure-suppression-type containments with reference to the design evaluation in item 3.c of this section should be discussed.

d. The sources and amounts of mass and energy that might be released into the containment and the postaccident time dependence of the mass and energy release should be discussed with reference to the design evaluations in Sections 6.2.1.3 and 6.2.1.4.

e. The effects of the engineered safety features as energyremoval systems in the containment should be discussed.

f. The capability for postaccident pressure reduction under various postulated single-failure conditions in the engineered safety feature equipment should be discussed.

g. The capability for energy removal from the containment under various postulated single-failure conditions in the engineered safety feature should be discussed.

$h$. The bases for establishing the containment depressurization rate should be discussed and justified with reference to the assumptions used in the analysis of the offsite radiological consequences of the accident.

i. The bases for the analys is of the minimum containment pressure used in the emergency core cooling system performance studies for PWR reactor systems should be discussed with reference to the design evaluation in Section 6.2.1.5. 
j. Other design bases peculiar to pressure-suppression-type containments should be discussed with reference to the design evaluation in item $3 . c$ of this section.

2. Design Features. This section should describe the design features of the containment structure and internal structures and should include appropriate general arrangement drawings. The following information should be included:

a. The design provisions to protect the containment structure and engineered safety feature systems against loss of function from dynamic effects (e.g., missiles and pipe whip) that could occur following postulated accidents should be discussed. Reference should be made to the detailed discussions of Chapter 3.

b. With reference to Chapter 3 , the codes, standards, and guides applied in the design of the containment structure and internal structures should be identified.

c. For pressure-suppression-type containments, describe the qualification tests that are intended to demonstrate the functional capability of the structures, systems, and components (PSAR). Discuss the status of any developmental test programs that are not complete (FSAR).

d. The design provisions to protect the containment structure against loss of integrity under external pressure loading conditions resulting from inadvertent operation of containment heat removal systems or other possible modes of plant operation that could result in significant external structural loadings should be described and the functional capability of these provisions discussed. The external design pressure of the containment and the margin between the design value and the lowest expected internal pressure should be specified.

e. Identify the locations in the containment where water may be trapped and prevented from returning to the containment sump. The quantity of water involved should be specified. Discuss how the static head for recirculation pumps may be affected. Discuss the provisions that permit the water entering such regions as the refueling canal or the upper compartment of an ice condenser containment to be drained to the containment sump.

f. Discuss the functicnal capability and frequency of operations of the systems provided to maintain the containment and subcompartment atmospheres within prescribed pressure, temperature, and humidity limits during normal plant operation (e.g., containment penetration cooling systems, containment internal ventilation systems, and containment purge systems).

3. Design Evaluation. This section should provide evaluations of the functional capability of the containment design. The information to be included depends on the type of containment being considered (i.e., 
dry containments, ice condenser containments, or BWR water pressuresuppression-type containments) as indicated below. For new types of containment designs, information of a similar nature should be provided.

tainment). Provide Dry Containment (Including Subatmospheric-Type Conto 2 spectrum of postulated reactor coolant system pipe ruptures (e.g. hot leg, cold leg (pump suction), and cold leg (pump discharge) breaks). The break size and location of each postulated loss-of-coolant accident analyzed should be specified. The pressure and temperature response of the containment and the sump water temperature response as functions of time for each accident analyzed should be graphically presented up to at least $10^{6}$ seconds after the accident, or it shculd be demonstrated that a lesser time includes ali important aspects of the transient.

Describe the method of analysis and identify the containment computer codes used to determine the pressure and temperature response.

6.2.1.3 used in the analyses.

Refer to the mass and energy release rate data in Section:

The conservatisms in the assumptions made in the analyses regarding initiai containmerit conditions* (pressure, temperature, free volume, and humidity), containment heat removal, and emergency core cooing system operability should be discussed and demonstrated.

Provide the results of a failure mode and effects analysis of the emergency core cooling systems and containment cooiing systems to determine the single active failure that maximizes the energy reiease to the containment and mirimizes containment heat removal.

and $6-2$.

Provide the types of information described in rables 6-1

Summarize and tabulate the results of each lass-of-coolant accident analyzed as shown in Table 6-3.

I

Provide analyses of the temperature and pressure response of the containment to postulated secondary system pipe ruptures (e.g., steam and feecwater line breaks). The break size and location of each postuiated break analyzed should be specified. Describe the method of anaiysis and identify the computer codes used. (Detailed mass and energy release analyses should be presented in Section 6.2.1.4.) Discliss and justify the assumptions made regarding the operating condition of the reactor, the closure times of secondary system isolation valves, and single active failures. The resultis of each accident analyzed sholilu be tabulated as shown in Table 6-3.

₹Best estimate at PSAR stage, more detailed listing at FSAR stage. 
Provide a tabulation of the siructural heat sinks within the containment in accordance with Tables 6-4A through 6-40. * With respect to the modeling of heat sinks for heat transfer calculations, provide and justify the computer mesh spacing used for the concrete, steel, and stee $1-l$ ined concrete heat sinks. Provide justification for the steelconcrete interface resistance used for the steel-lined concrete heat sinks. Provide justification for the heat transfer correlations used in the heat transfer calculations. Graphically show the condensing heat transfer coefficient as a function of time for the most severe hot leg, cold leg (pump suction), cold leg (pump discharge), and steam or feedwater line pipe breaks.

Discuss the provisions for protecting the integrity of the containment structure against the consequences of inadvertent operation of the containment heat removal systems or other systems that could result in pressures lower than the external design pressure of the containment structure. For example, if a containment vacuum relief system is provided, describe the system and show the extent to which the requirements of paragraph NE-7116 of Section III of the ASME Boiler and Pressure Vessel Code are satisfied; discuss the functional capability of the vacuum relief system. Also, discuss the administrative controls and/or electrical interlocks that would prevent such occurrences. Identify the worst single failure that could result in the inadvertent operation of the containment heat removal systems. Discuss the analytical methods and assumptions used to determine the pressure response of the containment and provide the results of analyses performed. Specify the external design pressure of the containment and setpoint for actuation of the vacuum relief system.

For the most severe reactor coolant system hot leg, cold leg (pump suction), and cold leg (pump discharge) pipe breaks, provide accident chronologies. Indicate the time of occurrence (in seconds after the break occurs) of events such as the beginning of core flood tank injection, the beginning of the ECCS injection phase, the peak containment pressure during the blowdown phase, the end of the blowdown phase, the beginning of fan-cooler operation, the beginning of the containment spray injection phase (specify the water level in the water storage tank), the peak containment pressure subsequent to the end of the blowdown phase, the end of the core reflood phase, the end of the ECCS injection phase and beginning of the recirculation phase (specify the water level in the water storage tank), the end of the containment spray injection phase (specify the water level in the water storage tank), the beginning of the containment spray recirculation phase (specify the water level in the water storage tank), the end of steam generator energy release for the post-reflood phase, and the depressurization of the containment ( 0 psig for subatmospheric containments, $50 \%$ of containmert design pressure for conventional dry containments).

*At the PSAR stage, the information requested may be provided on the basis of conservative estimates; however, at the FSAR stage, the information should be more definitive to complete the listing requested. 
For the most severe reactor coolant system pipe breaks (i.e., the most severe pipe break in the hot leg, cold leg pump discharge, and cold leg pump suction lines) and the most severe secondary coolant system pipe break, provide energy inventories that show the distribution of energy prior to the accident, at the time of peak pressure, at the end of the blowdown phase, at the end of the core reflood phase (for lossof-coolant accidents), and steam generator energy release during the postreflood phase (for loss-of-coolant accidents).

The long-term performance of the containment should be described, and the capability to depressurize and maintain a low pressure (or subatmospheric pressure) within the containment should be evaluated.

Provide an evaluation of the functional capability of the normal containment ventilation system to maintain the temperature, pressure, and humidity in the containment and subcompartments within prescribed limits, assuming various single-failure conditions. Specify the limiting containment conditions for normal plant operation. Discuss the action that will be taken if these conditions are exceeded in the containment or locally, within a subcompartment.

Describe the instrumentation provided to monitor and record the containment pressure and temperature and sump temperature during the course of an accident within the containment. Discuss the range, accuracy, and response of the instrumentation and the tests conducted to qualify the instruments for use in the postaccident containment environment. Describe the recording system provided for these instruments and the accessibility of the recorders to control room personnel during a lossof-coolant accident. Material included in Chapter 7 may be incorporated by reference.

b. Ice Condenser Containments. Provide an analysis of the pressure response of the containment to double-ended ruptures of the following high-energy lines for each control volume containing one of these lines: hot leg of reactor coolant system, cold leg of reactor coolant system, main steam line, and main feedwater line. The following information should be provided for these analyses:

(1) A graph showing the pressure response of the control volumes as functions of time for each postulated pipe break accident.

(2) A schematic diagram of the transient mass distribution (TMD) code flow network, showing all control volumes and vent flow paths used for the analys is of the particular plant design under review. Describe and justify any revisions made to the TMD code since it was reported in WCAP 8078, "Ice Condenser Containment Pressure Transient Analys is Methods," (1973).* Indicate whether the unaugmented critical flow correlation, compressibility factor " $Y$, " and the heat transfer correlation developed

₹Avallable for inspection and copying for a fee at the NRC Public Document Room, 1717 H Street, N.W., Washington, D.C. 
from the 1974 full scale ice condenser tests reported in WCAP 8110, Supplements 6 and 7, "Test Plans and Results for the Ice Condenser System," are used in the TMD analysis.

(3) A table itemizing the volume of each control volume, the area of each vent flow path, the initial conditions for each control volume, the length of each vent flow path, the vent flow path resistances and loss coefficients, and the mass of ice, ice bed heat transfer area, and ELJAC number (condensate layer length) for each ice condenser control volume.

(4) A table comparing the maximum calculated differential pressure with the design pressure for each control volume or subcompartment. Identify the pipe break that yields the maximum calculated differential pressure for each control volume or subcompartment.

(5) The moment of inertia of the ice condenser lower inlet door, intermediate deck door, and top deck door, as well as a curve showing the flow proportioning spring force of the lower inlet door vs the door position.

(6) The types of information identified in Tables 6-2, 6-4, and 6-5, as appropriate.

Describe the ice condenser components and discuss the test programs that have been conducted to qualify the components for use in the ice condenser. If the design of components has not changed from those previously reported and accepted by the staff, the documents containing the appropriate information should be referenced. Identify all components whose designs have been changed from the design found acceptable by the staff. Describe and document the results of tests and analyses performed to qualify the new design for use in the ice condenser.

Provide an analysis of the expected reduction in the mass of ice due to sublimation during normal plant operation. Discuss the effects on the ice condenser condensing capability during a loss-of-coolant accident.

Describe the computer code (LOTIC or equivalent) used for long-term containment response analysis. Discuss and justify any changes in the mathematical models and assumptions utilized in the code relative to those utilized in previous analysis.

For the design basis accident long-term containment transient response, provide graphs from the LOTIC analysis showing the following containment parameters as functions of time:

(1) Containment pressure

compartments

(2) Temperatures of the atmosphere in the upper and lower 
(3) Temperatures in the active and inactive sumps

(4) Containment spray temperature

Also provide energy distribution tables for the following events:

(1) Energy distribution at initiation

(2) End of blowdown

(3) End of reflood

release

(4) Completion of post-refiood steam generator energy

(5) Completion of ice meltout

(6) Time of peak containment pressure

The tables should include the following energy sources: reactor coolant, accumulators, core stored energy, thick metal of reactor coclant system, thin metal of reactor coolant system, steam generator secondary-side fluid, and steam generator metal and the following sinks (best estimate at PSAR stage; more detailed assessment at FSAR stage): ice, structural heat sinks, spray heat exchangers, active sump, and inactive sump.

A sump model that incorporates active and inactive volumes has been utilized in the LOTIC computer code to simulate sump level and temperature history following an accident. To ensure that sufficient cooling water may be retained in the active containment sump for long-term cooling of the core and operation of the containment spray system, the foltowing
information should be provided:

(1) The capacities of the active and inactive sumps;

(2) The methods and accuracy with which the capacities of the sumps are calculated; and

a LOCA.

(3) The time required to fill the active sump following

Provide analyses of the temperature and pressure response of the containment to postulated secondary system pipe ruptures (e.g., steam and feedwater line breaks). The break size and location of each postulated break analyzed should be specified. Describe the method of analysis and identify the computer codes used. (Detailed mass and energy release analyses should be presented in Section 6.2.1.4.) Discuss and justify the assumptions made regarding the operating condition of the reactor, the closure times of secondary system isolation valves, and single active failures. The results of each accident analyzed should be tabulated as shown in Table 6-3. 
Discuss the manner whereby containment spray water will be returned from the upper containment to the lower compartment following a LOCA. The following information should be provided:

(1) A detailed description of the flow path by which the spray water will be abie to drain back to the sump;

(2) The number and size of the drain holes;

adequately sized;

(3) An analysis demonstrating that the drain holes are

and

(4) Drawings to show the arrangement of the drain holes;

(5) The adminstrative control to ensure that the drain holes are open during normal operation (FSAR). ing information:

Describe the air return fan system, and provide the followreturn fans;

(1) The initiating time and the basis for sizing the air

(2) An analysis or test to demonstrate that the back draft dampers provided at the air return fan discharges have been adequately designed to withstand the dynamic force and the differential pressure across the divider deck;

(3) Fan performance curves;

(4) Analyses to show that the air return fans have sufficient head to overcome the divider barrier differential pressure;

and

(5) Process and instrumentation diagrams of the system;

(6) The safety class of the system.

Describe the hydrogen skimmer system, and provide the following information:

(1) Bases and assumptions used for establishing the compartment flow rates and initiating time for the hydrogen skimmer fans;

(2) Process and instrumentation diagrams of the system;

(3) Safety class of the system; 


\section{(4) Fan performance curves; and}

(5) An analysis to demonstrate that the components and ducting have been adequately designed to withstand the dynamic forces and differential pressures resulting from a LOCA.

Describe the containment vacuum relief system by providing the following information:

(1) A description of the system proposed to mitigate the consequences of inadvertent operation of the containment sprays and return air fans. Show the extent to which the requirements of paragraph NE-7116 of Section III of the ASME Boiler and Pressure Vessel Code (at least two independent relief devices) are satisfied.

(2) The worst single failure that could result in inadvertent operation of the sprays and fans.

shell.

(3) The maximum external design pressure of the containment

(4) The analytical methods and assumptions used to determine the containment response to inadvertent operation of the sprays and fans.

(5) The results of analyses performed to determine the response of the containment to inadvertent operation of the sprays and fans both with and without operation of the vacuum relief system.

Describe the analytical methods and results used to establish the "external" design pressure of the internal structures (e.g., reverse pressure differentials on the operating deck and crane wali). Assumed depressurization rates in the lower compartment should be identified and justified.

Provide a table of maximum allowable operating deck bypass area as a function of reactor coolant system break size for a spectrum of break sizes up to a double-ended rupture of the largest reactor coolant system pipe. Describe the analytical methods used to determine these areas and demonstrate the conservatism in the assumptions used in the analyses. Identify all potential steam bypass leak paths and describe the design provisions taken to limit steam bypass leakage.

Discuss the potential for maldistribution of flow through the ice condenser (i.e., flow "channeling" through the ice condenser) and the effect on containment pressure response.

Discuss the design provisions made to preclude the direct impingement of a stream of fluid from high-energy lines in the lower compartment upon the ice condenser lower inlet doors. 
Provide an evaluation of the functional capability of the normal containment ventilation system to maintain the temperature, pressure, and humidity in the containment and subcompartments within prescribed limits, assuming various single-failure conditions. Specify the maximum allowable containment conditions for normal plant operation. Discuss the action that will be taken if these conditions are exceeded in the containment or locally, within a subcompartment.

Provide a curve that shows the minimum containment pressure transient used in the analysis of the emergency core cooling system. Show that the containment pressure is conservatively low by describing the conservatism in the assumptions of initial containment conditions, in the modeling of the containment heat sinks, heat transfer coefficients to the heat sinks, and any other input parameter used in the containment pressure analysis. Discuss the effect of ice condenser drain water as an additional heat sink in the lower compartment and how this effect is considered in the containment pressure calculation. Identify the computer code and/or other analytical methods used to determine the minimum containment pressure transient and describe any code revisions made after the 1975 staff review of the Westinghouse ECCS evaluation model. Provide graphs showing, as functions of time, (a) the pressure, temperature, and steam condensation rates in the containment upper and lower compartments, (b) the mass and energy release rates to the containment lower compartment, (c) the containment sump temperature, and (d) the air (or vapor) flow rate between upper and lower compartments and the direction of flow.

Describe the instrumentation provided to monitor and record the containment pressure and temperature and sump temperature during the course of an accident within the containment. Discuss the range, accuracy, and response of the instrumentation and the tests conducted to qual ify the instruments for use in the postaccident containment environment. Describe the recording system provided for these instruments and the accessibility of the recorders to control room personnel during a loss-ofcoolant accident. Material included in Chapter 7 may be incorporated by reference.

Discuss the design provisions for monitoring the status of the ice condenser during plant operation. Discuss the ice condenser design provisions that will allow inspection and functional testing of such ice condenser components as the ice bed temperature instrumentation system; lower inlet door position monitoring system; lower, intermediate, and top deck doors; floor drains; ice condenser flow passages; divider barrier seals; refueling canal drains; and operating deck access hatches. Describe the design provisions and equipment provided to allow weighing of each ice basket.

c. BWR Containments. Provide the types of containment design information identified in Tables 6-6 and 6-7. 
For Mark II containments, provide the results of analyses of the pressure response of the drywell and suppression chamber to a postulated rupture of the recirculation line. For Mark III containments, provide the results of analyses of the pressure response of the drywell, wetwell (that volume between the suppression pool surface and hydraulic control unit floor in the containment), and containment to postulated ruptures of the main steam line and recirculation line. Specify and justify the assumptions used in the analyses regarding the initial containment conditions, initial reactor operating conditions, energy sources, mass and energy release rates, and break areas. Graphically show the drywell pressure, wetwel1. pressure (Mark III), containment pressure, and deck differential pressure (Mark II) as functions of time and energy addition (e.g., blowdown, decay heat, sensible heat, pump heat) and energy removal (e.g., the RHR system, heat sinks) as a function of time.

For Mark III containments, provide the results of analyses of the pressure response of the containment and drywell to postulated ruptures of unguarded high-energy lines located in the containment. Specify and justify the assumptions used in the analyses. Describe the provisions for orificing and/or leak detection and isolation to limit the mass and energy released. Discuss the functional capability of these provisions. Grapiically show the containment and drywell pressure and temperature as functions of time. Tabulate the blowdown data (time, mass flow, and enthalpy) for each pipe break analyzed.

The following tables should be provided:

(1) The initial reactor coolant system and containment conditions as identified in Table 6-8.

(2) Energy source information as identified in Table 6-9.

(3) The mass and energy release data in the format given in Table 6-10 for each pipe break accident analyzed.

(4) The information identified in Table 6-11 on the passive heat sinks* that may have been used.

(5) The results of the postulated pipe break accidents for each postulated line break in the format given in Table 6-12.

Provide the results of analyses of the transients that could lead to external pressure loads on the drywell and containment (suppression chamber). In addition, for Mark II containments provide the results of analyses of the transients that could lead to upward differential pressure loads on the drywell deck. Show that the transient used for design purposes

Provide best estimate of heat sink data at the PSAR stage; provide a more detailed listing of the "as built" heat sinks at the FSAR stage. 
in each case is the controlling event for external pressure loading. Discuss and demonstrate the consarvatism in the assumptions used in the analysis. Graphically show the containment (suppression chamber) and drywell pressures as functions of time. If a vacuum relief system is provided, describe the system and show the extent to which the requirements of paragraph NE-7116 of Section III of the ASME Boiler and Pressure Vessel Code are satisfied. Discuss the functional capability of the system. Provide the design and performance parameters for the vacuum relief devices.

Provide the results of analyses of the capability of the containment to tolerate direct steam bypass of the suppression pool for the spectrum of potential reactor coolant system break sizes. Discuss what measures are planned to minimize the potential for steam bypassing, and describe any systems provided to mitigate the consequences of steam bypass. Discuss and demonstrate the conservatism in the assumptions used in the analysis.

Describe the manner in which suppressicn pool dynamic loads resulting from postulated loss-of-coolant accidents, transients (e.g. relieí valve actuation), and seismic events have been integrated into the affected containment structures. Provide large-size plan and section drawings of the containment illustrating all equipment and structural surfaces that could be subjected to poo? dynamic loads. For each structure or group of structures, specify the dynamic loads as a funcition of time, and specify the relative magnitude of the pool dynamic load compared to the design basis load for each structure. Provide justification for each of the dynamic load histories by the use of appropriate experimental data and/or analyses.

Describe the manner by which potential asymmetric loads were considered in the containment design. Characterize the iype and magnitude of possible asymmetric loads and the capabilities of the affected structures to withstand such a loading profile. Include consideration. of seismically induced pool motion that could lead to locally deeper submergences for certain drywell to wetwell vents.

Discuss in detail the analytical models that were used to evaluate the containment and drywe 11 responses to the postulated accidents and transients identified above. Discuss the conservatism in the models and the assumptions used. Refer to applicable test data to support the selected analytical methods. Discuss the sensitivity of the analyses to changes in key parameters.

Provida an evaluation of the functional sapability of the normal containment ventilation system to maintain the temperature, pressure, and humidity in the containment and subcompartments within prescribed limits, for various assumed single-failure conditions. Specify the maximum allowable containnent conditions for normal plant operation. Discuss the action that will be taken. if these conditions are exceeded in the containment or loca!iy, within a subcompartment. 
Describe the instrumentation provided to monitor and record the containment pressure and temperature and sump temperature during the course of an accident within the containment. Discuss the range, accuracy, and response of the instrumentation and the tests conducted to qualify the instruments for use in the postaccident containment environment. Describe the recording system provided for these instruments and the accessibility of the recorders to control room personnel during a loss-of-coolant accident. Material included in Chapter 7 may be incorporated by reference.

\subsubsection{Containment Subcompartments}

1. Design Bases. This section should discuss the bases for the design of the containment subcompartments. The following information should be included:

a. A synopsis of the pipe break analyses performed and a justification for the selection of the design basis accident (break size and location) for each containment subcompartment,

b. The extent to which pipe restraints are used to limit the break area of pipe ruptures, and

c. The margin applied to calculated differential pressures for use in the structural design of the subcompartment walls and equipment supports.

2. Design Features. This section should provide descriptions of each subcompartment analyzed, including plan and elevation drawings showing component and equipment locations, the routing of high energy lines, and the vent locations and configurations. The subcompartment free volumes and vent areas should be tabulated (best estimate at PSAR stage; more detajled listing at FSAR stage). In addition, vent areas that become available only after the occurrence of a postulated pipe break accident (e.g., as a result of insulation collapsing or blowing out, blowout panels being blown out, or hinged doors swinging open) should be identified and the manner in which they are treated described. The availability of these vent areas should be justified. Dynamic analyses of the available vent area as a function of time should be provided and supported by appropriate test data.

3. Design Evaluation. This section should identify the computer program(s) used, and/or should present a detailed description of the analytical model, for subcompartment pressure response analyses. The results of the analyses should also be presented. The following information should be included:

a. A description of the computer program used to calculate the mass and energy release from a postulated pipe break. Provide the nodalization scheme for the system model, and specify the assumed initial operating conditions of the system. Discuss the conservatism of the blowdown model with respect to the pressure response of the subcompartment. 
If the computer code being used has not been previously reviewed by the staff, provide a comparison of the blowdown to that predicted by an accepted code as justification of its acceptability.

b. The assumed initial operating conditions of the plant such as reactor power level and subcompartment pressure, temperature, and humidity.

c. A description of and justification of the subsonic and sonic flow models used in vent flow calculations. The degree of entrainment assumed for the vent mixture should also be discussed and justified.

d. The piping system within a subcompartment that is assumed to rupture, the location of the break within the subcompartment, and the break size. Give the inside diameter of the rupture of line and the location and size of any flow restrictions within the line postulated to fail.

e. The subcompartment nodalization information in accordance with the formats of Figure 6-1 and Tables 6-13 and 6-14. Demonstrate that the selected nodalization maximizes the differential pressures as a basis for establisting the design pressures for the structures and component supports.

f. Graphs of the pressure responses of all subnodes within a subcompartment as functions of time to permit evaluations of the effect on structures and component supports.

g. The mass and energy release data for the postulated pipe breaks in tabular form, with time in seconds, mass release rate in $1 \mathrm{bm} / \mathrm{sec}$, enthalpy of mass released in $B t u / 1 \mathrm{bm}$, and energy release rate in $\mathrm{Btu} / \mathrm{sec}$. A minimum of 20 data points should be used from time zero to the time of peak pressure. The mass and energy release data should be given for at least the first three seconds.

h. For all vent flow paths, the flow conditions (subsonic or sonic) up to the time of peak pressure.

i. A detailed description of the method used to determine vent loss coefficients. Provide a tabulation of the vent paths for each subcompartment and the loss coefficients.

\subsubsection{Mass and Energy Release Analyses for Postulated Loss-of-} Coolant Accidents. This section should identify the computer codes used and/or present a detailed description of the analytical models employed to calculate the mass and energy released following a postulated loss-ofcoolant accident. Various reactor coolant system pipe break locations (e.g., hot leg, cold leg pump suction, and cold leg pump discharge) and a spectrum of pipe break sizes at each location should be analyzed to ensure that the most severe pipe break location and size (i.e., the design basis loss-of-coolant accident) has been identified. The discussion should be divided into the accident phases in which different physical processes occur, as follows: 
1. The blawdown phase (i.e., when the primary coolant is being rapidly injected into the containment);

2. The core reflood phase (i.e., when the core is being re-covered with water); and

3. The long-term cooling phase (i.e., when core decay heat and the remaining stored energy in the primary and secondary systems are being added to the containment).

The following information should be included:

1. Mass and Energy Release Data. For each break location, mass and energy release data should be provided for the most severe break size during the first 24 hours following the accident. (If a shorter time period is selected for some accidents, justification should be provided.) This information should be presented in tabular form, with time in seconds, mass release rate in $1 \mathrm{bm} /$ second, and enthalpy of mass released in $B t u / 1 \mathrm{bm}$. The table format is shown in Table 6-15. The safety injection fluid that is assumed to spill from the break directly to the containment floor should aiso be tabulated as a function of time.

2. Energy Sources. The sources of generated and stored energy in the reactor coolant system and secondary coolant system that are considered in anaiyses of ioss-of-coolant accidents should be identified, and the methods used and assumptions made in calculations of the energy available for release from these sources should be described. The conservatism in the calculation of the available energy for each source should be addressed. The stcred energy sources and the amounts of stored energy should be tabulated. For the sources of generated energy, curves showing the energy release rates and integrated energy released should be provided.

3. Description of Blowdown Model. The calculationai procedure for determining the mass and energy released from the reactor coolant system during the blowdown phase of a loss-of-coolant accident should be described in detail or referenced as appropriate. The description should include all significant equations and correlations used in the analysis. The conservatism in the mass and energy release calculations from the standpoint of predicting the highest containment pressure response should be discussed and demonstrated. For example, caiculations of the energy transferred to the primary coolant from heated surfaces and the release of primary coclant to the containment during blowdown should be described and justified. Also, the heat transfer correlations used should be presented and their application justified.

4. Description of Core Reflood Model. The calculational procedure for determining the mass and energy released to the containment during the core reflood phase of a loss-of-coulant accident shouid be described or referred to as appropriate. The descriftion should include all significant equations and correlations used in the analys is. The conservatism in the mass and energy release calculations from the standpoint of predicting 
the highest containment pressure response should be discussed and justified. For example, the methods of calculating the energy transferred to the emergency core cooling injection water from primary system metal surfaces and the core, the core inlet flow rate, the core exit flow rate, and the energy transferred from the steam generators should be discussed and justified. The carryout fraction used to predict the mass flow rate out of the core should be justified by comparison to experimental data such as that from the FLECHT experiments. Any assumptions made regarding the quenching of steam by ECCS injection water should be justified by comparison to appropriate experimental data. The carryout fractions, core inlet flow rate, and core inlet temperature should be provided as a function of time.

5. Description of Long-Term Cooling Model. The calculational procedure for determining the mass and energy released to the containment during the long-term cooling (or post-reflood) phase of a loss-of-coolant accident should be described or referenced as appropriate. The description should include all significant equations and correlations used in the analysis. The conservatism in the mass and energy release calculations from the standpoint of predicting the highest containment pressure response should be discussed and justified. For example, the methods of calculating (1) the core inlet and exit flow rates and (2) the removal of all sensible heat from primary system metal surfaces and the steam generators should be discussed and justified. Heat transfer correlations used should be described and their application justified. Liquid entrainment correlations for fluid leaving the core and entering the steam generators should be described and justified by comparison with experimental data. Experimenta? data should be provided to justify any assumptions made regarding steam quenching by ECCS water.

E. Single Failure Analysis. Provide a failure mode and effects analysis of the emergency core cooling systems to determine the single active failure that results in maximizing the energy release to the containment following a loss-of-coolant accident. This analysis should be done for each postulated break location.

7. Metal-water Reaction. Discuss the potential for additional energy being added to the containment 35 a result of metal-water reaciion within the core. Provide a conservative analysis of the containment pressure as a function of metal-water reaction eriergy adcition, and demonstrate that the metal-water reaction time is conservative.

8. Energy inventories. For the worst hot ieg, cold leg pump suction, and cold leg pump discharge pipe treaks, provide inventories of the energy transferred from the primary and secondary syscems to the coritainment and the energy remaining in the primary and secondary systems. The table format is shown in Table 6-16.

9. Additional Information Reguired for Confirmetory Analysis. To permit confirmatory analyses to be performed, the following information should be tabulated: the eievations, flow areas, and friction coefficients 
within the primary system that are used for the containment analyses and the safety injection flow rate as a function of time. Representative values with justification should be provided for empirical correlations (such as those used to predict heat transfer and liquid entrainment) that are significant to the analysis.

6.2.1.4 Mass and Energy Release Analys is for Postulated Secondary System Pipe Ruptures Inside Containment (PWR) This section should identify the computer code used and/or present a detailed description of the analytical model used to calculate the mass and energy released following a secondary system steam or feedwater line break. A spectrum of break sizes and various reactor operating conditions should be analyzed to ensure that the most severe secondary system pipe rupture has been identified. Smaller and smaller break areas of steam 1 ine breaks should be considered starting with the double-ended rupture, until no liquid entrainment is calculated to occur. The following information should be included:

1. Mass and Energy Release Data. Mass and energy release data for the most severe secondary system pipe rupture with regard to break size and location and operating power level of the reactor should be presented in tabular form with time in seconds, mass flow rate in $1 \mathrm{bm} / \mathrm{sec}$, and corresponding enthalpy in Btu/ $\mathrm{bm}$. Separate tables should be provided for the mass and energy released from each side of a double-ended break.

2. Single-Failure Analysis. A failure mode and effects analys is should be performed to determine the most severe single active failure for each break location for the purpose of maximizing the mass and energy released to the containment and the containment pressure response. The analysis should consider, for example, the failure of a steam or feedwater line isolation valve, the feedwater pump to trip, and containment heat removal equipment.

3. Initial Conditions. The analysis, including assumptions, to determine the fluid mass available for release into the containment should be described. In general, the analysis should be done in a manner that is conservative from a containment response standpoint (i.e., that maximizes the fluid mass available for release).

4. Description of Blowdown Model. The computer code used should be identified, and the calculational procedure should be described in detail or referenced to the appropriate topical report. All significant equations solved should be provided. Calculations of the energy transferred from the primary system to the secondary system, the stored energy removed from the secondary system metal, the break flow, and the steam-water separation should be conservative for containment analysis. This conservatism should be discussed and justified. The heat transfer correlations used to calculate the heat transferred from the steam generator tubes and shell should be presented and their application justified. If liquid entrainment is assumed in the break flow, appropriate experimental data should be provided. 
5. Energy Inventories. For the most severe secondary system pipe rupture, inventories of the energy transferred from the primary and secondary systems to the containment should be provided. The distribution of the mass and energy released and available for release and the fluid and component temperatures within the primary and secondary systems and the containment should be given. Values should be provided for prerupture conditions, for the time of peak pressure, for the end of blowdown, and for any time a different computer code or calculational method is used in the analysis.

6. Additional Information Required for Confirmatory Analyses. To permit confirmatory analyses to be performed, the following information should be tabulated: the elevations, flow areas, and friction coefficients within the secondary system and the feedwater flow rate as a function of time. Representative values with justification should be provided for empirical correlations (such as those used to predict heat transfer and liquid entrainment) that are significant to the analysis.

6.2.1.5 Minimum Containment Pressure Analysis for Performance Capability Studies on Emergency Core Cooiing System (PWR). This section should identify the computer codes used or present detailed descriptions of the analytical models used to calculate (1) the mass and energy released from the reactor coolant system following a postulated loss-of-coolant accident and (2) the containment pressure response for the purpose of determining the minimum containment pressure that should be used in analyzing the effectiveness of the emergency core cooling system. The response of the containment pressure and temperature and the sump water temperature should be platted as functions of time. The information provided at the PSAR stage should be based on conservative values; however, as the design and construction of the facility nears completion (FSAR), more definitive data should be provided. The following information should be presented:

1. Mass and Energy Release Data. For the most severe break, state the size of the break and provide the mass and energy release data used for the minimum containment pressure analysis. This information should be presented in tabular form, with time in seconds, mass release rate in $\mathrm{lbm} / \mathrm{sec}$, and enthalpy of mass released in Btu/lbm. The quantity of safety injection fluid that is assumed to spill from the break directly to the containment floor should also be tabulated as a function of time. Discuss the conservatism in the mass and energy release analys is with regard to minimizing the containment pressure.

2. Initial Containment Internal Conditions. Specify the initial containment conditions assumed in the analysis (i.e., temperature, pressure, and humidity). Show that the initial conditions selected are conservative with respect to minimizing the containment pressure.

3. Containment Volume. Specify the assumed containment net free volume. Show that the estimated free volume of the containment has been maximized to ensure a conservative prediction of the minimum containment pressure. Discuss the uncertainty in determining the volume of the 
internal structures and equipment that should be subtracted from the gross containment volume to arrive at the net free volume.

4. Active Heat Sinks. Identify the containment heat removal system and emergency core cooling system equipment that is assumed to be operative for the containment analysis. Discuss the conservatism of this assumption with respect to minimizing the containment pressure. The heat removal capacity of the engineered safeguards should be maximized by using the minimum temperature of stored water and c0oling water and minimum delay times in bringing the equipment into service. Provide a figure or table showing the heat removal rate of fan cooling units as a function of containment temperature. State the containment spray flow rate and temperature assumed for the containment minimum pressure analysis. State the assumotions used in establishing the actuation times for the active heat removal systems.

5. Steam-Water Mixing. Discuss the potential for the mixing and condensation of containment steam with any spilled ECCS water during blowdown and core reflood. Comparisons with appropriate experimental data should be presented.

6. Passive Heat Sinks. With regard to the heat sink data given in Table $6-4 A, 6-4 B, 6-4 C$, and $6-40$, the uncertainty in accounting for heat sinks and in determining the heat sink parameters (such as mass, surface area, thickness, volumetric heat capacity, and thermal conductivity) should be discussed.

7. Heat Transfer To Passive Heat Sinks. The condensing heat transfer coefficients between the containment atmosphere and passive heat sinks should be discussed and justified. Comparisons with appropriate experimental data should be presented. Graphicaliy show the condensing heat transfer coefficient as a function of time for the passive heat sinks.

8. Other Parameters. Identify any other parameters that may have a substantial effect on the minimum containment pressure analysis, and discuss how they affect the analysis. If the containment purge system is used during plant power operations, discuss the effect of a LOCA during the plant purge operation on the minimum containment pressure analysis. The radiological consequences of a LOCA during containment purge should be discussed in Chapter 15.

6.2.1.6 Testing and Inspection. This section should provide information about the coniainnent testing and inspection program, with regard tc preoperational testing and periodic inservice surveiliance to ensure the functional capability of the containment and associated structures, systems, and components. Emphasis should be given to those tests and inspections considered essential to a determination that performance objectives have been achieved and performance capability is being maintained throughout the plant lifetime above preestablished limits. Such tests may inciude, for example, tests to determine that the ice condenser or suppression pool bypass leakage area is within allowable limits, 
operability tests of the air return fan system of an ice condenser containment, inspection for serviceability of the drain holes provided in the operating deck of an ice condenser containment for returning spray water in the upper compartment to the lower compartment, inspection of the ice condenser (including the condition of the ice beds and operability tests of components important to the ice condenser functional capability), and operability tests of vacuum relief systems and of mechanical devices that are required to open foilowing a pipe break accident within a subcompartment to provide vent area. The information provided in this section should include, for example (FSAR):

1. The planned tests and inspections, including a discussion of the need and purpose of each test and inspection,

2. The selected frequency for performing each test and inspection, including justification, be conducted,

3. A description of the manner in which tests and inspections will

4. The requirements and bases for acceptability, and

5. The action to be taken in the event acceptability requirements are not met.

Particular emphasis should be given to those surveillance type tests that are of such importance to safety that they may become a part of the technical specifications of an operating license. The bases for such surveillance requirements should be discussed.

6.2.i.7 Instrumentation Requirements. This section shouid discuss the instrumentation to be employed for monitoring the containment conditions and actuating those systems and components having a safety function. Design details and logic of the instrumentation should be discussed in Chapter 7 of the SAR.

\subsubsection{Containment Heat Removal Systems.}

General Design Criterion 38, "Containment Heat Removal," of Appendix A, "General Design Criteria for Nuclear Power Plants," to 10 CFR Part 50 requires that systems to remove heat from the reactor containment be provided to rapidly reduce (consistent with the functioning of other associated systems) the containment pressure and temperature following a loss-of-coolant accident and to maintain them at acceptably low levels. General Design Criteria 39 and 40 require that the containment heat removal systems be designed to permit appropriate periodic inspection and testing to ensure the integrity and operability of the systems. The systems provided for containment heat removal include fan cooler and spray systems. The design and functional capability of these systems shouid be considered in this section. The design and heat removal capability of the pressuresuppression containments should be considered in Section 6.2.l. 
General Design Criterion 41 requires that systems to control fission products that may be released to the containment be provided as necessary to reduce, consistent with the functioning of other associated systems, the concentration and quantity of fission products released to the environs following postulated accidents. The systems designed for containment heat removal may also possess the capability to meet this requirement. The fission product removal effectiveness of the containment heat removal systems should be considered in Section 6.5.2 of the SAR.

6.2.2.1 Design Bases. Discuss the design bases for the containment heat removal systems (i.e., the functional and mechanical and electrical design requirements of the systems). The design bases should include such considerations as:

1. The sources of energy, the energy release rates as a function of time, and the integrated energy released following postulated loss-ofcoolant accidents for sizing each heat removal system;

2. The extent to which operation of the heat removal systems is relied upon to attenuate the postaccident conditions imposed on the containment (i.e., the minimum required availability of the containment heat removal systems);

3. The required containment depressurization time;

4. The capability to remain operable in the accident environment;

5. The capability to remain operable assuming a single failure;

6. The capability to withstand the Safe Shutdown Earthquake without loss of function;

7. The capability to withstand dynamic effects; and

8. The capability for periodic inspection and testing of the systems and/or system components.

6.2.2.2 System Design. Describe the design features, and provide piping and instrumentation diagrams of the containment heat removal systems. Provide a tabulation of the design and performance data for each containment heat removal system and its components.

Discuss system design requirements for redundancy and independence to ensure single-failure protection.

Discuss the system design provisions that facilitate periodic inspection and operability testing of the systems and system components.

Identify the codes, standards, and guides applied in the design of the containment heat removal systems and system components. 
Specify the plant protection system signals and setpoints that actuate the containment heat removal system; alternatively, reference the section in the SAR where this information is tabulated. Provide the rationale for selecting the actuation signals and establishing the
setpoints.

Specify the times following postulated accidents that the containment heat removal systems are assumed to be fully operational. Discuss the delay times following receipt of the system actuation signals that are inherent in bringing the systems into service.

Discuss the extent to which the containment heat removal systems and system components are required to be remote manually operated from the main control room and the extent of operator intervention in the
operation of the systems.

Describe the qualification tests that have been or will be performed on system components, such as spray nozzles, fan cooler heat exchangers, recirculation heat exchangers, pump and fan motors, valves, valve operators, and instrumentation. Discuss the test results. Demonstrate that the water $\mathrm{pH}$ ) are representations (temperature, pressure, humidity, radiation, would be expected tontative of postaccident conditions that the equipment test conditions as a function of time. Graphically show the environmental where this information can be found.

With respect to the fan systems, provide the following additional information:

1. Identify the ductwork and equipment housings that must remain intact following a loss-of-coolant accident;

2. Discuss the design provisions (e.g., pressure relief devices, conservative structural design) that ensure that the ductwork and equipment
housings will remain intact; and

3. Provide plan and elevation drawings of the containment showing the routing of airflow guidance ductwork.

Describe the design features of the recirculation intake structures (sumps). Provide plan and elevation drawings of the structures; show the level of water in the containment following a loss-of-coolant accident in relation to the structures. Compare the design of the recirculation intake structures to the positions in. Regulatory Guide 1.82, "Sumps for Emergency Core Cooling and Containment Spray Systems."

Specify the mesh size of each stage of screening and the maximum particle size that could be drawn into the recirculation piping. of the systems that receive or may receive water from the recirculation intake structures under postaccident conditions, identify the system component that places the limiting requirement on the maximum particle size of debris 
that may be allowed to pass throligh the intake structure screening and specify the limiting particle size that the component can circulate without impairing system performance. Describe how the screening is attached to the intake structures to preclude the possibility of debris bypassing the screening.

Discuss the potential for the intake structure screening to become clogged with debris; e.g., insulation, in the light of the effective flow area of the screening and approach velocity of the water. Identify and discuss the kinds of debris that might be developed following a loss-ofcoolant accident. Consider the following potential sources of debris:

1. Piping and equipment insulation,

2. Sand plug materials,

3. All structures displaced by accident pressure to provide vent area,

4. Loose insulation in the containment,

5. Debris generated by failure of non-safety-related equipment.

Describe the precautions made to minimize the potential for debris clogging the screens.

Discuss the types of insulation used inside the contairment and identify where and in what quantities each type is used. List the materials of construction used for the identified insulation and describe the behavior of the insulation during and after a loss-of-coolant accident. Describe the tests performed or reference test reports available to the Commission that determined the behavior of the insulation under simulated LOCA conditions. Describe the methods of attaching the insulation to piping and components.

5.2.2.3 Design Evaluation. Describe and present the results of the spray nozzle test program to determine the drop size spectrum and mean drop size emitted from each type of nozzle as a function of pressure drop across the nozzles. Describe the analytical method employed to determine the mean spray drop size.

Provide plan and elevation drawings of the containment showing the expected spray patterns. Specify the volume of the containnent covered by the sprays and the extent of overlapping of the sprays. Provide an analys is of the heat removal effectiveness of the sprays. Provide justification for the values of parameters used in the anaiys is (e.g., spray system flow rate as a function of time and mean spray drop size) for both full and partial spray system operation.

Graphically show the heat removal rate of the fan cooler as a function of the containment atmosphere temperature under loss-of-coolant accident conditions. Provide a figure showing the fan cooler heat removal rate as a function of the degrees of superheat for a family of curves that 
bound the expected containment steam-to-air ratio for the main steam line break accident. Describe the test program conducted to determine the heat removal capability of a fan cooler heat exchanger. Discuss the potential for surface fouling on the secondary side of the fan cooler heat exchanger by the cooling water and the effect on the heat removal capabiiity of the fan cooler.

Provide analyses of the net positive suction head (NPSH) available to the recirculation pumps in accordance with the recommendations of NRC Regulatory Guide 1.1 (Safety Guide 1), "Net Positive Suction Head for Emergency Core Cooling and Containment Heat Removal System Pumps. "Provide a tabulation of the values of containment pressure head, vapor pressure head of pumped fluid, suction head, and friction head used in the analyses. Discuss the uncertainty in determining the suction head. Compare the calculated values of available NPSH for the recirculation pumps to the required NPSH of the pumps. Demonstrate the conservatism of the analyses by assuming, for the postulated loss-of-coolant accident, conditions that maximize the sump temperature and minimize the containment pressure.

Provide failure mode and effects analyses of the containment heat removal systems.

Graphicaliy show the integrated energy content of the containment atmosphere and recirculation water as functions of time following the postulated design basis loss-of-coolant accident. Graphically show the integrated eriergy absorbed by the structural heat sinks and removed by the fan cooler and/or recirculation heat exchangers.

Provide an estimate of the amount of debris that could be generated during a loss-of-coolant accident and of the amount of debris to which sump inlet screens may be subjected during postulated pipe break accidents.

6.2.2.4 Tests and Inspections. Describe the program for the initia? performance testing after installation and for subsequent periodic operability testing of the containment heat removal systems and system components. Discuss the scope and limitations of the tests. Describe the periodic
inspection program for the systems arid system components. The results of tests performed and a detailed, updated testing program should be provided in the FSAR.

6.2.2.5 Instrumentation Requirements. Describe the instrumentation provisions for actuating and monitoring the performance of the containment heat removal systems and sysiem components. Identify the plant conditions and system operating parameters to be monitored and justify the selection of the setpoints for system actuation or alarm annunciation. Specify the locations outside the containment for instrumentation readicut and alarm. The design details and logic of the instrumentation should be discussed in Chapter 7 of tine SAR. 


\subsubsection{Secondary Containment Functional Design}

The secondary containment system includes the secondary containment structure and the safety-related systems provided to control the ventilation and cleanup of potentially contaminated volumes (exclusive of the primary containment) following a design basis accident. This section will discuss the secondary containment functional design. The vertilation systems (i.e., systems used to depressurize and clear the secondary containment atmosphere) should be discussed in Section 6.5.3, "Fission Product Control Systems," and Chapter 15, "Accident Analyses."

6.2.3.1 Design Bases. This section should discuss the design bases (i.e., the functional design requirements) of the secondary containment system, including the following considerations:

1. The conditions that establish the need for controlling the leakage from the primary containment structure to the secondary containment structure;

2. The functional capability of the secondary containment system to depressurize and/or maintain a negative pressure throughout the secondary containment structure and to resist the maximum potential for exfiltration under all wind loading conditions characteristic of the site;

3. The seismic design, leak tightness, and internal and external design pressures of the secondary containment structure;

4. The capability for periodic inspection and functional testing of the secondary containment structure.

6.2.3.2 System Design. Describe the design features of the secondary containment structure and provide plan and elevation drawings of the plant showing the boundary of the structure.

Provide a tabulation of the design and performance data for the secondary containment structure. Provide the types of information indicated in Table 6-17.

Discuss the performance objectives of the secondary containment structure. Identify the codes, standards, and guides applied in the design of the secondary containment structure.

Describe the valve isolation features used in support of the secondary containment. Specify the plant protection system signals that isolate and/or activate the secondary containment isolation systems or reference the section in the SAR where this information can be found.

Discuss the design provisions that prevent primary containment leakage from bypassing the secondary containment filtration systems and escaping directly to the environment. Include a tabulation of potential bypass leakage paths, including the types of information indicated in Table 6-18. 
Provide an evaluation to potential bypass leakage paths considering realistic barriers in design limitations and test sensitivities. The following leakage should be considered potential terminate within the secondary containment collection and filtration systems of the leakage paths around the leakage

1. Isolation valves in piping that penetrates both the primary and secondary containment barriers,

2. Seals and gaskets on penetrations that pass through both the primary and secondary containment barriers, and

3. Welded joints on penetrations (e.g., guard pipes) that pass through both the primary and secondary containment barriers.

Specify and justify the maximum allowable fraction of primary containment leakage that may bypass the secondary containment structure. Technical Specificatons for the identification and testing of bypass leakage paths and determination of the bypass leakage fraction should be provided in
Chapter 16 of the SAR.

6.2.3.3 Design Evaluation. Provide analyses of the functional capability of the ventilation and/or cleanup systems to depressurize and/or maintain a uniform negative pressure throughout the secondary containment structure following the design basis loss-of-cuolant accident. These analyses should include the effect of single active failures that could compromise the performance objective of the secondary containment system. For example, for containment purge lines that have three isolation valves in series and a leakoff valve that can be opened to the secondary containment volume between the two outboard valves, show that the failure of the outboard isolation valve to close will not prevent a negative pressure in leakage from the brined in the secondary containment structure or result environment.
in the primary containment across the inboard valve to the

If the secondary containment design leakage rate is in excess of 100\%/day, an evaluation of the secondary containment system's ability to function as intended under adverse wind loading conditions characteristic of the plant site should be provided.

For analyses of the secondary containment system, provide the following information for each secondary containment volume:

1. Pressure and temperature as functions of time.

2. Primary containment wall temperature as a function of time.

3. Purge flow rate and recirculation flow rate as a function of fan differential pressure. 
4. Discussion of the manner in which heat transfer from the primary containment atmosphere to the secondary containment atmosphere is calculated, including a description of the heat transfer coefficients and material properties.

5. Initial conditions assumed for the secondary containment structure and atmosphere and justification therefor.

6. Manner in which equipment heat loads within the secondary containment are considered.

7. The decrease in the secondary containment volume due to thermal and pressure expansion of the primary containment structure, and a description and justification of the methods used to calculate the volume reduction.

Identify all high-energy lines within the secondary containment structure, and provide analyses of line ruptures for any of these lines that are not provided with guard pipes.

6.2.3.4 Tests and Inspections. Describe the program for the initial performance testing and subsequent periodic functional testing of the secondary containment siructures and secondary containment isolation system and system components. Discuss the scope and limitations of the tests. Describe the inspection program for the systems and system comporients. Results of tests performed and a detailed updated program should be frovided in the FSAR. Subsequent test results should be provided as they become available.

6.2.3.5 Instrumentation Requirements. This section should describe the instrumentation to be employed for the monitoring and actuation of the ventilation and cleanup systems. Design details and logic of the instrumentation should be discussed in Chapter 7 of the SAR.

\subsubsection{Containment Isolation System}

General Design Criteria 54,55, 56, and 57 address design and isolation requirements for piping systems penetrating primary reactor containment. The design and functional capability of the containment isolation system should be considered in this section.

6.2.4.1 Design Bases. Discuss the bases for the design of the containment isolation system, including:

1. The governing conditions under which containment isolation becomes mandatory;

2. The criteria used to establish the isolation provisions for fluid systems penetrating the containment; 
3. The criteria used to establish the isolation provisions for fluid instrument lines penetrating the containment; and

4. The design requirements for containment isolation barriers.

6.2.4.2 System Design. Provide a table of design information regarding the containment isolation provisions for fluid system lines and fluid instrument lines penetrating the containment. Include the following infor-
mation in this table:

1. Containment penetration number;

2. General design criteria or regulatory guide recommendations that have been met or other defined bases for acceptability;

3. System name;

4. Fluid contained;

5. Line size (inches);

6. Engineered-safety-feature system (yes or no);

7. Through-line leakage classification (dual containments);

8. Reference to figure in SAR showing arrangement of containment isolation barriers;

9. Isolation valve number;

10. Location of valve (inside or outside containment);

11. Type $C$ leakage test (yes or no);

12. Length of pipe from containment to outermost isolation vaive (or the maximum length that will not be exceeded);

13. Vaive type and operator;

14. Primary mode of valve actuation;

15. Secondary mode of valve actuation;

16. Normal valve position;

17. Shutdown vaive position;

18. Postaccident valve position;

19. Power failure valve position; 
20. Containment isolation signals;

21. Valve closure time; and

22. Power source.

Specify the plant protection system signals that initiate closure of the containment isolation valves or refer to the section in the SAR where this information can be found.

Provide justification for any containment isolation provisions that differ from the explicit requirements of General Design Criteria 55, 56 , and 57.

Discuss the bases for the containment isolation valve closure times and, in particular, the closure times of isolation valves in system lines that can provide an open path from the containment to the environs (e.g., containment purge system).

Cescribe the extent to which the containment isolation provisions for fluid instrument lines meet the recommendations of Regulatory Guide 1.11 (Safety Guide 11), "Instrument Lines Penetrating Primary Reactor Containment."

Discuss the design requirements for the containment isolation barriers, including the following:

1. The extent to which the quality standards and seismic design classification of the containment isolation provisions follow the recommendations of Regulatory Guides 1.26, "Quality Group Classifications and Standards for Water-, Steam-, and Radioactive-Waste-Containing Components of Nuclear Power Plants," and 1.29, "Seismic Design Classification;"

2. Assurance of protection against loss of function from missiles, jet forces, pipe whip, and earthquakes. Describe the provisions made to ensure that closure of the isolation valves will not be prevented by debris that could become entwined in the escaping fluid;

3. Assurance of the operability of valves and valve operators in the containment atmosphere under normal plant operating conditions and postulated accident conditions;

4. Qualification of clased systems inside and outside the containment as isolation barriers;

5. Qualification of a valve as an isolation barrier;

6. Required isolation valve closure times;

7. Mechanical and electrical redundancy to preclude common mode failures; 


\section{Primary and secondary modes of valve actuation.}

Discuss the provisions for detecting leakage from a remote manually controlled system (such as an engineered-safety-feature system) for the purpose of determining when to isolate the affected system or system train.

Discuss the design provisions for testing the operability of the isolation valves and the leakage rate of the containment isoiation barriers. Show on system drawings the design provisions for testing the leakage rate of the containment isolation barriers. Discuss the design and functional capability of associated containment isolation systems (such as isolation valve seal systems) that provide a sealing fluid or vacuum between isolation barriers and of fluid-filled systems that serve as seal systems.

Describe the environmental qualification tests that have been or will be performed on the mechanical and electrical components that may be exposed to the accident environment inside the containment. Discuss the test results. Demonstrate that the environmental test conditions (temperature, pressure, humidity, and radiation) are representative of conditions that would be expected to prevail inside the containment following an accident. Graphically show the environmental test conditions as functions of time or refer to the section in the SAR where this information can be found.

Identify the codes, standards, and guides applied in the design of the system and system components.

6.2.4.3 Design Evaluation. Provide an evaluation of the functional capability of the containment isolation system in conjunction with a failure mode and effects analysis of the system.

Provide evaluations of the functional capability of isolation valve seal systems and of fluid-filled systems that serve as seal systems.

6.2.4.4 Tests and Inspections. Describe the program for the initial functional testing and subsequent periodic operability testing of the containment isolation system and associated isolation valve seal systems if they are provided. Discuss the scope and limitations of the tests. Describe the inspection program for the isolation system and system components. The results of tests performed and a detailed updated testing and inspection program should be provided in the FSAR.

\subsubsection{Combustible Gas Control in Containment}

General Design Criterion 41 requires that systems be provided, as necessary, to control the concentrations of hydrogen and oxygen that may be released into the containment following postulated accidents to ensure that containment integrity is maintained.

The systems provided for combustible gas control include systems to mix the containment atmosphere, monitor combustible gas concentrations 
within containment regions, and reduce combustible gas concentrations within the containment. The design and functional capability of these systems should be considered in this section.

6.2.5.1 Design Bases. Discuss the bases for the design of the combustible gas control systems (i.e., the conditions under which combustib?e gas control may be necessary) and the functional and mechanical design requirements of the systems. The design bases should include such considerations as:

1. The generation and accumulation of combustible gases within the containment;

2. The capability to uniformly mix the containment atmosphere for as long as accident conditions require and to prevent high concentrations of combustible gases from forming locally;

3. The capability to monitor combustible gas concentrations within containment regions and to alert the operator in the main control room of the need to activate systems to reduce combustible gas concentrations;

4. The capability to prevent combustible gas concentrations within the containment from exceeding the concentration limits given in Regulatory Guide 1.7 (Safety Guide 7), "Control of Combustible Gas Concentrations in Containment Following a Loss-of-Coolant Accident;"

5. The capability to remain operable, assuming a single failure;

6. The capability to withstand dynamic effects;

7. The capability to withstand the Safe Shutdown Earthquake without loss of function;

8. The capability to remain operable in the accident environment;

9. The capability to periodically inspect and test systems and/or system components;

10. The sharing of combustibie gas control equipment between nuclear units at multi-unit sites;

11. The capability to transport portable hydrogen recombiner urits after a loss-of-coolant accident;

12. The protection of personnel from radiation in the vicinity of the operating hydrogen recombiner units;

13. The capability to purge the containmert as a backup means for combustible gas controi. 
6.2.5.2 System Design. Describe the design features and provide piping and instrumentation diagrams of the systems or portions of systems that comprise the combustible gas control systems and the backup purge system.

Provide a tabulation of the design and performance data for each system and its components.

Discuss system design requirements for redundancy and independence. Discuss the design provisions that facilitate periodic inspection and operability testing of the systems and system components. Identify the codes, standards, and guides applied in the design of the systems and system components.

Specify the plant protection system signals that actuate the systems and components of the combustible gas control systems and the backup purge system or refer to the section in the SAR where this information can be found.

Discuss the extent to which systems or system components are required to be manually operated from the main cantrol room or from another point outside the containment that is accessible following an accident.

Describe the environmental qualification tests that have been or will be performed on systems (or portions thereof) and system componerts that may be exposed to the accident environment. Describe the test results and their applicability to the system design. Demoristrate that the environmental test conditions (temperature, pressure, humidity, and radiation) are representative of conditions that would be expected to prevail inside the containment foilowing a loss-of-coolant accident. Graphically show the envirormental test conditions as functions of time or refer to the section in the SAR where this information can be found.

With regard to the fan systems that are re? ied on to mix the containment atmosphere, provide the following additionai information:

1. Identify the ductwork that must remain intact fol iowing $\equiv$ loss-ofcoolant accident,

2. Discuss the design provisions (e.g., pressure relief devices, conservative structural design) that ensure that the ductwork and equipment housings will remain intact, and

3. Provide plan and elevation drawings of the containment showing the routing of the airflow guidance ductwork.

Describe the design features of the coritzinmerit interna? structures that promote and permit mixing of gases within the contairment and subcompartments. Identify the subcompartments that are dead-ended or wcuid not te positiveiy vanitilated following a ioss-of-coolant accident and 
provide analyses, assumptions, and mathematical mode 15 that ensure that combustible gases will not accumulate within them.

With regard to the system provided to continuously monitor the combustible gas concentrations within the containment following a LOCA, provide the following information:

1. A discussion of the operating principle and accuracy of the combustible gas analyzers;

2. A description of the tests conducted to demonstrate the performance capability of the analyzers or a reference to the report where such information may be found; containment;

3. The locations of the multiple sampling points within the

4. A discussion of the capability to monitor combustible gas concentrations within the containment independent of the operation of the combustible gas control systems; and

5. Failure mode and effects analyses of the containment combustible gas concentration monitoring systems.

With regard to the recombiner system provided to reduce combustible gas concentrations within the containment, provide the following additional information:

1. The operating principle of the system;

2. A description of the developmental program conducted to demonstrate the performance capability of the system and a discussion of the program results or a reference to the report where this information can be found;

3. A discussion of any differences between the recombiner system on which the qualification tests were conducted and the recombiner system that is proposed; and

4. A discussion of the extent to which equipment will be shared between nuclear power units at a multi-unit site, and the availability of the shared equipment.

6.2.5.3 Design Evaluation. Provide an analys is of the production and accumulation of combustible gases within the containment following a postulated loss-of-coolant accident, including the following information: of time.

1. The assumed corrosion rate of aluminum plotted as a function 

time.

2. The assumed corrosion rate of zinc plotted as a function of

3. An inventory of aluminum inside the containment with the mass and surface area of each item.

4. An inventory of zinc inside the containment with the total mass and surface area.

5. The mass of Zircaloy fuel cladding.

6. The quantities of hydrogen and oxygen contained in the reactor coolant system.

7. The total fission product decay power as a fraction of operating power plotted versus time after shutdown with a comparison to the decay power curve shown in Figure 6-2. Specify the reactor core thermal power rating and the assumed operating history of the reactor core.

8. The beta, gamma, and beta plus gamma energy release rates and integrated energy releases plotted as functions of time for the fission product distribution model based on the thermal power rating and operating history of the reactor core assumed in item 7 above. Indicate the extent to which the model presented in Table 1 of Regulatory Guide 1.7 is utilized.

9. The integrated production of combustible gas within the containment plotted as a function of time for each source and the concentration of combustible gas in the containment plotted as a function of time for all sources.

10. The combustibie gas concentration in the containment plotted as a function of time with operation of the combustible gas reduction system assumed at full and partial capacity. Also plot the combustible gas concentration in the containment as a function of time with operation of the backup purge system assumed.

11. The basis (time or combustible gas concentrations) for activation of the combustible gas reduction and backup purge systems. Specify the design flow rates and the flow rates used in the analysis for both systems.

12. Analyses of the functional capability of the spray and/or fan systems to mix the containment atmosphere and prevent the accumulation of combustible gases within containment subcompartments. Provide plan and elevation drawings of the containment showing the airflow patterns that would be expected to result from operation of the spray and/or fan systems with a single failure assumed.

13. Analyses or test results that demonstrate the capability of the airflow guidance ductwork and equipment housings to withstand, without loss of function, the external differential pressures and internal pressure surges that may be imposed on them following a loss-of-coolant accident. 
Provide failure mode and effects analyses of the combustible gas control systems.

6.2.5.4 Tests and Inspections. Describe the program for the initial periormance testing and subsequent periodic operability testing of the combustible gas control systems and system components. Discuss the scope and limitations of the tests. Describe the inspection programs for the systems and system components. For those equipments that will be shared between nuclear power units at multi-unit sites, describe the program that will be conducted to ensure that the equipment can be transported within the allotted time safeiy and by qualified personne?. The results of tests performed and a detailed updated testing and inspection program shou?d be provided in the FSAR.

6.2.5.5 Instrumentation Requirements. Discuss the instrumentation provisions for actuating the combustible gas control systems and backup purge system (e.g., automatically or remote manually) and monitoring the performance of the systems and system components. Identify the plant conditions and system operating parameters to be monitored and justify the selection of the setpoints for system actuation or alarm annunciation. Specify the instrumentation readout and aiarm jocation(s) outside the containment. Design details and logic of the instrumentation should be discussed in Chapter 7 of the SAR.

\subsubsection{Containment Leakage Testing}

General Design Criteria 52, 53, and 54 require that the reactor containment, containment penetratiors, and containment isolation barriers be designed to permit periodic leakage rate testing.

Appendix J, "Primary Reactor Containment Leakage Testing for WaterCooled Power Reactors," to 10 CFR Part 50 specifies the leakage testing requirements for the reactor containment, containment penetrations, ard containment isolation barriers.

This section should present a proposed testing progran that complies with the requirements of the Gerieral Design Criteria and Appendi $x \mathrm{~J}$ to 10 CFR Part 50. A 11 exceptions to the explicit requirements of the General Design Criteria and Appendix $J$ should be identified and justified.

6.2.6. 1 Containment Integrated Leakage Rate Test. Specify the maximum allowable containment integrated leakage rate. Describe the testing sequence for the containment structural integrity test and the containment leakage rate test.

Discuss the pretest requirements, including the requirements for inspecting the containment, taking corrective action ard retesting in the event that structural deterioration of the containment is found, and reporting. Also discuss the criteria for positioning isolation valves, the manner in which isolation valves will be positioned, and the requirements for venting or draining of fluid systems prior to containment testing. 
Fluid systems that will be vented or opened to the containment atmosphere during testing should be listed; the systems that will not be vented should be identified and justification given.

Describe the measures that will be taken to ensure the stabilization of containment conditions (temperature, pressure, humidity) prior to containment leakage rate testing.

Describe the test methods and procedures to be used during containment leakage rate testing, including local leakage testing methods, test equipment and facilities, period of testing, and verification of leak test accuracy.

Identify the acceptance criteria for containment leakage rate tests and for verification tests.

Discuss the provisions for additional testing in the event acceptance criteria cannot be met.

6.2.6.2 Containment Penetration Leakage Rate Test. Provide a listing of all containment penetrations. Identify the containment penetrations that are exempt from leakage rate testing and give the reasons.

Describe the test methods that will be used to determine containment penetration leakage rates. Specify the test pressure to be used.

Provide the acceptance criteria for containment penetration leakage rate testing. Specify the leakage rate limits for the containment penetrations.

6.2.6.3 Containment Isolation Valve Leakage Rate Test. Provide a listing of all containment isolation valves. Identify the containment isolation valves that are not incluced in the leakage rate testing and provide justification.

Describe the test methods that will be used to determine isolation valve leakage rates. Specify the test pressure to be used.

Provide the acceptance criteria for leakage rate testing of the containment isolation valves. Specify the leakage rate limits for the isolation valves.

6.2.6.4 Scheduling and Reporting of Periodic Tests. Provide the proposed schedule for performing preoperational and periodic leakage rate tests for each of the following:

1. Containment integrated leakage rate;

2. Containment penetrations; and 


\section{Containment isolation valves.}

Describe the test reports that will be prepared and include provisions for reporting test results that fail to meet acceptance criteria.

6.2.6.5 Special Testing Requirements. Specify the maximum allowable leakage rate for the following:

1. Inleakage to subatmospheric containment, and

2. Inleakage to the secondary containment of dual containments.

Describe the test procedures for determining the above inleakage rates. Describe the leakage rate testing that will be done to determine the leakage from the primary containment that bypasses the secondary containment and other plant areas maintained at a negative pressure following a loss-of-coolant accident. Specify the maximum al lowable bypass leakage.

Describe the test procedures for determining the effectiveness following postulated accidents of isolation valve seal systems and of fluid-filled systems that serve as seal systems.

\subsection{Emergency Core Cooling System}

\subsubsection{Design Bases}

A summary description of the emergency core cooling system (ECCS) should be provided. All major subsystems of the ECCS such as active highand low-pressure safety injection systems and passive safety injection tanks should be identified. Nuclear plants that employ the same ECCS design and that are operating or have been licensed should be referenced. The purpose of the ECCS should be described and each accident or transient for which the required protection includes actuation of the ECCS should be listed.

The design bases for selecting the functional requirements for each subsystem of the ECCS should be specified. Bases for selecting such system parameters as operating pressure, ECC flow delivery rate, ECC storage capacity, boron concentration, and hydraulic flow resistance of ECCS piping and valves should be discussed.

Design bases concerned with reliability requirements should be specified. Protection against single failure in terms of piping arrangement and layout, selection of valve types and locations, redundancy of various system components, redundancy of power supplies, redundant sources of actuation signals, and redundancy of instrumentation should be described. Protection against valve motor flooding and spurious singie failures should be described.

Requirements estab? ished for the purpose of protecting the ECCS from physical damage should be specified. This discussion should include design 
bases for ECCS support structure design, for pipe whip protection, for missile protection, and for protection against such accident loads as loss-of-coolant accident or seismic loads.

Environmental design bases concerned with the high-temperature steam atmosphere and containment sump water level that might exist in the containment during ECCS operation should be specified.

\subsubsection{System Design}

6.3.2.1 Schematic Piping and Instrumentation Diagrams. Piping and instrumentation diagrams showing the location of a/7 components, piping, storage facilities, points where connecting systems and subsystems tie together and into the reactor system, and instrumentation and controls associated with subsystem and component actuation should be provided for all modes of ECCS operation along with a complete description of component inter locks.

6.3.2.2 Equipment and Component Descriptions. Each component of the system should be described. The significant design parameters for each component should be identified. The design pressure and temperature of components for various portions of the system should be stated along with an explanation of the bases for their selection. State the quantity of coolant available (e.g., in each safety injection tank, refueling water storage tank, condensate storage tank, torus). Provide pump characteristic curves and pump power requirements. Specify the available and required net positive suction head for the ECCS pumps and identify any exceptions to the regulatory position stated in Regulatory Guide No. 1.1 (Safety Guide 1), "Net Positive Suction Head for Emergency Core Cooling and Containment Heat Removal System Pumps." Describe heat exchanger characteristics, including design flow rates, inlet and outlet temperatures for the cooling fluid and for the fluid being cooled, the overall heat transfer coefficient, and the heat transfer area.

The relief valve capacity and settings or venting provisions included in the system should be stated. Specify design requirements for ECC delivery lag times. Describe provisions with respect to the control circuits for motor-operated isolation valves in the ECCS, including consideration of inadvertent actuation prior to or during an accident. This description should include discussions of the controls and interlocks for these valves (e.g. , intent of IEEE Std 279-1971) and considerations for automatic valve closure (e.g., reactor coolant system pressure exceeds design pressure of residual heat removal system), automatic valve opening (e.g., preselected reactor coolant system pressure or ECCS signal), valve position indications, valve interlocks, and alarms.

6.3.2.3 Applicable Codes and Classifications. The applicable industry codes and classifications for the design of the system should be identified. 
6.3.2.4 Material Specifications and Compatibility. Identify the material specifications for the ECCS and discuss material compatibility and chemical effects of all sorts. List the materials used in or on the ECCS by commercial name, quantity (estimate where necessary), and chemical composition. Show that the radiolytic or pyrolytic decomposition products, if any, of each material will not interfere with the safe operation of this or any cther engineered safety feature.

6.3.2.5 System Reliability. Discuss the reliability considerations incorporated in the design to ensure that the system will start when needed and will deliver the required quantity of coolant within specified lag times (e.g., redundancy and separation of components, transmission lines, and power sources). Provide a failure mode and effects analys is of the ECCS. Identify the functional consequences of each possible single failure, including the effects of any single failure or operator error that causes any manualiy controlled electrically operated valve to move to a position that could adversely affect the ECCS. The potential for passive failures of fluid systems during long-term cooling should be considered as well as single failures of active components. For PWR plants, the singlefailure analysis should consider the potential boron precipitation problem as an integral part of the requirement for providing for long-term core cooling.

Identify the specific equipment arrangement for the plant design and provide an evaluation to ensure that valve motor operators located within containment will not become submerged following a LOCA. Include all equipment in the ECCS or any other system that may be needed to limit boric acid precipitation in the reactor vessel during long-term cooling or that may be required for containment isolation.

6.3.2.6 Protection Provisions. Describe the provisions for protecting the system (including connections to the reactor coolant system or other connecting systems) against damage that might result from movement (between components within the system and connecting systems), from missiles, from thermal stresses, or from other causes (LOCA, seismic events).

6.3.2.7 Provisions for Performance Testing. The provisions to facilitate performance testing of components (e.g., bypasses around pumps, sampling lines, etc.) should be described.

6.3.2.8 Manual Actions. Identify all manual actions required to be taken by an operator in order for the ECCS to operate properly. Identify all process instrumentation available to the operator in the control room to assist in assessing postaccident conditions. Discuss the information available to the operator, the time delay during which his failure to act properly will have no unsafe consequences, and the consequences if the action is not performed at all. 


\subsubsection{Performance Evaluation}

ECCS performance is evaluated through the safety analyses of a spectrum of postulated accidents. These anaiyses should be included in Chapter 15, "Accident Analyses." This section should list the accidents discussed in Chapter 15 that result in ECCS operation. The conclusions of the accident analyses should be summarized. The bases for any operational restrictions such as minimum functional capacity or testing requirements that might be appropriate for inclusion in the Technical Specifications of the license should be provided. All existing criteria that are used to judge the adequacy of ECCS performance, including those contained in § 50.46, "Acceptance Criteria for Emergency Core Cooling Systems for Light-Water-Cooled Nuclear Power Reactors," of 10 CFR Part 50 should be mentioned. ECCS cooling performance evaluation should include an evaiuation of single failures, potential boror precipitation (PWRs), submerged valve motors, and containment pressure assumptions (PWRs) used to evaluate the ECCS performance capability.

Simplified functional flow diagrams showing the alignment of valves, flow rates in the system, and the capacity of the ECC water supply should be provided for typical accident conditions (e.g., small-and large-break loss-of-coolant accident, steam line break). Typical flow delivery curves as a function of time should also be given for the various accidents. The time sequence of ECCS operation for short-term and long-term cooling should be discussed. Analysis supporting the selection of lag times (e.g., the period between the time an accident has occurred and the time ECC is discharged into the core) should include valve opening time, pump starting time, and other pertinent parameters. Credit for operator action should be specified.

Discuss the extent to which components or portions of the ECCS are required for operation of other systems and the extent to which components or portions of other systems are required for operation of the ECCS. An analys is of how these dependent systems would function should include system priority (which system takes preference) and conditions when various components or portions of one system function as part of another system [for example, when the water level in the reactor is below a limiting value, the racirculation pumps (i.e., residual or decay heat removal pumps) or feed pumps will supply water to the ECCS and not to the containment spray system]. Delineate any limitations on operation or maintenance included to ensure minimum capability (e.g., the storage facility common to both core cooling and containment spray systems should have provisions whereby the quantity available for core cooling will not be less than some specified quantity).

State the bounds within which principal system parameters must be maintained in the interests of constant standby readiness, e.g., such things as the minimum poison concentrations in the coolant, minimum coolant reserve in storage volumes, maximum number of inoperable components, and maximum allowable time period for which a component can be out of service. 
The failure mode and effects analysis presented in Section 6.3.2.5 identifies possible degraded ECCS performances caused by single component failures. The accident analyses presented in Chapter 15 considered each of the degraded ECCS cases in the selection of the worst single failure to be analyzed. The conclusions of the various accident analyses should be discussed to show that the ECCS is adequate to perform its intended function.

\subsubsection{Tests and Inspections}

6.3.4.1 ECCS Performance Tests. Provide a description or reference the description of the preoperational test program performed on the ECCS. The program should provide for testing of each train of the ECCS under both ambient and simulated hot operating conditions. The tests should demonstrate that the flow rates delivered through each injection flow path using all pump combinations are within the design specifications. The adequacy of the electric power supply should be verified by testing under maximum startup loading conditions. Recirculation tests should be included in the program to demonstrate system capability to realign valves and injection pumps to recirculate coolant from the containment sump. Justify any exceptions to the regulatory position stated in Regulatory Guide 1.79, "Preoperational Testing. of Emergency Core Cooling Systems for Pressurized Water Reactors."

6.3.4.2 Reliability Tests and Inspections. The emergency core cooling system is a standby system that is not norinally operating. Consequently, a measure of the readiness of the system to operate in the event of an accident must be achieved by tests and inspections. The periodic tests and inspections program should be identified and reasons explained as to why the program of testing planned is believed to be appropriate. The information should include:

1. Description of tests planned.

2. Considerations that led to periodic testing and the selected test frequency.

3. Test methods to be used.

4. Requirements set for acceptability of observed performance and the bases for them.

5. A description of the program for inservice inspection, including items to be inspected, accessibility requirements, and the types and frequency of inspection.

Information presented elsewhere in the SAR for the tests planned need not be repeated but only cross-referenced. 
Particular emphasis should be given to those surveillance-type tests that are of such importance to safety that they may become a part of the Technical Specifications of an operating license. The bases for such surveillance requirements should be developed as a part of the SAR.

\subsubsection{Instrumentation Requirements}

This section should discuss the instrumentation provisions for various methods of actuation (e.g., automatic, manual, different locations). The conditions requiring system actuation together with the bases for the selection (e.g., during periods when the system is to be available, whenever the reactor coolant system pressure is less than some specified pressure, the core spray system should be actuated automatically using equipment designed to IEEE Std 279 requirements) should be included in the discussion. Design details and logic of the instrumentation should
be discussed in Chapter 7 of the SAR.

\subsection{Habitability Systems}

The term "habitability systems" refers to the equipment, supplies, and procedures provided to ensure that control room operators can remain in the control room and take actions to operate the nuclear power unit safely under normal conditions and to maintain it in a safe condition under accident conditions, including loss-of-coolant accidents, as required by General Design Criterion 19 of Appendix A to 10 CFR Part 50. The habitability systems should include systems and equipment to protect the control room operators against such postulated releases as radioactive materials, toxic gases, smoke, and steam and should provide materials and facilities to permit them to remain in the control room for an extended period.

The term "control room" typically includes the main control room, areas adjacent to the main control room containing plant information and equipment that may be needed during an emergency, and kitchen and sanitary facilities. It is also the entire zone serviced by the control room ventilation system.

The habitability systems for the control room should include shielding, air purification systems, control of climatic conditions, storage capacity for food and water, and kitchen and sanitary facilities. Detailed descriptions of these systems should be included in the SAR together with an evaluation of their performance. The evaluation should provide assurance that the systems will operate under all postulated conditions to permit the control room operators to remain in the control room and to take appropriate actions as required by General Design Criterion 19. Sufficient information should be provided to permit an independent evaluation of the adequacy of the systems. Information and evaluations in other sections of the SAR that relate to the adequacy of the habitability systems should be referenced (see Sections 6.5.1, 9.4.1, and 15.X.X, paragraph 5). 


\subsubsection{Design Basis}

This section should summarize the bases on which the functional design of the habitability system and the ir features were established. For exampie, the criteria used to establish the following should be provided:

1. Control room envelope

2. Period of habitability

3. Capacity (number of people)

4. Food, water, medical supplies, and sanitary facilities

5. Radiation protection

6. Toxic or noxious gas protection

7. Respiratory, eye, and skin protection for emergencies

8. Habitability system operation during emergencies

9. Emergency monitors and control equipment

\subsubsection{System Design}

6.4.2.1 Definition of Control Room Envelope. The areas, equipment, and materials to which the control room operator could require access during an emergency should be identified. Those spaces requiring continuous or frequent operator occupancy should be listed. The selection of those spaces inciuded in the control room envelope should be based on need during postulated emergencies. This information should be summarized in this section.

6.4.2.2 Ventilation System Design. This section should present the design features and fission product removal and protection capability of the control room ventilation system. Although emphasis should be placed on the emergency ventilation portion of the system, the normal ventilation system and its components also should be discussed insofar as they may affect the habitability of the control room during a design basis accident. Specifically, the following information is pertinent to the evaluation of the control room ventilation system and should be included in this section: *

1. A schematic of the control room ventilation system, including equipment, ducting, dampers, and instrumentation, and air flows for both normal and emergency modes should be noted. All dampers and valves should

If portions of this information appear elsewhere in the SAR, they may be referenced here by section number. 
be indicated with appropriate labeling (e.g., normally open or closed, manually or motor operated, fail closed or fail open).

2. A listing of major components giving their fiow rates, capacities, and major design parameters. Isolation dampers should also be included in this list. The ir leakage characteristics and closure times should be given.

3. The seismic classifications of components, instrumentation, and ducting. Components that are protected against missiles should be identified.

4. Layout drawings of the control room showing doors, corridors, stairwells, shielded wa!ls, and the placement and type of equipment within the control room.

5. Elevation and plan views showing building dimensions and locations, the location of potential radiological and toxic gas releases, and the location of control room air iniets.

6. A description and placement of ventilation system controls and instruments, including the instruments that monitor the control room for radiation and toxis gases.

7. A description of the charcoal fijter train, including design specifications, flow parameters, and charcoal typa, weight, and distribution; HEPA filter type and specifications; and specifications of any additional comporients. The degree to which the recommendations of Regulatory Guide 1.52, "Design, Testing, and Maintenance Criteria for Postaccident Engineered-Safety-Feature Atmosphere Cleanup System Air Filtration and Adsorption Units of Light-Water-Cooled Nuclear Power Plants," are fol iowed should be indicated and ciaimed filter efficiencies listed. (Reference may be made to Section 6.5 .1 .)

6.4.2.3 Leak Tightness. This section should summarize the exfi?tration and infitration analyses performed to determine unfiltered inleakage or pressurization air flow requirements. Include a listing of all potentia? leak paths (such as cable, pipe, and ducting penetrations, doors, dampers, construction joints, and construction materials) and their appropriate leakage characteristics. Describe the precautions and methods used to limit leakage out of or into the control room. If pressurization flow rates of less than 0.25 volume change per hour or infiltration rates of less than 0.06 volume change per hour are used, periodic leakage rate testing is normally required, and a summary of the test procedures should be included in Section 6.4.5.

6.4.2.4 Interaction With Other Zones and Pressure-Containing Equipment. A sutficiently detailed discussion should be included to irdicate that the following have been taken into consideration: 
1. Potential adverse interactions between the control room ventilation zone and adjacent zones that may enhance the transfer of toxic or radioactive gases into the control room. Identification should be made of any other HVAC equipment (e.g., ducts, air handling units) that may service other ventilation zones (e.g., cable spreading room, battery room) but that may be physically located within the control room habitability zone. A description should be provided of any leak paths with respect to such equipment (e.g., pilot traverse holes, hatch covers in ducts). The direction and magnitude of the pressure difference across these leak paths should be provided.

2. Isolation from the control room of all pressure-containing tanks, equipment, or piping (e.g., $\mathrm{CO}_{2}$ firefighting containers, steam lines) that, upon failure, could cause transfer of hazardous material to the control room.

6.4.2.5 Shielding Design. Design basis accident sources of radiation other than that due to airborne contaminants within the control room should also be considered. Principal examples include fission products released to the reactor containment atmosphere, airborne radioactive contaminants surrounding the control room, and sources of radiation due to potentially contaminated equipment (e.g., control room charcoal filters and steam lines) in the vicinity of the control room. The SAR should include information describing radiation attenuation by shielding and separation. The corresponding evaluation of design basis accident doses to control room operators should be presented in Section 15.X.X, paragraph 5. Specifically, the description of the radiation shielding for the control room in a design basis accident should include the following information:

1. Accident radiation source description in terms of its origin, strength, geometry, radiation type, energy, and dose conversion factors. (Sources should include primary and secondary containments, ventilation systems, external cloud, and adjacent building air spaces.)

2. Radiation attenuation parameters (i.e., shield thickness, separation distances, and decay considerations) with respect to each source.

3. Description of potential sources of radiation streaming that may affect control room operators and the measures taken to reduce streaming to acceptable levels.

4. An isometric drawing of the control room and associated structures identifying distances and shield thicknesses with respect to each radiation source identified in 1 . above.

Information pertinent to this section appearing elsewhere in the SAR should be referenced here. 


\subsubsection{System Operational Procedures}

Discuss the method of operation during normal and emergency conditions. Discuss the automatic actions and manual procedures required to ensure effective operation of the system. If more than one emergency mode of operation is possible, indicate how the optimum mode is selected for a given condition.

\subsubsection{Design Evaluations}

6.4.4.1 Radiological Protection. Section 15.X.X, paragraph 5, "Radiological consequences," sets forth the documentation requirements for the evaluation of radiological exposures to plant operators from design basis accidents. The information presented in Chapter 15 should be referenced here.

6.4.4.2 Toxic Gas Protection. A hazards analys is should be performed as recomnended in Regulatory Guide 1.78, "Assumptions for Evaluating the Habitability of a Nuclear Power Plant Control Room During a Postulated Hazardous Chemical Release," for each toxic material identified in Section 2.2. For any of these materials that are used in the operation of the nuclear power plant, the container types and the methods of connection to the system serviced should be described. The distances between the storage locations and the air intakes to the control room should be listed along with the storage quantities. An analysis of the severity of postulated accidents involving these materials should be provided, and the steps to mitigate accident consequences should be discussed. Include descriptions of the following:

1. Principal toxic gas detector characteristics such as sensitivity, response time, principle of operation, testing and maintenance procedures, environmental qualifications, and physical location relative to the outside air intake. 2. Isolation damper transient characteristics (time to open and
close) and leakage.

3. Description of the number and type of individual respiratory devices, the type of operator training for respirator use, the estimated time for deploying or donning of the equipment, the length of time the equipment can be used, and the testing and maintenance procedures.

4. Description of special ventilation system operation modes, if any, provided specifically for toxic or noxious gas conditions (e.g., bottled air pressurization, manually selected control room air purge periods).

The description of the analyses should clearly list all assumptions. Regulatory Guide 1.78 describes acceptable calculational methods. If chlorine has been identified as a potential hazard to the operator, specific guidance is provided by Regulatory Guide 1.95, "Protection of Nuclear 
Power Plant Control Room Operators Against an Accidental Chlorine Release."

\subsubsection{Testing and Inspection}

This section should provide information about the program of testing and inspection applicable to (1) preoperational testing and (2) inservice survei?lance to erisure continued integrity.

Emphasis should be given to those tests and inspections considered essential to a determination that performance objectives have been achieved and that a performance capability is being maintained above some preestabTished limits throughout the plant lifetime. The information provided in this section should include, for example:

1. The planned tests and their purposes;

2. The considerations that led to the selected test frequency;

3. The test metrods to be used, including a sensitivity analysis;

4. The requirements for acceptability of cbserved performance and the bases for them; and

5. The action to be taken if acceptability requirements are not met.

Results of any tests performed to support the specification of the test program and a detailed update of the program should be provided in the FSAR.

\subsubsection{Instrumentation Requirement}

This section should describe the instrumentation to be used to monitor and actuate the habitability systems. Design details and logic of the instrumentation should be discussed in Chapter 7 of the SAR.

\subsection{Fission Product Removal and Control Systems}

This section should provide information in sufficient detai? to permit the NRC staif to Evaluate the performance capabi?ity of the fission procuct removal and control systems. Design criteria for other safety functions of the systems should be provided in other appropriate sections of this chapter. Fission product removal and control systems are considered to be those systems for which credit is taken in reducing accidental release of fission products.

The filter systems and containment spray systems for fission product removal are discussed in Sections 6.5 .1 and 6.5 .2 , the fission product control systems in Section 6.5.3, and the ice condenser for fission product cleanup in Section 6.5.4. 


\subsubsection{Engineered Safety Feature (ESF) Filter Systems}

All filter systems that are required to perform a safety-related function following a design basis accident should be discussed in this section. This could include filter systems internal to the primary containment, control room filters, filters on secondary confinement volumes, fuel-handlingbuilding filters, and filters for areas containing engineered-safety-feature components. (It should be indicated in Chapter 15 which of these filters are used in mitigating the consequences of accidents.) The type of information outlined below should be provided for each of the systems. Some systems may be described in detail in other sections such as Section 9.4, but they should be listed in this section and specific reference made to the location of the information requested in each of the following sections.

6.5.1.1 Design Bases. This section should provide the design bases for each filter including the following, for example:

1. The conditions that establish the need for the filters,

2. The bases employed for sizing the filters, fans, and associated ducting, and

3. The bases for the fission product removal capability of the filters.

6.5.1.2 System Design. This section should compare the design features and fission product removal capability of each filter system to each position detailed in Regulatory Guide 1.52, "Design, Testing, and Maintenance Criteria for Postaccident Engineered-Safety-Feature Atmosphere Cleanup System Air Filtration and Adsorption Units of Light-Water-Cooled Nuclear Power Plants." For each ESF atmosphere cleanup system, there should be presented in tabular form a comparison between the features of the proposed system and the appropriate acceptable methods and/or characteristics presented in Regulatory Guide 1.52 . For each design item for which an exception is taken, the acceptability of the proposed design should be justified in detail?

6.5.1.3 Design Evaluation. This section should provide evaluations of the filter systems to demonstrate their capability to attain the claimed filter efficiencies under the relevant accident conditions.

6.5.1.4 Tests and Inspections. Provide information concerning the program of testing and inspection applicable to preoperational testing and inservice surveillance to ensure a continued state of readiness required to reduce the radiological consequences of an accident as discussed in Regulatory Guide 7.52 .

6.5.1.5 Instrumentation Requirements. Describe the instrumentation to be employed for monitoring and actuating the filter system, including the extent to which the recommendations of Regulatory Guide 1.52 are 
followed. Design details and logic of the instrumentation should be discussed in Chapter 7 of the SAR.

6.5.1.6 Materials. List by commercial name, quantity (estimate where necessary), and chemical composition the materials used in or on the filter system. Show that the radioiytic or pyrolytic decomposition products, if any, of each material will not interfere with the safe operation of this or any other engineered safety feature.

\subsubsection{Containment Spray Systens}

A detailed description of the fission product removal function of the containment spray system should be provided in this section if the system is relied on to perform this function following a design basis accident.

6.5.2.1 Design Bases. This section should provide the design bases for the fission product removal function of the containment spray system, including the following, for example:

1. The postulated accident conditions that determine the design requirements for fission product scrubbing of the containment atmosphere,

2. A list of the fission products (including the species of iodine) that the system is designed to remove and the extent to which credit is taken for the cleanup function in the analyses of the radiological consequences of the accidents discussed in Chapter 15 of the SAR, and

3. The bases employed for sizing the spray system and any components required for the execution of the atmosphere cleanup function of the system.

6.5.2.2 System Design (for Fission Product Removal). This section should provide a description of systems and components employed to carry out the fission product removal function of the spray system, including the method of additive injection (if any) and delivery to the containment. Detailed information should be provided concerning:

1. Methods and equipment used to ensure adequate delivery and mixing of the spray additive (where applicable); operation;

2. Source of water supply during all phases of spray system

3. Spray header design, including the number of nozzles per header, nozzle spacing, and nozzle orientation (a plan view of the spray headers, showing nozzle location and orientation, should be included);

4. Spray nozzle design, including information on the drop size spectrum produced by the nozzles. This information should inciude a histogram of the observed drop size frequency for the spatial drop size 
distribution. If a mean diameter is used in the calculation of the spray effectiveness, all assumptions used for the conversion to a temporal drop size mean should be stated;

5. The operating modes of the system, including the time of system initiation, time of first additive delivery through the nozzles, length of injection period, time of initiation of recirculation (if applicable), and length of recirculation operation. Spray and spray additive flow rates should be supplied for each period of operation, assuming minimum spray operation coincident with maximum and minimum safety injection flow rates, and vice versa; and

6. The regions of the containment covered by the spray. List the containment volumes not covered by the spray and estimate the forced or convective postaccident ventilation of these unsprayed volumes. Indicate the extent to which credit is taken for the operability of ductwork, dampers, etc.

6.5.2.3 Design Evaluation. Provide an evaluation of the fission product removal function of the containment spray system. The system should be evaluated for fully effective and minimum safeguards operation, including the condition of a single faijure of any active component. If the calculation of the spray effectiveness is performed for a single set of postaccident conditions, attention should be given to the effects of such parameters as temperature, spray and sump pH (and the resulting change in iodine partition), drop size, and pressure drop across the nozzle in order to ascertain whether the evaluation has been performed for a conservative set of these parameters.

6.5.2.4 Tests and Inspections. Provide a description of provisions made for testing all essential functions required for the iodine-removal effectiveness of the system. In particular, this section should include:

1. A description of the tests to be performed to verify the capability of the systems, as installed, to deliver the spray solution with the required concentration of spray additives to be used for iodine removal. If the test fluids are not the actual spray additives, describe the liquids of similar density and viscosity to be employed. Discuss the correlation of the test data with the design requirements;

2. A description of the provisions made for testing the containment spray nozzles; and

3. The provisions made for periodic testing and surveillance of any of the spray additives to verify their continued state of readiness.

Provide the bases for surveillance, test procedures, and test intervals deemed appropriate for the system.

6.5.2.5 Instrumentation Requirements. This section should include a description of any instrumentation of the spray system required for 
actuation of the system and monitoring the fission product removal function of the system. Design details and logic of the instrumentation should be discussed in Chapter 7 of the SAR.

6.5.2.6 Materials. Specify and discuss the chemical composition, concentrations in storage, susceptibility to radiolytic or pyrolytic decomposition, corrosion properties, etc., of the spray additives (if any), the spray solution, and the containment sump solution.

\subsubsection{Fission Product Control Systems}

This section should include a detailed discussion of the operation of all fission product control systems following a design basis accident. Both anticipated and conservative operation should be described. Reference should be made to other SAR sections when appropriate. Fission product control systems are considered to be those systems whose performance controls the release of fission products following a design basis accident. These systems are exclusive of the containment isolation system and any fission product removal system, although they may operate in conjunction with fission product removal systems.

6.5.3.1 Primary Containment. This section should summarize information about the primary containment that pertains to its ability to control fission product releases following a design basis accident. This should include information such as that presented in Tabie 6-19. Layout drawings of the primary containment and the hydrogen purge system should be included.

Operation of containment purge systems prior to and during the accident should be discussed. Operation of the primary containment (e.g., anticipated and conservative leak rates as a function of time after initiation of the accident) should be described as applies to fission product contro? following a design basis accident. Where applicable, indicate when fission product removal systems are effective relative to the time sequence for operation of the primary containment following a design basis accident.

\subsubsection{Secondary Containments. A discussion of the operation of} each system used to control the release of fission products leaking from the primary containment following a design basis accident should be provided. Include the time sequence of events assumed in performing the dose estimates. Provide a table of events related to time following the design basis accident, including various parameters such as those in Table 6-2. For each time interval, indicate which fission product removal systems are effective.

Indicate both anticipated and conservative assumptions. Provide drawings that show each secondary containment volume and the ventilation system associated with that volume. Indicate the location of intake and return headers for recirculation systems and the location of exhaust intakes for once-through ventilation systems. Reference should be made to non-ESF systems that are used to control pressure in the volume. 


\subsubsection{Ice Condenser as a Fission Product Cleanup System}

The fission product cleanup function of the ice condenser system should be considered separately from its heat removal aspects; it should be described in this section only if credit is taken for this function in the accident analyses of Chapter 15.

6.5.4.1 Design Bases. Provide the design bases for the fission product removal function of the ice condenser system, including the following, for example:

1. The postulated accident conditions and the extent of simultaneous occurrences that determine the design requirements for fission, and

2. A list of the fission products (including the species of iodine) that the system is designed to remove and the extent to which credit is taken for the cleanup function in the analyses of the radiological consequences of the accidents discussed in Chapter 15 of the SAR.

6.5.4.2 System Design (for the Fission Product Removal). This section should describe those aspects of the ice condenser design that significantly affect the fission product removal function of the ice condenser system. The information provided should include, for example:

1. The steam and air flow rates through the ice condenser as a function of time following the accident,

2. The concentrations of all additives to the ice and the $\mathrm{pH}$ of the ice melt and the containment sump solution following an accident,

3. A description of the methods and equipment to be used to produce the ice with the proper additive content.

6.5.4.3 Design Evaluation. Provide an evaluation of the fission product removal function of the ice condenser system. The system should be evaluated for fully effective and minimum safeguards operation, including the condition of a single failure of any active component. If the calculation of the effectiveness is performed for a single set of postaccident conditions, attention should be given to the effects of such parameters as recirculation fan flow rate, temperature, pressure, and sump $\mathrm{pH}$ (and the resulting change in iodine partition) in order to ascertain that the evaluation has been performed for a conservative set of these parameters.

6.5.4.4 Tests and Inspections. Provide a description of provisions made for testing all essential functions required for the iodine-remova? effectiveness of the ice condenser system and for surveillance of the system. In particular, this section should describe the provisions made for sampling the ice to verify the proper additive content. 
6.5.4.5 Materials. Specify the concentrations of all additives in the ice. The effects of the additives on the long-term storage of the ice should be discussed. Address any possible reactions (e.g., slow oxidations) of the chemical additives in the ice.

\subsection{Inservice Inspection of Class 2 and 3 Components}

This section should discuss the inservice inspection program for Quality Group B and C components (i.e., Class 2 and 3 components in Section III of the ASME B\&PV Code).

\subsubsection{Components Subject to Examination}

Indicate that all Quality Group B components, including those listed in Table IWC- 2600 of Section XI will be examined in accordance with Code requirements. Indicate the extent to which Quality Group $C$ components, including those listed in Subarticle IWD-2600 of Section XI, will be examined in accordance with the Code.

A detailed inservice inspection program, including information on areas subject to examination, method of examination, and extent and frequency of examination, should be provided in the technical specifications.

\subsubsection{Accessibility}

Indicate that the design and arrangement of Class 2 system components will provide adequate clearances to conduct the required examinations at the Code-required inspection interval, and whether the design and arrangement of Class 3 system components will also provide adequate clearances. Describe any special design arrangenents made for those components that are to be examined during normal reactor operation.

\subsubsection{Examination Techniques and Procedures}

Indicate the extent to which the examination techniques and procedures described in Section XI of the Code will be used. Describe any special examination techniques and procedures that might be used to meet the Code requirements.

\subsubsection{Inspection Intervals}

Indicate that an inspection schedule for Class 2 system components will be developed in accordance with the guidance of Section XI, Subarticle IWC-2400; and whether a schedule for Class 3 system components will be developed according to Subarticle IWD- 2400 .

\subsubsection{Examination Categories and Requirements}

Indicate that the inservice inspection categories and requirements for Class 2 components are in agreement with Section XI, Subarticles IWC- 2520 and IWC-2600. Indicate the extent to which inservice inspection 

categories and requirements for Class 3 components are in agreement with
Section XI, Subarticle IWD-2600.

\subsubsection{Evaluation of Examination Results}

Indicate that the evaluation of Class 2 component examination results will comply with the requirements of Article IWA-3000 of Section XI. Describe the method to be utilized in the evaluation of examination results for Class 3 components and, until the publication of IWD-3000, indicate the extent to which these methods are consistent with the requirements of Article IWA-3000 of Section XI. In addition, indicate that repair procedures for Class 2 components will comply with the requirements of Article IWC-4000 of Section XI. Describe the procedures to be utilized for repair of Class 3 components and indicate the extent to which these procedures are in agreement with Article IWD-4000 of Section XI.

\subsubsection{System Pressure Tests}

Indicate that the program for Class 2 system pressure testing will comply with the criteria of Code Section XI, Article IWC-5000. Indicate the extent to which the program for Class 3 system pressure tests will comply with the criteria of Article IWD-5000.

\subsubsection{Augmented Inservice Inspection to Protect Against Postulated}

Provide an augmented inservice inspection program for high-energy fluid system piping between containment isolation valves or, where no isolation valve is used inside containment, between the first rigid pipe connection to the containment penetration or the first pipe whip restraint inside containment and the outside isolation valve. This program should contain information concerning areas subject to examination, method of examination, and extent and frequency of examination.

\subsection{Main Steam Line Isolation Valve Leakage Control System (BWRs)}

The PSAR should describe the design bases and criteria to be applied and the preliminary system design and operation. The FSAR should describe how these requirements have been met.

\subsubsection{Design Bases}

This section should provide design bases for the main steam isolation valve leakage control system (MSIVLCS) in terms of:

3. The safety-related function of the system;

2. The system functional performance requirements, including the ability to function following a postulated loss of offsite power;

3. The seismic and quality group classification of the system; 
4. The requirements for protection from missiles, pipe whip, and jet forces and for its ability to withstand adverse environments associated with a postulated loss-of-coolant accident (LOCA);

5. The requirements of the MSIVLCS to function following an assumed single active failure;

6. The system capabilities to provide sufficient capacity, diversity, reliability, and redundancy to perform its safety function consistent with the need for maintaining containment integrity for as long as postulated LOCA conditions require;

7. The requirements for the system to prevent or control radioactive leakage from component parts or subsystems, including methods of processing, diluting, and discharging any leakage to minimize contributing to site radioactive releases;

8. The requirements for initiation and actuation of the system consistent with the requirements for instrumentation, controls, and interlocks provided for engineered safely systems; and

9. The requirements for inspection and testing during and subsequent to power operations.

The extent to which the design guidelines of Regulatory Guide 1.96, "Design of Main Steam Isolation Valve Leakage Control Systems for Boiling Water Reactor Nuclear Power Plants," will be followed should be indicated.

\subsubsection{System Description}

A detailed description of the MSIVLCS should be provided, including piping and instrumentation diagrams, system drawings, and location of components in the station complex. The description and drawings should also include subsystems, system operation (function), system interactions, components utilized, connection points, and instrumentation and controls utilized.

\subsubsection{System Evaluation}

An evaluation of the capability of the MSIVLCS to prevent or control the release of radioactivity from the main steam lines during and following a LOCA should be provided. The evaluation should include:

1. The ability of the system to maintain its safety function when. subjected to missiles, pipe whip, jet forces, adverse environmental conditions, and loss of offsite power coincident with the LOCA;

2. The ability of the system to withstand the effects of a single active failure (including the failure of any one MSIV to close); 
3. The protection afforded the system from the effects of failure of any non-Seismic Category I system or component;

4. The capability of the system to provide effective isolation of components and nonessential systems or equipment;

5. The capability of the system to detect and to prevent or control leakage of radioactive material to the environment. The quantity of material that could be released and the time release for each release path should be presented. (An analysis of the radiological consequences associated with the performance of this system following a design bas is lossof-coolant accident should be presented in Chapter 15.)

6. A failure mode and effects analysis to demonstrate that appropriate safety-grade instrumentation, controls, and interlocks will provide safe operating conditions, ensure system actuation following a LOCA, and preclude inadvertent system actuation; and

7. Assurance that a system malfunction or inadvertent operation will not have an adverse effect on other safety-related systems, components,
or functions.

\subsubsection{Instrumentation Requirements}

The system instrumentation and controls should be described. The adequacy of safety-related interlocks to meet the single-failure criterion should be demonstrated.

\subsubsection{Inspection and Testing}

The inspection and testing requirements for the MSIVLCS should be provided. The provisions made to accomplish such inspections and testing should be described.

\section{X Other Engineered Safety Features}

The engineered safety features included in reactor plant designs vary from plant to $p$ ? ant. Accordingly, for each engineered safety feature, component, or system provided in a plant and not al ready referred to in this chapter of the Standard Format, the SAR should include separate sections (numbered 6.5 through $6 . X$ ) patterned after the above and providing information on:

\section{X.1 Design Bases}

6.X.2 System Design

6.X. 3 Design Evaluation

$6 . X .4$ Tests and Inspections

6.X.5 Instrumentation Requirements 


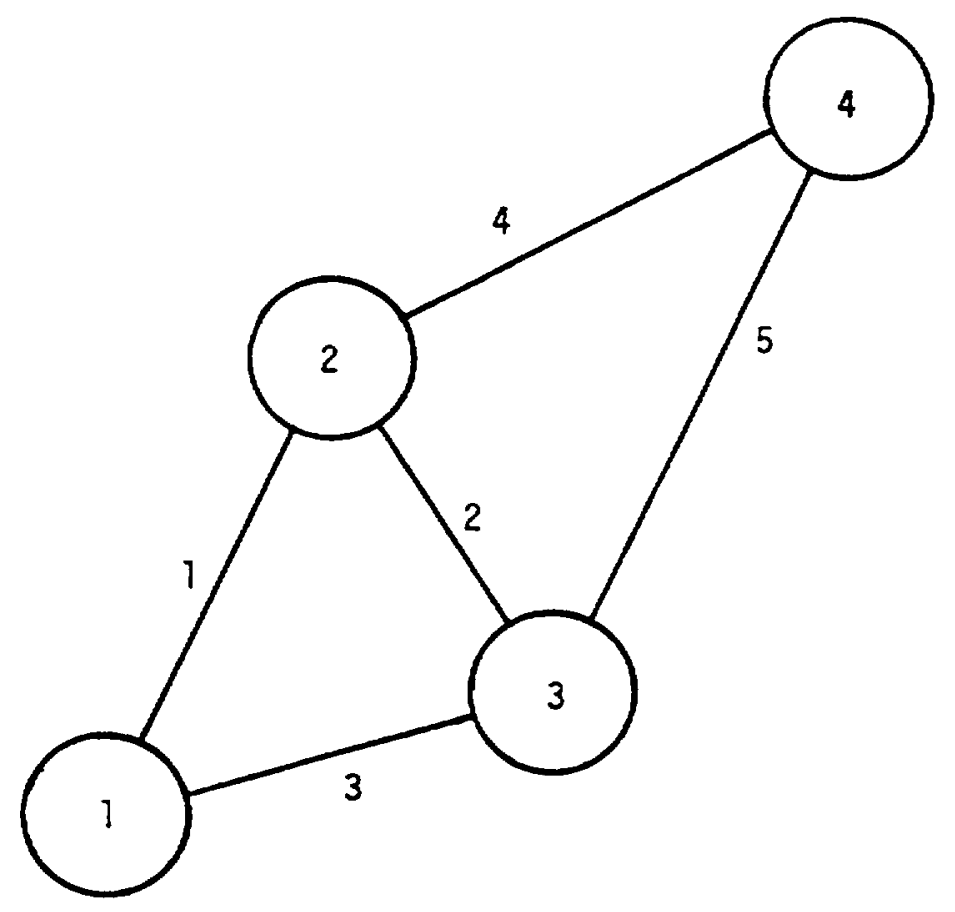

FIGURE $6-1$

EXAMPLE OF SUBCOMPARTMENT NODALIZATION DIAGRAM 


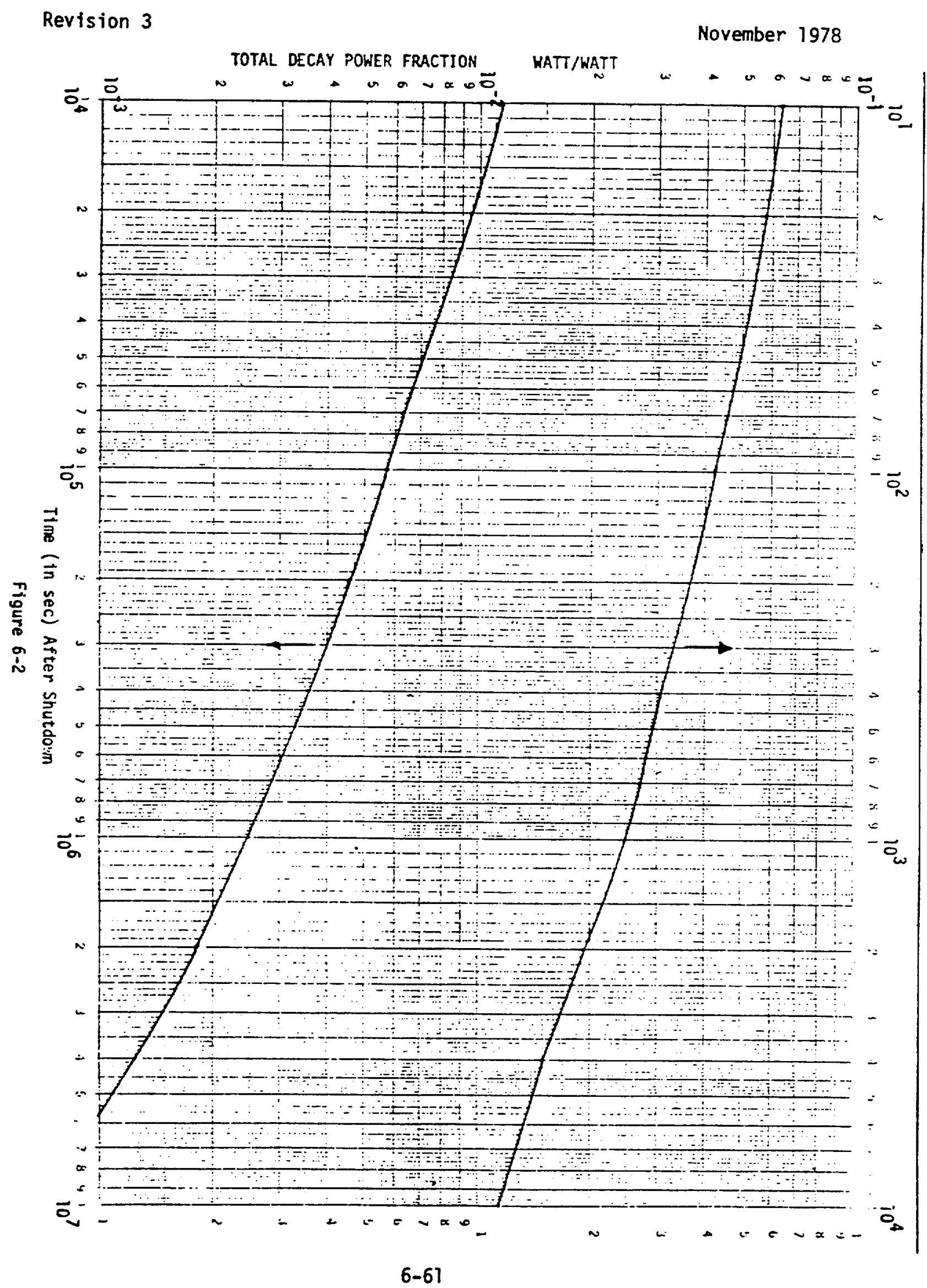




\section{TABLE 6-1}

INFORMATION TO BE PROVIDED FOR PWR DRY CONTAINMENTS

(INCLUDING SUBATMOSPHERIC CONTAINMENTS)

I. General Information
A. External Design Pressure, psig
B. Internal Design Pressure, psig
C. Design Temperature, ${ }^{\circ} \mathrm{F}$
D. Free Volume, $\mathrm{ft}^{3}$
E. Design Leak Rate, \&/day @ psig

II. Initial Conditions

A. Reactor Coolant System (at design overpower of $102 \%$ and at normal liquid levels)
1. Reactor Power Level, MWt
2. Average Coolant Temperature, ${ }^{\circ} \mathrm{F}$
3. Mass of Reactor Coolant System Liquid, $1 \mathrm{bm}$
4. Mass of Reactor Coolant System Steam, $1 \mathrm{bm}$
5. Liquid plus Steam Energy, ${ }^{\star}$ Btu

B. Containment
1. Pressure, psig
2. Temperature, ${ }^{{ }} \mathrm{F}$
3. Relative Humidity, $\%$
4. Service Water Temperature, ${ }^{\circ} \mathrm{F}$
5. Refueling Water Temperature, ${ }^{\circ} \mathrm{F}$
6. Outside Temperature, ${ }^{\circ} \mathrm{F}$
C. Stored Water (as applicable)
1. Borated-Water Storage Tank, $\mathrm{ft}^{3}$
2. All Accumulators (safety injection tanks), $\mathrm{ft}^{3}$
3. Condensate Storage Tanks, $\mathrm{ft}^{3}$

\footnotetext{
All energies are relative to $32^{\circ} \mathrm{F}$.
} 


\section{TABLE 6-2}

\section{PWR ENGINEERED SAFETY FEATURE SYSTEMS INFORMATION}

As indicated below, this information should be provided for two conditions: (1) full-capacity operation and (2) the capacities used in the containment analysis.

Full

Capacity
Value Used for Containment Analysis

A. Passive Safety Injection System

1. Number of Accumulators

(Safety Injection Tanks)

2. Pressure Setpoint, psig

B. Active Safety Injection Systems

1. High-Pressure Safety Injection

a. Number of Lines

b. Number of Pumps

c. Flow Rate, gpm

2. Low-Pressure Safety Injection
a. Number of Lines
b. Number of Pumps
c. Flow Rate, gpm

C. Containment Spray System

1. Injection Spray
a. Number of Lines
b. Number of Pumps
c. Number of Headers
d. Flow Rate, gpm

2. Recirculation Spray
a. Number of Lines
b. Number of Pumps 


\section{TABLE 6-2 (Continued)}

Full

Capacity
Value Used for

Containment Analysis c. Number of Headers

d. Flow Rate, gpm

D. Containment Fan Cooler

System

1. Number of Units

2. Air-Side flow Rate, cfm

3. Heat Removal Rate at

Design Temperature, $10^{6}$

Btu/hr

4. Overall Heat Transfer

Coefficient, Btu/hr- $\mathrm{ft}^{2}-^{\circ} \mathrm{F}$

E. Heat Exchangers

1. Recirculation Systems
a. System
b. Type
c. Number
d. Heat Transfer Area, $\mathrm{ft}^{2}$
e. Overall Heat Transfer Coefficient, Btu/hr- $\mathrm{ft}^{2}-{ }^{\circ} \mathrm{F}$
f. Flow Rates:

(1) Recirculation Side, gpm

(2) Exterior Side, gpm

g. Source of Cooling Water

h. Flow Begins, sec 
TABLE 6-3

\section{SUMMARY OF CALCULATED CONTAINMENT PRESSURE AND TEMPERATURES}

Pipe Break Location and Break Area, $\mathrm{ft}^{2}$ Calculated Value

Peak Pressure, psig

Peak Temperature, ${ }^{\circ} \mathrm{F}$

Time of Peak Pressure, sec

Energy Released to Containment up to the End of Blowdown, $10^{6} \mathrm{Btu}$ 


\section{TABLE 6-4}

\section{PASSIVE HEAT SINKS}

\section{A. LISTING OF PASSIVE HEAT SINKS ${ }^{\star}$}

The following structures, components, and equipment are examples of passive heat sinks that should be included in the submittal, as appropriate:

Containment Building

1. Building/liner

2. External concrete walls

3. Building liner steel anchors

4. Building floor and sump

5. Personnel hatches

6. Equipment hatches

\section{Internal Structures}

7. Internal separation walls and floors

8. Refueling pool and fuel transfer pit walls and floors

9. Crane wall

10. Primary shield walls

11. Secondary shield walls

12. Piping tunne?

13. Pressurizer room

14. Reheat exchanger room

15. Valve room

16. Fuel canal shielding

17. Jet impingement deflectors

18. Regenerative heat exchanger shield

19. Other

\section{Lifting Devices}

20. Lifting rig

21. Refueling machine

22. Vessel head lifting rig

23. Polar crane

24. Manipulator crane

25. Other

\section{Supports}

\section{Reactor vessel supports}

27. Steam generator supports

* Provide best estimates of these heat sinks in the PSAR stage and a detailed listing in the FSAR. 


\section{TABLE 6-4 (Continued)}

28. Fuel canal support

29. Reactor coolant pump supports

30. Safety injection tank supports

3). Pressure relief tank supports

32. Drain tank supports

33. Fan cooler support

34. Other

Storage Racks

35. Fuel storage

36. Head storage

37. Other

Gratings, Ladders, etc.

38. Ladders, stainways

39. Floor plates

40. Steel handrails and platform railings

41. Steel gratings

42. Steel risers

43. Steel tread and stringers

Electrical Equipment

44. Cables, conduits

45. Cable trays

46. Instrumentation and control equipment, electrical boxes

47. Electric penetrations

Piping Support Equipment

48. Restraints

49. Hangers

50. Piping penetrations

Components

51. Reactor heat removal pumps and motors

52. Reactor coolant pump motors

53. Hydrogen recombiners

54. Fan coolers

55. Reactor cavity and support cooling units

56. Air filter units

57. Air blowers

58. Air heating equipment 
Revision 3

\section{TABLE 6-4 (Continued)}

59. Safety injection tanks

60. Pressurizer quench tank

61. Reactor drain tank

62. Other

Uninsulated Cold-Water-Filled Piping and Fittings

63. Reactor heat removal system

64. Service water system

65. Component cooling water system

66. Other

Drained Piping and Fittings

67. Containment spray piping and headers

68. Other

Heating, Ventilation, and Air Conditioning

69. Ducting

70. Duct dampers 
IABLE 6-4 PASSIVE HEAT SINKS (Continued)

B. MODELING OF PASSIVE HEAT SINKS

The following data should be provided for the passive heat sinks listed in Table 6-4A (best estimates in the PSAR stage and a detailed listing in the FSAR stage):

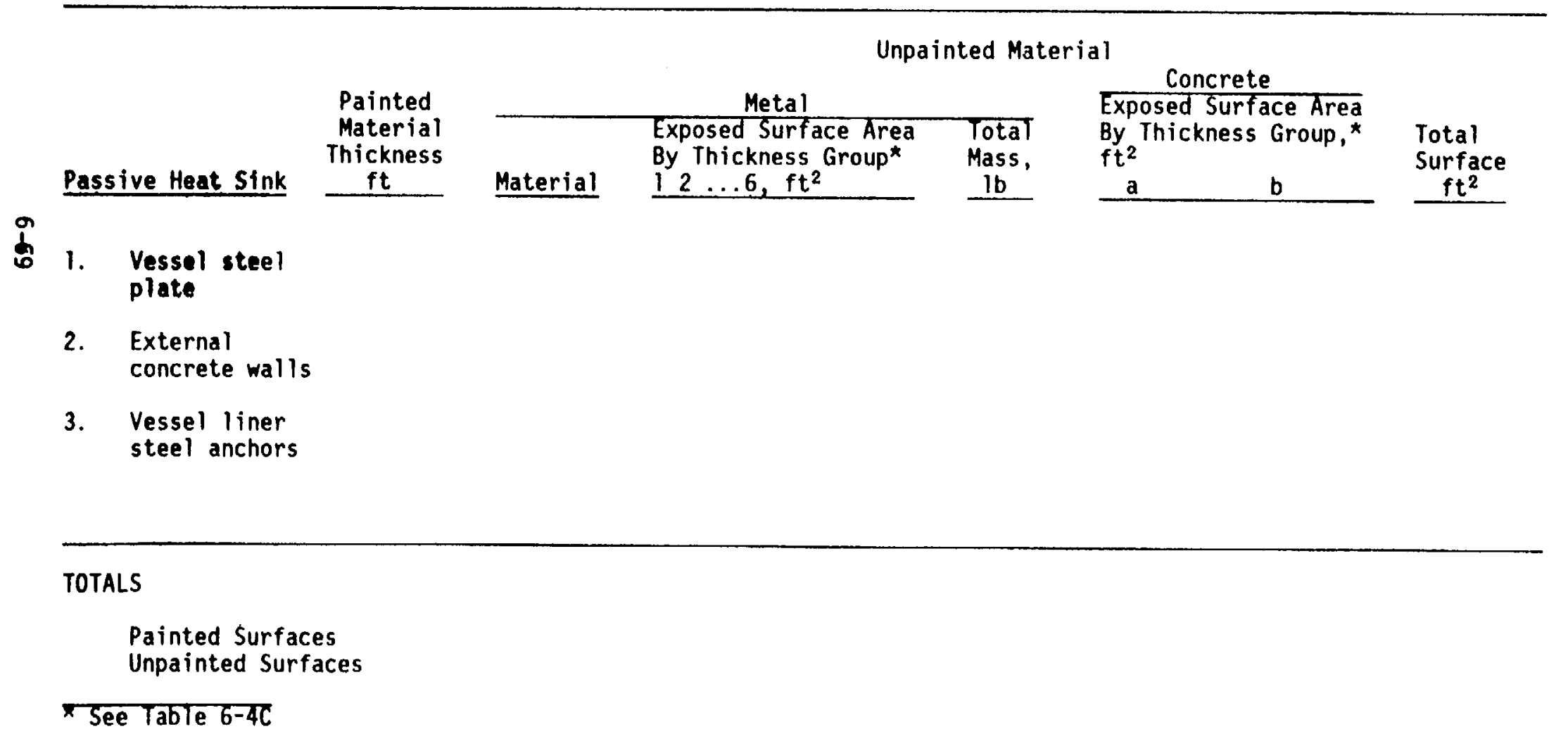


Revision 3

November 1978

TABLE 6-4 PASSIVE HEAT SINKS (Continued)

C. THICKNESS GROUPS

Material

Group

Designation

Thickness Range,

Metal

1 in.

$0-0.125$

2

$0.125-0.25$

3

$0.25-0.5$

4

$0.50-1.00$

5

$1.00-2.50$

6

$>2.50$

Concrete

a

$0-3.0$

b

$>3.0$ 


\section{TABLE 6-4 PASSIVE HEAT SINKS (Continued)}

D. THERMOPHYSICAL PROPERTIES OF PASSIVE HEAT SINK MATERIALS

\begin{tabular}{|c|c|c|c|}
\hline Mate & $\begin{array}{l}\text { Density, } \\
1 \mathrm{~b} / \mathrm{ft}^{3}\end{array}$ & $\begin{array}{l}\text { Heat, } \\
\text { Btu/lb-o F }\end{array}$ & $\begin{array}{l}\text { Conductivity } \\
\text { Btu/hr-ft-oF }\end{array}$ \\
\hline
\end{tabular}


TABLE 6-5

INFORMATION TO BE PROVIDED FOR ICE CONDENSER CONTAINMENTS

I. Lower Compartment
A. Free Volume, $\mathrm{ft}^{3}$
B. Design Pressure, psig
C. Design Temperature, ${ }^{\gamma} \mathrm{F}$
D. Peak Pressure; DBA, psig
E. Pressure Margin, $\mathscr{X}$
F. Normal Operating Temperature, ${ }^{\circ} \mathrm{F}$
G. Normal Operating Pressure, psia
H. Normal Operating Relative Humidity, $x$

II. Upper Compartment
A. Free Volume, ft
B. Design Pressure, psig
C. Design Temperature, ${ }^{8} F$
D. Peak Pressure, DBA, psig
E. Pressure Margin, $\%$
F. Normal Operating Temperature, ${ }^{\circ} \mathrm{F}$
G. Normal Operating Pressure, psia
H. Normal Operating Relative Humidity, $X$

III. Ice Condenser
A. Ice Weight, Ib
B. Flow Area, $\mathrm{ft}^{2}$
C. Length/Hydraulic Diameter
D. Channel Surface Area, $\mathrm{ft}^{2}$
E. Ice Basket Diameter, $\mathrm{ft}$
$F$. Inlet Door Area, $\mathrm{ft}^{2}$
G. Ice Condenser Fiow Area, $\mathrm{ft}^{2}$
H. Volume, $\mathrm{ft}^{3}$
I. Ice Bed Height, ft
J. Inlet Door Opening Pressure, psf
K. Ice Boron Concentration, ppm
L. O.D., ft
M. I.D., ft

IV. Refrigeration Cooling Capacity
A. Cooling Capacity for Compartment, tons
B. Number of Fan Coolers per Unit
C. Air Temperature to Insulated Panels, ${ }^{\circ} \mathrm{F}$ 
TABLE 6-5 (Continued)

V. General Information

A. External Design Pressure, psig

B. Internal Design Pressure, psig

C. Design Leak Rate, $\% /$ day psig

VI. Initial Conditions

A. Reactor Coolant System (at design overpower of 1026 and at normal liquid levels)

1. Reactor Power Level, Mwt

2. Average Coolant Temperature, ${ }^{\circ} \mathrm{F}$

3. Mass of Reactor Coolant System Liquid, 1bm

4. Mass of Reactor Coolant System Steam, Ibm

5. Liquid plus Steam Energy, ${ }^{\star}$ Btu

B. Containment

1. Pressure, psig

2. Temperature, ${ }^{\circ} \mathrm{F}$ (upper compartment, lower compartment, and ice condenser)

3. Relative Humidity, $\%$ (upper compartment, lower compartment, and ice condenser)

4. Service Water Temperature, ${ }^{\circ} \mathrm{F}$

5. Refueling Water Temperature, of

6. Outs ide Temperature, ${ }^{\circ} \mathrm{F}$

C. Stored Water (as applicable)

1. Borated Water Storage Tank, $\mathrm{ft}^{3}$

2. All Accumulators (safery injection tanks), $\mathrm{ft}^{3}$

3. Condensate Storage Tanks, $\mathrm{ft}^{3}$

Thl energies are relative to $32^{\circ} \mathrm{F}$. 


\section{TABLE 6-6}

INFORMATION TO BE PROVIDED FOR WATER POOL PRESSURE-SUPPRESSION CONTAINMENTS

A. Drywe11

1. Internal Design Pressure, psig (Mark II)

2. Drywe 1] Deck Design Differential Pressure, psid (Mark II)

3. Drywe ll Design Differential Pressure, psid (Mark III)

4. External Design Pressure, psig

5. Design Temperature, of

6. Free Volume, $\mathrm{ft}^{3}$

7. Design Leak Rate, $\% /$ day o psig

B. Containment (Wetwell)

1. Internal Design Pressure, psig

2. External Design Pressure, psig

3. Design Temperature, ${ }^{\circ} \mathrm{F}$

4. Air Volume (min/max), $\mathrm{ft}^{3}$

5. Wetwell Air Volume, $\mathrm{ft}^{3}$ (Mark III)

6. Pool Volume (min/max), $\mathrm{ft}^{3}$

7. Suppression Pool Makeup Volume, $\mathrm{ft}^{3}$ (Mark III)

8. Pool Surface Area, $\mathrm{ft}^{2}$

9. Pool Depth (min/max), ft

10. Design Leak Rate, $\mathscr{X} /$ day psig

11. Hydraulic Control Unit Floor Flow Restriction, \& restricted (Mark III)

C. Vent System

1. Number of Vents

2. Vent Diameter, ft

3. Net Free Vent Area, $\mathrm{ft}^{2}$

4. Vent Submergence(s) (min/max), ft

5. Vent System Loss Factors

6. Drywell Wall to Weir Wall Distance, ft (Mark III)

7. Net Weir Annulus Cross-Sectional Area, $\mathrm{ft}^{2}$ (Mark III) 


\section{TABLE 6-7}

ENGINEERED SAFETY FEATURE SYSTEMS INFORMATION FOR WATER-POOL PRESSURESUPPRESSION CONTAINMENTS

This information should be provided for two conditions: (1) fullcapacity operation and (2) the capacities used in the containment analysis.

A. Containment Spray System

1. Number of Spray Pumps

2. Capacity per Pump, gpm

3. Number of Spray Headers

4. Spray Flow Rate - Drywe I1, Ib/hr

5. Spray Flow Rate - Wetwe 1], lb/hr

6. Spray Thermal Efficiency, $\mathscr{x}$

B. Containment Cooling System

1. Number of Pumps

2. Capacity per Pump, gpm

3. Number of Heat Exchangers

4. Heat Exchanger Type

5. Heat Transfer Area per Exchanger, $\mathrm{ft}^{2}$

6. Overall Heat-Transfer Coefficient, Btu/hr $\mathrm{ft}^{2}$ of

7. Secondary Coolant Flow Rate per Exchanger, $\mathrm{lb} / \mathrm{hr}$

8. Design Service Water Temperature $(\min / \max ),{ }^{\circ} \mathrm{F}$ 
TABLE 6-8

INITIAL CONDITIONS FOR ANALYSIS OF WATER-POOL PRESSURESUPPRESSION CONTAINIENTS

A. Reactor Coolant System (at design overpower of $102 \%$ and at normal liquid levels)

1. Reactor Power Level, Mwt

2. Average Coolant Pressure, psig

3. Average Coolant Temperature, ${ } F$

4. Mass of Reactor Coolant System Liquid, Ib

5. Mass of Reactor Coolant System Stean, ib

6. Volume of Water in Reactor Vesse ], $\mathrm{ft}^{3}$

7. Volume of Steam in Reactor Vessel, $\mathrm{ft}^{3}$

8. Volume of Water in Recirculation Loops, $\mathrm{ft}^{3}$

B. Drywell

1. Pressure, psig

2. Temperature, ${ }^{8} F$

3. Relative Humidity, $\mathscr{x}$

C. Containment (suppression chamber)

1. Pressure, psig

2. Air Temperature, ${ }^{\circ} \mathrm{F}$

3. Water Temperature, ${ }^{\circ} \mathrm{F}$

4. Relative Humidity, $\varnothing$

5. Water Volume, $\mathrm{ft}^{3}$

6. Vent Submergence, $f t$ 
TABLE 6-9

\section{ENERGY SOURCES FOR WATER-POOL PRESSURE-SUPPRESSION \\ CONTAINMENT ACCIDENT ANALYSES}

1. Decay heat rate, Btu/sec, as a function of time

2. Primary system sensible heat release to containment, Btu/sec, as a function of time

3. Metal-water reaction heat rate, $B t u / s e c$, as a function of time

4. Heat release rate from other sources, $B t u / s e c$, as a function of time 


\section{TABLE $6-10$}

MASS AND ENERGY RELEASE DATA FOR ANALYSIS OF WATER-POOL PRESSURE-SUPPRESSION CONTAINMENT ACCIDENTS

A. Recirculation Line Break

1. Pipe I.D., in.

2. Effective Total Break Area, $f t^{2}$, versus time

3. Name of Blowdown Code

4. Blowdown Table

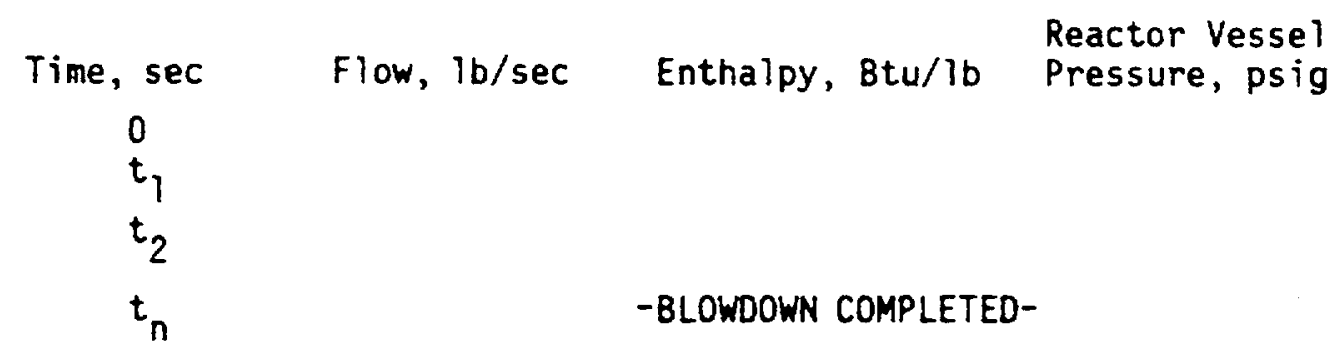

B. Main Steam Line Break

1. Pipe I.D., in.

2. Effective Total Break Area, $\mathrm{ft}^{2}$, versus time

3. Name of Blowdown Code

4. Blowdown Table

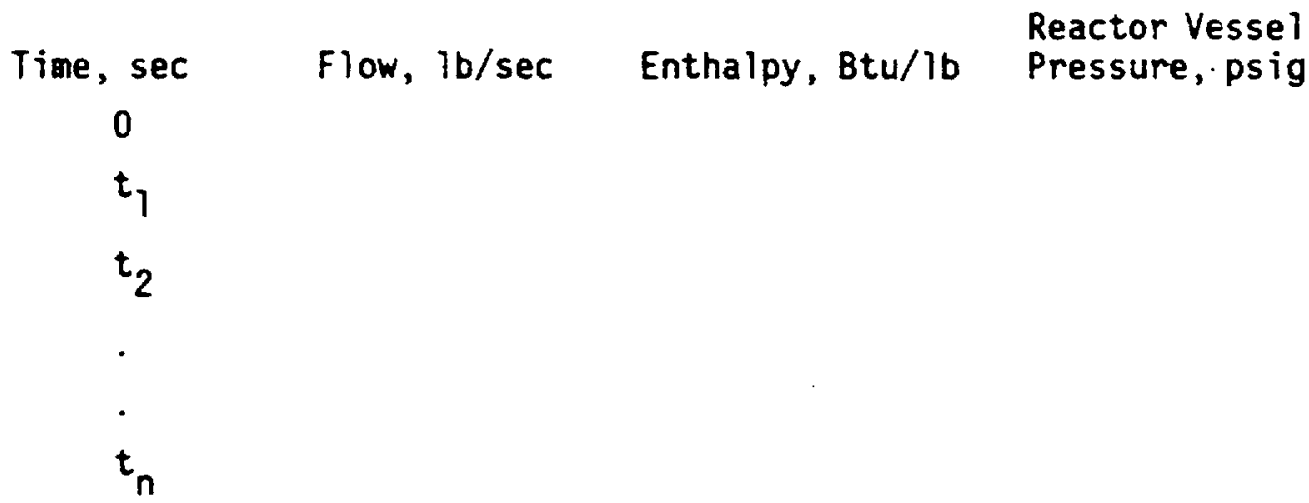




\section{TABLE 6-11}

PASSIVE HEAT SINKS USED IN THE ANALYSIS OF BWR PRESSURESUPPRESSION CONTAIMMENTS

(If Applicable)

A. Listing of Passive Heat Sinks

Provide a listing of all structures, components, and equipment used as passive heat sinks (see Table 6-4A).

B. Detailed Passive Heat Sink Data

The information to be provided and the format are given in Table 6-4B, 6-4C, and 6-4D.

c. Heat Transfer Coefficients

Graphically show the condensing heat transfer coefficients as functions of time for the design basis accident. 


\section{TABLE 6-12}

\section{RESULTS OF WATER-POOL PRESSURE-SUPPRESSION}

CONTAINAENT ACCIDENT ANALYSES

The information presented below should be based on the values used for containment analysis presented in Table 6-7.

A. Accident Parameters

\begin{tabular}{ll}
$\begin{array}{c}\text { Recirculation } \\
\text { Line Break }\end{array}$ & $\begin{array}{c}\text { Steam Line } \\
\text { Break }\end{array}$ \\
\hline
\end{tabular}

1. Peak Drywe 11 Pressure, psig (Mark II)

2. Peak Drywell Deck Differential Pressure, psid (Mark II)

3. Peak Drywell Differential Pressure, psid (Mark III)

4. Time(s) of Peak Pressures, sec

5. Peak Drywell Temperature, of

6. Peak Containment (Suppression Chamber) Pressure, psig

7. Time of Peak Containment Pressure, sec

8. Peak Wetwell Pressure, psig

9. Time of Peak Wetwell Pressure, sec

10. Peak Containment Atmospheric Temperature, ${ }^{\circ} \mathrm{F}$

11. Peak Suppression Pool Temperature, ${ }^{\circ} \mathrm{F}$

The above tabulation should be supplemented by plots of containment and drywe 11 pressure and temperature, vent flow rate, energy release rate. and energy removal rate as functions of time to at least 106 seconds. 


\section{TABLE 6-12 (Continued)}

B. Energy Balance of Sources and Sinks

1. Reactor Coolant

2. Fuel and Cladding

3. Core Internals

4. Reactor Vessel Metal

5. Reactor Coolant System

Piping, Pumps, and Valves

6. Blowdown Enthalpy

7. Decay Heat

8. Metal-Water Reaction Heat

9. Drywell Structures

10. Drywell Air

11. Drywell Steam

12. Containment Air

13. Containment Steam

14. Suppression Pool Water

15. Heat Transferred by Heat Exchangers

16. Passive Heat Sinks

Time, sec

\begin{tabular}{c|l|l|l}
\hline & $\begin{array}{c}\text { Drywell } \\
\text { Peak } \\
\text { Pressure }\end{array}$ & $\begin{array}{l}\text { End of } \\
\text { Blowdown }\end{array}$ & $\begin{array}{c}\text { Long-Term } \\
\text { Peak } \\
\text { Pressure }\end{array}$ \\
\hline 0 & Energy, $10^{6}$ Btu & \\
\hline & & & \\
& & & \\
& & & \\
& & &
\end{tabular}


TABLE $6-13$

SUBCOMPARTMENT VENT PATH DESCRIPTION

\begin{tabular}{|c|c|c|c|c|c|c|c|c|c|c|c|}
\hline VEN & $\begin{array}{l}\text { FROM } \\
\text { VOL. }\end{array}$ & $\begin{array}{l}\text { TO } \\
\text { VOL. }\end{array}$ & $\begin{array}{c}\text { DESCRIPTION } \\
\text { OF }\end{array}$ & & & HYORAULIC & & HEAL & LOSS & & \\
\hline $\begin{array}{l}\text { PATH } \\
\text { NO. }\end{array}$ & $\begin{array}{l}\text { NODE } \\
\text { NO. }\end{array}$ & $\begin{array}{l}\text { NODE } \\
\text { NO. }\end{array}$ & $\begin{array}{l}\text { VENT PATH FLOW } \\
\text { CHOKED UNCHOCKED }\end{array}$ & $\begin{array}{l}\text { AREA } \\
\mathrm{ft}^{2}\end{array}$ & $\begin{array}{c}\text { LENGTH } \\
\mathrm{ft}\end{array}$ & $\begin{array}{l}\text { DIAMETER } \\
\mathrm{ft}\end{array}$ & $\begin{array}{l}\text { FRICTION } \\
\mathrm{K}, \mathrm{ft} / \mathrm{d}\end{array}$ & $\begin{array}{l}\text { TURNING } \\
\text { LOSS, K }\end{array}$ & $\begin{array}{l}\text { EXPAN- } \\
\text { SION, K }\end{array}$ & $\begin{array}{l}\text { CONTRAC- } \\
\text { TION, K }\end{array}$ & TOTAL \\
\hline
\end{tabular}

0
1
0
0 
TABLE $6-14$

SUBCOMPARTMENT NODAL DESCRIPTION

\begin{tabular}{|c|c|c|c|c|c|c|c|c|c|c|c|c|c|}
\hline & & & & INITIAL & CONOII & IONS & & BREAK & CONDITION & & CAL & DESIGN & SIG \\
\hline $\begin{array}{l}\text { VOLUME } \\
\text { NO. }\end{array}$ & DESCRIPTION & $\begin{array}{c}\text { HEIGHT, } \\
\mathrm{ft}\end{array}$ & $\begin{array}{l}\text { SECT IONAL } \\
\text { AREA, } \\
\mathrm{ft}^{2}\end{array}$ & $\begin{array}{l}\text { TEMP. } \\
{ }^{\circ} \mathrm{F}\end{array}$ & $\begin{array}{l}\text { PRESS. } \\
\text { psia }\end{array}$ & $\begin{array}{l}\text { HUMID. } \\
\%\end{array}$ & $\begin{array}{l}\text { BREAK } \\
\text { LOC. } \\
\text { VOL. } \\
\text { NO. }\end{array}$ & $\begin{array}{l}\text { BREAK } \\
\text { LINE }\end{array}$ & $\begin{array}{l}\text { BREAK } \\
\text { AREA } \\
\mathrm{ft}^{2}\end{array}$ & $\begin{array}{l}\text { BREAK } \\
\text { TYPE }\end{array}$ & $\begin{array}{l}\text { PEAK } \\
\text { PRESS } \\
\text { DIFF. } \\
\text { psig } \\
\end{array}$ & $\begin{array}{l}\text { PEAK } \\
\text { PRESS } \\
\text { DIFF. } \\
\text { Dsig } \\
\end{array}$ & $\begin{array}{c}\text { MARGIN } \\
x\end{array}$ \\
\hline
\end{tabular}

0
1
0
$\omega$ 
TABLE 6-15

MASS AND ENERGY RELEASE RATE DATA

FOR POSTULATED LOSS-OF-COOLANT ACCIDENTS

Pipe I.D., in.

Break Area, $f t^{2}$

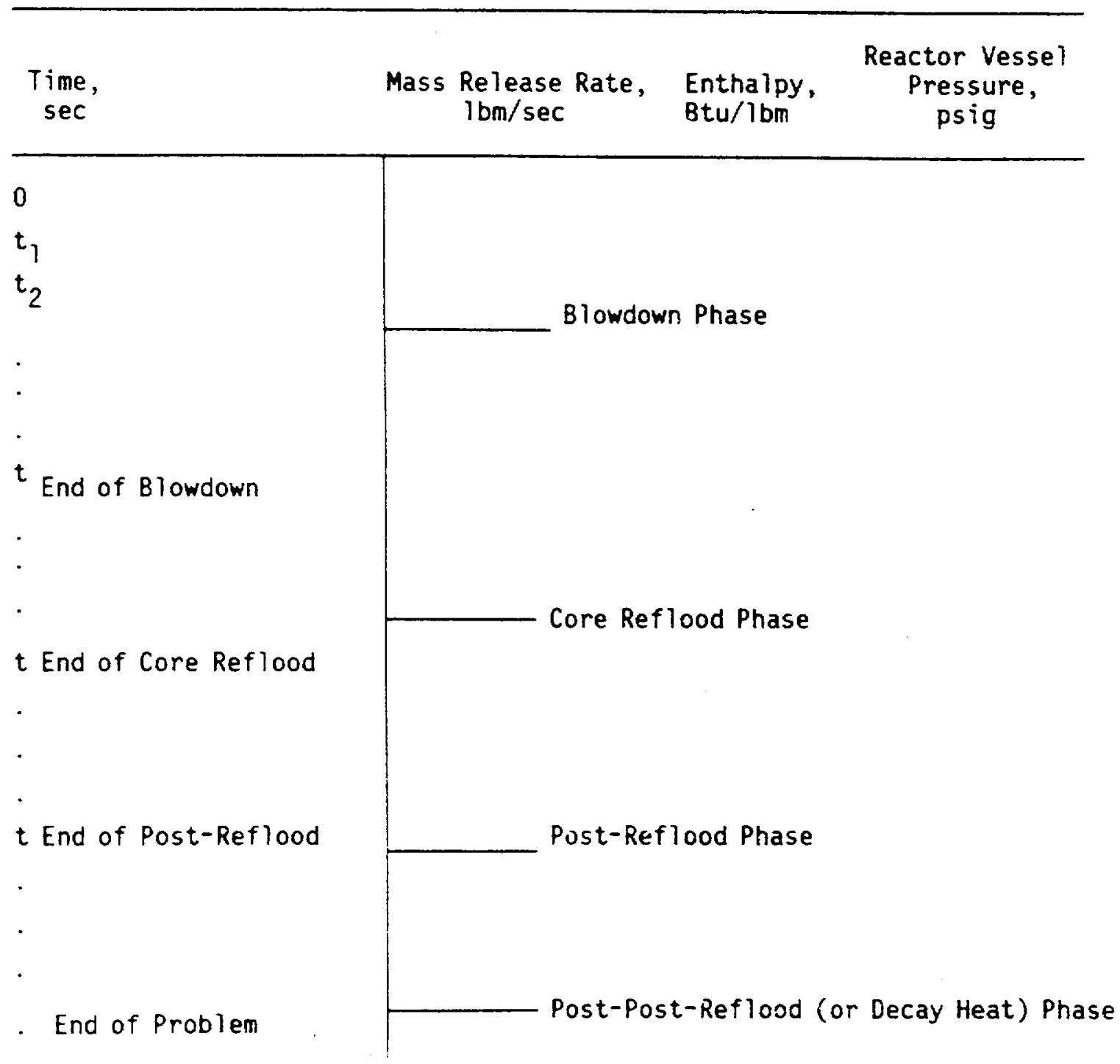

6-84 
TABLE 6-16

REACTOR CONTAINMENT BUILDING ENERGY DISTRIBUTION

PIPE BREAK LOCATION AND PIPE BREAK AREA

Note: The datum temperature is $32^{\circ} \mathrm{F}$ unless otherwise noted.

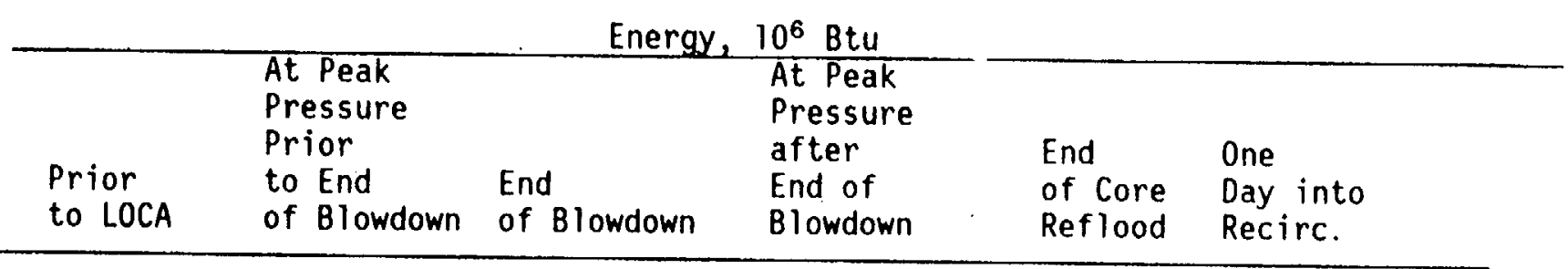

Reactor Coolant

Internal Energy

o) Core Flood Tank Coolant

ó Internal Energy

Energy Stored in Core

Energy Stored in RV Internals

Energy Stored in RV Metal

Energy Generated During

Shutdown from Decay Heat

Energy Stored in Pressurizer,

Primary Piping, Valves, and Pumps

Energy Stored in Steam

Generator Metal

Secondary Coolant Internal

Energy (in Steam Generators)

Energy Content of RCB

Atmosphere * 
TABLE 6-16 (Continued)

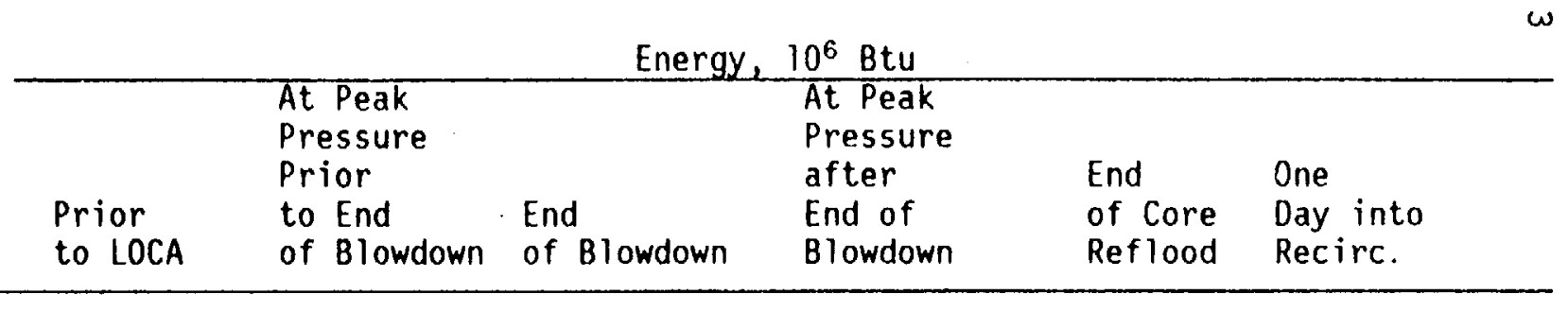

Energy Content of RCB and

Internal Structures $\star \star$

Energy Content of

Recirculation Intake

Water

En
$\stackrel{1}{o}$ Energy Content of BWST
on

Energy Removed by Decay

Heat Removal Coolers

Energy Removed by

Reactor Containment

Building Fan Coolers

Atmospheric constituent datums are $120^{\circ} \mathrm{F}$ for air and $32^{\circ} \mathrm{F}$ for water vapor.

** Datum for energy content of Reactor Containment Building and internal structures is $120^{\circ} \mathrm{F}$. 


\section{TABLE 6-17}

\section{ADDITIONAL INFORMATION TO BE PROVIDED FOR \\ DUAL-CONTAINMENT PLANTS}

I. Secondary Containment Design

For each volume comprising the secondary containment, provide the following information:
A. Free Volume, $\mathrm{ft}^{3}$
B. Pressure, inches of water, gauge
1. Normal Operation
2. Postaccident
C. Leak Rate at Postaccident Pressure (\%/day)
D. Exhaust Fans
1. Number
2. Type
E. Filters
1. Number
2. Type

II. Transient Analysis

A. Initial Conditions (provide for each volume if different)

1. Pressure, psia

2. Temperature, ${ }^{\circ} \mathrm{F}$

3. Outside Air Temperature, ${ }^{\circ} \mathrm{F}$

4. Thickness of Secondary Containment Wall, in

5. Thickness of Primary Containment wall, in 
TABLE 6-17 (Continued)

B. Thermal Characteristics

1. Primary Containment Wall

a. Coefficient of Linear Expansion, in $/ \mathrm{in}^{\circ} \mathrm{F}$ (if applicable)

b. Modulus of Elasticity, psi (if applicable)

c. Thermal Conductivity, Btu/hr-ft-of

d. Thermal Capacitance, $B t u / \mathrm{ft}^{3}{ }^{\circ} \mathrm{F}$

2. Secondary Containment Wall

a. Thermal Conductivity, Btu/hr-ft- ${ }^{\circ} \mathrm{F}$

b. Thermal Capacitance, $\mathrm{Btu} / \mathrm{ft}^{3}-^{\circ} \mathrm{F}$

3. Heat Transfer Coefficients

a. Primary Containment Atmosphere to Primary Containnent Wall, Btu/hr-ft ${ }^{2}-{ }^{\circ} \mathrm{F}$

b. Primary Containment Wall to Secondary Containment Atnosphere, Btu/hr-ft ${ }^{2}-{ }^{\circ} \mathrm{F}$

c. Secondary Containment Wall to Secondary Containment Atmosphere, Btu/hr- $\mathrm{ft}^{2}-^{\circ} \mathrm{F}$

d. Primary Containment Enissivity, $B t u / h r-\mathrm{ft}^{2}-{ }^{\circ} \mathrm{F}$

e. Secondary Containment Enissivity, Btu/hr-ft ${ }^{2-0} \mathrm{~F}$ 


\section{TABLE $6-18$}

EVALUATION OF POTENTIAL BYPASS LEAKAGE PATHS

FOR DUAL-CONTAINHENT PLANTS

\section{System}

List all primary

containment penetrations

by system or line and

penetration designation
Termination
Region
Bypass

Leakage Barriers

Key to a list of

leakage barriers

(e.g., valves,

collection systems, closed systems)
Potential

Bypass Path

(Yes or No) 


\section{TABLE 6-19}

PRIMARY CONTAINMENT OPERATION

FOLLOWING A DESIGN BASIS ACCIDENT

General

Type of Structure

Appropriate Internal Fission Product Removal Systems

Free Volume of Primary Containment

Mode of Hydrogen Purge (e.g., direct to environs, to recirculation system, to annulus)

Time-Dependent Parameters

Anticipated Conservative

Leak Rate of Primary Containment

Leakage Fractions to Volumes Outside the Primary Containment (including the environment).

Effectiveness of Fission Product Removal Systems

Initiation of Hydrogen Purge

Hydrogen Purge Rate 
Revision 3

November 1978

TABLE $6-20$

SECONDARY CONTAINMENT OPERATION

FOLLOWING A DESIGN BASIS ACCIDENT*

General

Type of Structure

Free Volume

Annulus Width (where applicable)

Location of Fission Product Removal Systems

Time-Dependent Parameters

Anticipated

Conservative

Mixing Fraction

Leak Rate

Total Recirculation Flow

Exhaust Flow

Pressure

Effectiveness of Fission Product

Removal Systems

There should be a table such as this for each secondary containment volume. 


\section{INSTRUMENTATION AND CONTROLS}

The reactor instrumentation senses the various reactor parameters and transmits appropriate signals to the regulating systems during normal operation, and to the reactor trip and engineered-safety-feature systems during abnormal and accident conditions. The information provided in this chapter should emphasize those instruments and associated equipment which constitute the protection system (as defined in IEEE Std 279-1971, "Criteria for Protection Systems for Nuclear Power Generating Stations"). The analys is of regulating systems and instrumentation should be provided, particularly considerations of regulating system-induced transients which, if not terminated in a timely manner, could result in fuel damage, radiation release, or other public hazard. Details of seismic design and testing should be provided in Section 3.10 .

\subsection{Introduction}

\subsubsection{Identification of Safety-Related Systems}

List all instrumentation, control, and supporting systems that are safety related, including alarm, communication, and display instrumentation. Distinguish between those systems designed and built by the nuclear steam system supplier and those designed or built by others. Identify the systems that are identical to those of a nuclear power plant of similar design that has recently received a construction permit or an operating license; identify those that are different and discuss the differences and their effects on safety-related systems.

\subsubsection{Identification of Safety Criteria}

List all design bases (including considerations of instrument errors), criteria, regulatory guides, standards, and other documents that will be implemented in the design of the systems listed in section 7.1.1.

The specific information identified below should be included in this section of the SAR when it applies equally to all safety-related instrumentation and control systems; otherwise it should be in the section of this chapter that discusses the system to which the information applies.

Provide a description of the technical design bases for all the various functions of the protection system (e.g., scram if reactor vessel water level is __ this is needed because ; ; is is required to operate within In addition to the reactor scran function, bases should be given for all other protection system fanctions, including engineered safety features, emergency power, interlocks, bypasses, and equipment protection. Diversity requirements should be stated (see IEEE Std 279-1971).

Describe the extent to which the recommendations of the regulatory guides listed below are followed. Wherever alternative approaches are used, demonstrate that an acceptable level of safety has been attained. 
Regulatory Guide 1.11 (Safety Guide 11), "Instrument Lines Penetrating Primary Reactor Containment;"

Regulatory Guide 1.22 (Safety Guide 22), "Periodic Testing of Protection System Actuation Functions;"

Regulatory Guide 1.29, "Seismic Design Classification;"

Regulatory Guide 1.30 (Safety Guide 30), "Quality Assurance Requirements for the Installation, Inspection, and Testing of Instrumentation and Electric Equipment;"

Regulatory Guide 1.40, "Qualification Tests of Cont inuous-Duty Motors Installed Inside the Containment of Water-Cooled Nuclear Power Plants;"

Regulatory Guide 1.47, "Bypassed and Inoperable Status Indication for Nuclear Power Plant Safety Systems;"

Regulatory Guide 1.53, "Application of the Single-Failure Criterion to Nuclear Power Plant Protection Systems;"

Regulatory Guide 1.62, "Manual Initiation of Protective Actions;"

Regulatory Guide 1.63, "Electric Penetration Assemblies in Containment Structures for Light-Water-Cooled Nuclear Power Plants;"

Regulatory Guide 1.68, "Initial Test Program for Water-Cooled Reactor Power Plants;"

Regulatory Guide 1.73, "Qualification Tests of Electric Valve Operators Installed Inside the Containment of Nuclear Power Plants;"

Regulatory Guide 1.75, "Physical Independence of Electric Systems." The physical identification of safety-related equipment should also be addressed in this section; Systems;"

Regulatory Guide 1.80, "Preoperational Testing of Instrument Air

Regulatory Guide 1.89, "Qualification of Class IE Equipment for Nuclear Power Plants;"

Regulatory Guide 1.97, "Instrumentation for Light-Water-Cooled Nuclear Power Plants to Assess Plant Conditions During and Following an Accident;"

Regulatory Guide 1.100, "Seismic Qualification of Electric Equipment for Nuclear Power Plants;"

Regulatory Guide 1.105, "Instrument Setpoints;" and 

Regulatory Guide 1.118 , "Periodic Testing of Electric Power and Pro-
tection Systems."

\subsection{Reactor Trip System}

For standardized systems, it is preferred that the information listed be supplied in a topical report and that the topical report be referenced
in the appropriate place in the SAR.

\subsubsection{Description}

7.2.1.1 System Description. Provide a description of the reactor trip system to include initiating circuits, logic, bypasses, interlocks, should be identified and and actuated devices. Any supporting systems for safety should be identified.

7.2.1.2 Design Basis Information. Provide the design basis information required by Section 3 of IEEE Std 279-1971. Provide preliminary drawings of all reactor trip instrumentation diagrams, and location layout

7.2.1.3 Final System Drawings. In the FSAR, provide electrical schematic diagrams for all reactor trip systems and supporting systems, layout drawings. Describe diagrams and schematics submitted ifferences, if any, between the logic the effects on safety-related systems.

\subsubsection{Analysis}

Provide analyses, including a failure mode and effects analysis, to demonstrate how the requirements of the General Design Criteria, IEEE Std 279-1971, applicable regulatory guides, and other appropriate criteria and standards are satisfied. In addition to postulated accidents and failures, these analyses should include, but not be limited to, considerations of instrumentation installed to prevent or mitigate the con-
sequences of:

1. Spurious control rod withdrawals,

2. Loss of plant instrument air systems,

3. Loss of cooling water to vital equipment,

4. Plant load rejection, and

5. Turbine trip. 
The analyses should also discuss the need for and method of changing to more restrictive trip setpoints during abnormal operating conditions such as operation with fewer than all reactor coolant loops operating. Reference may be made to other sections of the SAR for supporting systems.

\subsection{Engineered-Safety-Feature Systems}

For standardized systems, it is preferred that the information listed be supplied in a topical report and that the topical report be referenced in the appropriate place in the SAR.

\subsubsection{Description}

7.3.1.1 System Description. Provide a description of the instrumentation and controls associated with the engineered safety features (ESF), including initiating circuits, logic, bypasses, interlocks, sequencing, redundancy, diversity, and actuated devices. Any supporting systems should be identified and described. Those parts of any system not required for safety should be identified.

7.3.1.2 Design Basis Information. Provide the design basis information required by Section 3 of IEEE Std 279-1971. For the PSAR review, provide preliminary electrical schematic diagrams, logic diagrams, piping and instrumentation diagrams, and location layout drawings of all engineeredsafety-feature instrumentation, control systems, and supporting systems.

7.3.1.3 Final System Drawings. In the FSAR, provide electrical schematic diagrams for all ESF circuits and supporting systems, and final logic diagrams, piping and instrumentation diagrams, and location layout drawings. Describe the differences, if any, between the logic diagrams and schematics submitted in the PSAR and those in the FSAR and the effects on safety-related systems.

\subsubsection{Analysis}

Provide analyses, including a failure mode and effects analysis, to demonstrate how the requirements of the General Design Criteria and IEEE Std 279-1971 are satisfied and the extent to which applicable regulatory guides and other appropriate criteria and standards are satisfied. In addition to postulated accidents and failures, these analyses should include considerations of (1) loss of plant instrument air systems and. (2) loss of cooling water to vital equipment. The method for periodic testing of engineered-safety-feature instrumentation and control equipment and the effects on system integrity during testing should be described.

\subsection{Systems Required for Safe Shutdown}

For standardized systems, it is preferred that the information listed be supplied in a topical report and that the topical report be referenced in the appropriate place in the SAR. 


\subsubsection{Description}

Provide a description of the systems that are needed for safe shutdown of the plant, including initiating circuits, logic, bypasses, interlocks, redundancy, diversity, and actuated devices. Any supporting systems should be identified and described. Provide the design bas is information required by Section 3 of IEEE Std 279-1971. Provide logic diagrams, piping and instrumentation diagrams, and location layout drawings for these systems. In the FSAR, provide electrical schematic diagrams.

Describe the provisions taken in accordance with NRC General Design Criterion 19 to provide the required equipment outside the control room for hot and cold shutdown.

\subsubsection{Analysis}

Provide analyses that demonstrate how the requirements of the General Design Criteria, IEEE Std 279-1971, applicable regulatory guides, and other appropriate criteria and standards are satisfied. These analyses should include considerations of instrumentation installed to permit a safe shutdown in the event of:

1. Loss of plant instrument air systems,

2. Loss of cooling water to vital equipment,

3. Plant load rejection, and

4. Turbine trip.

\subsection{Safety-Related Display Instrumentation}

\subsubsection{Description}

Include a description of the instrumentation systems (including control rod position indicating systems) that provides information to enable the operator to perform required safety functions.

\subsubsection{Analysis}

Provide an analysis to demonstrate that the operator has sufficient information to perform required manual safety functions (e.g., ensuring safe control rod patterns, manual engineered-safety-feature operations, possible unanticipated postaccident operations, and monitoring the status of safety equipment) and sufficient time to make reasoned judgments and take action where operator action is essential. Identify appropriate safety criteria in the PSAR and demonstrate compliance with these criteria in the FSAR. 
Information should be provided to identify the information readouts or indications provided to the operator for monitoring conditions in the reactor, the reactor coolant system, and in the containment and safetyrelated process systems, including engineered safety features, throughout all operating conditions of the plant, including anticipated operational occurrences and accident and postaccident conditions (including instrumentation to follow the course of accidents). The information should include the design criteria, the type of readout, number of channels provided, their range, accuracy, and location, and a discussion of the adequacy of the design.

\subsection{All Other Instrumentation Systems Required for Safety}

This section should contain information on a!l other instrumentation systems required for safety that are not included under reactor trip, engineered safety features, safe shutdown, safety-related display instrumentation systems, or any of their supporting systems (e.g., fire protection instrumentation and detection systems, cold water s]ug interlocks, refueling interlocks, and interlocks that prevent overpressurization of low-pressure systems).

\subsubsection{Description}

Provide a description of all systems required for safety not already discussed, including initiating circuits, logic, bypasses, interlocks, redundancy, diversity, and actuated devices. Any supporting systems should be identified and described (reference may be made to other sections of the SAR). Provide the design basis information required by Section 3 of IEEE Std 279-1971. For an FSAR, sufficient schematic diagrams should be provided to permit an independent evaluation of compliance with the safety criteria.

\subsubsection{Analysis}

Provide anaiyses to demonstrate how the requirements of the General Design Criteria, IEEE Std 279-1971, applicable regulatory guides, and other appropriate criteria and standards are satisfied. These analyses should include, but not be limited to, considerations of instrumentation installed to prevent or mitigate the consequences of:

1. Cold water slug injections,

2. Refueling accidents,

3. Overpressurization of lowpressure systens, and

4. Fires.

Reference may be made to other sections of the SAR for supporting systens and analyses. 


\subsection{Control Systems Not Required for Safety}

For standardized systems, it is preferred that the information listed be supplied in a topical report and that the topical report be referenced in the appropriate place in the SAR.

\subsubsection{Description}

The following information should be provided with regard to the control systems not required for safety:

1. Identification of the major plant control systens (e.g., primary temperature control, primary water level control, steam generator water level control) that are identical to those in a nuclear power plant of similar design by the same nuclear steam system supplier that has recently received a construction permit or an operating license; and

2. A i ist and discussion of the design differences in those systems not identical to those used in the reference nuclear power plant. This discussion should include an evaluation of the safety significance of each design difference.

\section{7 .2 Analysis}

Provide analyses to demonstrate that these systems are not required for safety. The analyses should demonstrate that the protection systems are capable of coping with all (including gross) failure modes of the control systems. 


\section{ELECTRIC POWER}

The electric power system is the scurce of power for the reactor coolant pumps and other auxiliaries during nomal operation and for the protection system and engineered safety features during abnormal and accident conditions. The information in this chapter should be directed toward establishing the functional adequacy of the safety-related electric power systems and ensuring that these systems have adequate redundancy, independence, and testability in conformance with current criteria. Details of seismic design and testing should be provided in Section 3.10.

\subsection{Introduction}

A brief description of the utility grid and its interconnection to other grids should be included, and the onsite electric system should be described briefly in general terms. The safety loads (i.e., the systems and devices that require electric power to perform their safety functions) should be identified; the safety functions performed (e.g., emergency core cooling, containment cooling) and the type of electric power (a.c. or d.c.) requirad by each safety load should be indicated. The design bases, criteria, regulatory guides, standards, and other documents that will be implemented in the design of the safety-related electric systems should be presented and discussed.

Describe the extent to which the recommendations of the regulatory guides listed below are followed. Wherever alternative approaches are used, demonstrate that an acceptable level of safety has been attained.

Regulatory Guide 1.6 (Safety Guide 6), "Independence Between Redundant Standby (Onsite) Power Sources and Between Their Distribution Systems;"

Regulatory Guide 1.9 (Safety Guide 9), "Selection of Diesel Generator Set Capacity for Standby Power Supplies;"

Regulatory Guide 1.22 (Safety Guide 22), "Periodic Testing of Protection System Actuation Functions;"

Regulatory Guide 1.29, "Seismic Design Classification;"

Regulatory Guide 1.30 (Safety Guide 30), "Quality Assurance Requirements for the Installation, Inspection, and Testing of Instrumentation and Electric Equipment;"

Regulatory Guide 1.32, "Criteria for Safety-Related Electric Power Systems for Nuclear Power Plants;"

Regulatory Guide 1.40, "Qualification Tests of Continuous-Duty Motors Installed Inside the Containnent of Water-Cooled Nuclear Power Plants;"

Regulatory Guide 1.41, "Preoperational Testing of Redundant Onsite Electric Power Systens to Verify Proper Load Group Assignments;" 
Regulatory Guide 1.47, "Bypassed and Inoperable Status Indication for Nuclear Power Plant Safety Systems;"

Regulatory Guide 1.53, "Application of the Single-Failure Criterion to Nuclear Power Plant Protection Systems;"

Regulatory Guide 1.62, "Manual Initiation of Protective Actions;"

Regulatory Guide 1.63, "Electric Penetration Assemblies in Containment Structures for Light-Water-Cooled Nuclear Power Plants;"

Regulatory Guide 1.73, "Qualification Tests of Electric Valve Operators Installed Inside the Containment of Nuclear Power Plants;"

Regulatory Guide 1.75, "Physical Independence of Electric Systems;"

Regulatory Guide 1.81, "Shared Emergency and Shutdown Electric Systems for Multi-Unit Nuclear Power Plants;"

Regulatory Guide 1.89, "Qualification of Class IE Equipment for Nuclear Power Plants;"

Regulatory Guide 1.93, "Availability of Electric Power Sources;"

Regulatory Guide 1.100, "Seismic Qualification of Electric Equipment for Nuclear Power Plants;"

Regulatory Guide 1.106, "Thermal Overload Protection for Electric Motors on Motor-Operated Valves;"

Regulatory Guide 1.108, "Periodic Testing of Diesel Generator Units Used As Onsite Electric Power Systems at Nuclear Power Plants;"

Regulatory Guide 1.118, "Periodic Testing of Electric Power and Protection Systems;"

Regulatory Guide 1.128, "Installation Design and Installation of Large Lead Storage Batteries for Nuclear Power Plants;"

Regulatory Guide 1.129, "Maintenance, Testing, and Replacement of Large Lead Storage Batteries for Nuclear Power Plants;" and

Regulatory Guide 1.131, "Qualification. Tests of Electric Cables, Field Splices, and Connections for Light-Water-Cooled Nuclear Power Plants."

Indicate whether IEEE Std 387, "Criteria for Diesel Generator Units Applied as Standby Power Supplies for Nuclear Power Stations," is followed. If an alternative approach is used, demonstrate that an acceptable level of safety has been attained. 


\subsection{Offsite Power System}

\subsubsection{Description}

A system description and an analysis sufficient to demonstrate compliance with 10 CFR Part 50 and the Commission's General Design Criteria (GDC) in Appendix A to 10 CFR Part 50 should be provided. In addition, the SAR should indicate the extent to which the applicant has followed the recommendations of regulatory guides and other applicable standards and criteria (e.g., industry standards normally used by the applicant in the installation of safety systems and interna standards and criteria). In particular, the circuits that supply power for safety loads from the transmission network should be identified and shown to meet GDC 17 and 18. Voltage level and length of each transmission line from the site to the first major substation that connects the line to the grid should be provided. All unusual features of these transmission lines should be described (e.g., crossovers or proximity of other lines, rugged terrain, vibration or galloping conductor problems, icing or other heavy loading conditions, and high thunderstom occurrence rate). Describe and provide layout drawings of the circuits that connect the onsite distribution system to the preferred power supply; include transmission lines, switchyard arrangement, rights-of-way, etc.

\subsubsection{Analysis}

The results of steady-state and transient stability analyses should be provided to demonstrate compliance with the final paragraph of GDC 17. In determining the most critical transmission line, consider lines that use a common tower to be a single line. Provide information and a discussion of grid availability, including the frequency, duration, and causes of outages.

\subsection{Onsite Power Systems}

\subsubsection{A.C. Power Systems}

8.3.1.1 Description. Describe the onsite a.c. power systems with emphasis placed on those portions of the systems that are safety related. Those portions that are not related to safety need only be described in sufficient detail to permit an understanding of their interactions with the safety-related portions. The description of the safety-related portions should include:

1. Power supply feeders (i.e., network configuration),

2. Busing arrangements,

3. Loads supplied from each bus,

4. Manual and automatic interconnections between buses, buses and loads, and buses and supplies, 
5. Interconnections between safety-related and non-safety-related buses,

6. Redundant bus separation,

7. Equipment capacities,

8. Automatic loading and stripping of buses,

9. Safety-related equipment identification,

10. Instrumentation and control systems for the applicable power systems with the assigned power supply identified,

11. Electric circuit protection system network (e.g., selective trip), including setting criteria,

12. The scheme for testing these systems during power operation, and

13. Any systems and equipment shared between units.

The basis for the power required for each safety load (e.g., motor nameplate rating, pump runout condition, or estimated load under expected flow and pressure) should be given. The continuous and short-tern ratings for the onsite power source should be provided. In some cases, the bas is for the requested information is engineering judgment or correlation with other similar plants; nevertheless, the information requested should be subaitted and all limitations cited. The FSAR should completely update all previously transmitted information and should verify that all systems are adequately sized and that all pertinent criteria are met.

The following design aspects of the onsite emergency electric power sources (e.g., diesel generators) should be described in preliminary form in the PSAR:

1. Starting initiating circuits,

2. Starting mechanism and system,

3. Tripping devices,

4. Interlocks,

5. Permissives,

6. Load shedding circuits,

7. Testability, 
8. Fuel oil storage and transfer system,

9. Cooling and heating systems,

10. Instrumentation and control systems, including status alarms and indications, with assigned power supply, and

11. Prototype qualification program.

This description should be complete in the FSAR. Any features or components not previously used in similar applications in nuclear generating stations should be identified. Provide single-line diagrams of the onsite a.c. distribution systems, including jentification of all safety loads. The physical arrangement of the components of the system should be described in sufficient detail to permit independent verification that single events and accidents will not disable reaundant features. Sufficient plant layout drawings should be provided to permit evaluation of the physical separation and isolation of redundant portions of the system. The PSAR should provide a table that illustrates the automatic and manual loading and unloading of each standby power supply. The FSAR stroutd provide an updated table reflecting any changes or revisions. Include the time (sequence) of each event, size of load, inrush current or starting kVA, identification of redundant equipment, and length of time each load is required. For the safety-related systems, describe the bases and provide the design criteria that establish:

1. Motor size,

2. Minimum notor accelerating voltage,

3. Motor starting torque,

4. Minimum motor torque margin over pump torque through accelerating period,

5. Motor insulation,

6. Temperature monitoring devices provided in large horsepower motors,

7. Interrupting capacity of switchgear, load centers, control centers, and distribution panels,

8. Electric circuit protection, and

9. Grounding requirements.

The FSAR should identify all deviations fron these criteria as described in the PSAR and provide justification for any deviations. Sufficient logic and schematic diagrams should be provided to permit an independent evaluation of compliance with the safety criteria. 
8.3.1.2 Analysis. Provide analyses to demonstrate compliance with the Commission's General Design Criteria and to indicate the extent to which the recommendations of regulatory guides and other applicable criteria are followed. Especially important are the analyses to demonstrate compliance with GDC 17 and 18 and the discussion to indicate the extent to which the recommendations of Regulatory Guides 1.6 and 1.9 (Safety Guides 6 and 9) and of Regulatory Guide 1.32 are followed. The discussion should identify all aspects of the onsite power system that do not conform to Regulatory Guides $1.6,1.9$, and 1.32 and should explain why such deviations are not in conflict with applicable General Design Criteria.

Identify all safety-related equipment that must operate in a hostile environment (e.g., radiation, temperature, pressure, humidity) during and/or subsequent to a postulated accident (e.g., loss-of-coolant accident, steam line break). All the conditions under which the equipment must operate should be tabulated. Provide bases, criteria, and analyses of the potential effects of (I) radiation (i.e., radiation due to accident conditions superimposed on that for long-term normal operation) on safetyrelated electric equipment throughout the plant and (2) loss-of-coolant accidents or steam line breaks on all safety-related electric equipment within primary reactor containment (e.g., motors, cables) that must operate during and/or subsequent to such an accident. The successful completion of any applicable qualification tests for the above cases should be documented. Where such tests have not been previously completed, plans and schedules of the qualification tests proposed should be documented. The FSAR should document the results of these tests.

8.3.1.3 Physical Identification of Safety-Related Equipment. Describe the means proposed to identify physically the onsite power system equipment as safety-related equipment in the plant to ensure appropriate treatment, particularly during maintenance and testing operations. The description should include the method used to readily (without the necessity for consulting reference material) distinguish between redundant Class IE systems, associated circuits assigned to redundant Class $1 E$ divisions, and non-Class IE systems.

8.3.1.4 Independence of Redundant Systems. Present the criteria and their bases that establish the minimum requirements for preserving the independence of redundant Class IE electric systems* through physical arrangement and separation and for ensuring the minimum required equipment availability during any design basis event.* A discussion should be included of the administrative responsibility and control to be provided to ensure compliance with these criteria during the design and installation of these systems. The criteria and bases for the installation of electrical cable for these systems should, as a minimum, include a description of the extent to which the recommendations of Regulatory Guide 1.75, "Physical Independence of Electric Systems," are followed.

\footnotetext{
Class IE electric systems and design basis events are defined in IEEE Std 308-1971.
} 


\subsubsection{D.C. Power Systems}

8.3.2.1 Description. A description of the d.c. power systems clearly delineating the safety-related portions should be provided. The non-safetyrelated portion need only be described in sufficient detail to permit an understanding of its interaction with the safety-related portions. The description of the safety-related portion should include requirements for separation, capacity, charging, ventilation, loading, redundancy, and testing. The safety loads should be clearly identified, and the length of time they would be operable in the event of loss of all a.c. power should be stated. Sufficient schematic diagrams should be provided in the FSAR to permit an independent evaluation of compliance with the safety criteria.

8.3.2.2 Analysis. Provide an analysis to demonstrate compliance with the Commission's General Design Criteria, and describe the extent to which recommendations of regulatory guides and other applicable criteria are followed. The same information described in sections 8.3.1.2 and 8.3.1.3, as applicable. should be provided.

\subsubsection{Fire Protection for Cable Systems}

The measures employed for the prevention of and protection against fires in electrical cables should be described in Section 9.5.1. The following should be described in Sections 8.3.1 and 8.3.2:

1. Cable derating and cable tray fill, and

2. Fire barriers and separation between redundant trays. 


\section{AUXILIARY SYSTEMS}

This chapter should provide information concerning the auxiliary systems included in this facility. The information in the PSAR should reflect the preliminary design of the auxiliary systems, and the FSAR information should reflect the final design.

Those systems that are essential for the safe shutdown of the plant or the protection of the health and safety of the public should be identified. The description of each system, the design bases for the system and for critical components, a safety evaluation demonstrating how the system satisfies the design bases, the testing and inspection to be performed to verify system capability and reliability, and the required instrumentation and controls should be provided. There may be aspects of the auxiliary systems that have little or no relationship to protection of the public against exposure to radiation. In such cases, enough information should be provided to allow understanding of the auxiliary system design and function with emphasis on those aspects of design and operation that might affect the reactor and its safety features or contribute to the control of radioactivity.

The capability of the system to function without compromising the safe operation of the plant under both normal operating or transient situations should be clearly shown by the information provided, i.e., a failure analysis.

Seismic design classifications should be stated with reference to detailed information provided in Chapter 3, where appropriate. Radiological considerations associated with operation of each system under normal and accident conditions, where applicable, should be summarized and reference made to detailed information in Chapters 11 or 12 as appropriate.

\subsection{Fuel Storage and Handling}

\subsubsection{New Fuel Storage}

9.1.1.1 Design Bases. The design bases for new fuel storage facilities should be provided and should include such considerations as quantity of fuel to be stored, means for maintaining a subcritical array, and the degree of subcriticality provided for the most reactive condition possible together with the assumptions used in this calculation and design loadings to be withstood.

9.1.1.2 Facilities Description. A description of the new fuel storage facilities, including drawings, and location in the station complex should be provided.

9.1.1.3 Safety Evaluation. An evaluation of the capability of the new fuel storage facilities to reduce the probability of occurrence of unsafe conditions should be presented and should include the degree of 
subcriticality, governing codes for design, ability to withstand external loads and forces, and safety implications related to sharing (for multiunit facilities). Details of the seismic design and testing should be presented in Section 3.7.

\subsubsection{Spent Fuel Storage}

9.1.2.1 Design Bases. The design bases for the spent fuel storage facilities should be provided and should include such considerations as quantity of fuel to be stored, means for maintaining a subcritical array, degree of subcriticality provided together with the assumptions used in this calculation, shielding requirements, and design loadings to be withstood.

9.1.2.2 Facilities Description. A description of the spent fue ? storage facilities, including drawings, and location in the station complex should be provided.

9.1.2.3 Safety Evaluation. An evaluation of the protection of the spent fuel storage facilities against unsafe conditions should be presented and should include the degree of subcriticality, governing codes for design, ability to withstand external loads and forces, ability to ensure continuous cooling, provisions to avoid accidental dropping of heavy objects on spent fuel, material compatibility requirements, radiological considerations (details should be presented in Chapter 12), ability of the fuel storage racks to withstand lifting forces if a fiel assembly accidentally engages a rack while being lifted, and safety implications related to sharing (for multi-unit facilities). Additional guidance regarding acceptable design of the spent fuel storage facilities is given in Regulatory Guide 1.13, "Spent Fuel Storage Facility Design Basis."

\subsubsection{Spent Fuel Pool Cooling and Cleanup System}

9.1.3.1 Design Bases. The design bases for the cooling and cleanup system for the spent fuel facilities should be provided and should include the requirements for continuous or intermittent cooling, the quantity of spent fuel to be cooled, the requirements for pool water temperature and cleanliness from fission and corrosion products, makeup requirements, and level and radiation shielding requirements.

9.1.3.2 System Description. A description of the cooling and cleanup system, including a description of the instrumentation utilized, should be provided. The FSAR should include a detailed updated description and drawings.

9.1.3.3 Safety Evaluation. An evaluation of the cooling system, including the capability for spent fuel cooling during normal and abnorma? conditions, provisions to ensure that pool water will not be lost at a rate greater than the makeup capability, and ability to maintain acceptable pool water conditions, should be provided. The radiological evaluation 
of the cleanup system should be presented in Chapters 11 and 12 . Additional guidance regarding acceptable coolant makeup requirements is given in Regulatory Guide 1.13.

9.1.3.4 Inspection and Testing Requirements. The inspection and testing requirements for the cooling and cleanup system should be described.

\subsubsection{Fuel Handling System}

9.1.4.1 Design Bases. The design bases for the fuel handling system (FHS) should be provided; the performance and load handling requirements, handling control features, and provisions to prevent fuel handling and cask drop accidents should be included.

9.1.4.2 System Description. A description of the FHS, including all components for transporting and handling fuel from the time it reaches the plant until it leaves the plant, should be provided. Descriptions of the containment polar crane and spent fuel cask handling crane should be included. An outline for the procedures used in new fuel receipt and storage, reactor refueling operations, and spent fuei storage and shipment should be provided. Component drawings, building layouts, and illustrations of the fuel handling procedures should also be provided. Detailed descriptions and drawings should be included in the FSAR. Design data, seismic category, and quality class should be provided for all principa? components. The design codes and standards used for design, manufacture, testing, maintenance and operation, and seismic design aspects should be enumerated.

9.1.4.3 Safety Evaluation. The safety evaluation should demonstrate that the system design meets the applicable redundancy and diversity requirements. It should be demonstrated that the FHS design precludes inadvertent operations or equipment malfunctions or failures that could prevent safe shutdown of the reactor or cause a release of radioactivity. The results of a failure mode and effects analys is should be presented to demonstrate that the individual subsystems and components, including controls and interlocks, are designed to meet the single-failure criterion without compromising the capability of the system to perform its safety functions.

Compliance of the system with applicable General Design Criteria should be demonstrated. The extent to which the recomendations of applicable regulatory guides are followed should be indicated. It should be shown that the seismic design of the individual components will preclude system malfunctions that could prevent safe shutdown of the reactor or cause a release of radioactivity in the event of the Safe Shutdown Earthquake (SSE). It should also be shown that the component design standards and safety factors are adequate.

It should be demonstrated that failure of any part of the spent fuel cask handling crane will not cause any damage to spent fuel and safetyrelated equipment. This could be accomplished by using a crane design that will prohibit cask drop in the event of a single failure or by adequate 
facility design that prevents damaging the spent fuel and safety-related equipment for any manner of cask drop, including drop of a tilted cask.

9.1.4.4 Inspection and Testing Requirements. The inspection and testing requirements for the FHS subsystems and components should be described, including shop tests, preoperational tests, and periodic operational tests.

9.1.4.5 Instrumentation Requirements. The system instrumentation and controls should be described. The adequacy of safety-related interlocks to meet the single-failure criterion should be demonstrated.

\subsection{Water Systems}

This section of the SAR should provide discussions of each of the water systems associated with the plant. Because these auxiliary water systems vary in number, type, and nomenclature for various plant designs, the Standard Format does not assign specific subsection numbers to these systems. The applicant should provide separate subsections (numbered 9.2.1 through 9.2.X) for each of the systems. As they apply to a particular plant, these subsections should provide the following information:

1. Design bases,

2. System description, including drawings,

3. Safety evaluation,

4. Testing and inspection requirements, and

5. Instrumentation requirements for each system.

The following paragraphs provide examples of systems that should be discussed, as appropriate to the individual plant, and identify some specific information that should be provided in addition to the items identified above. The examples are not intended to be a complete list of systems to be discussed in this section.

\subsubsection{Station Service Water System}

Describe the capability of the service water system to meet the singlefailure criterion (when this system is safety related), the ability to withstand adverse environmental occurrences, requirements for normal operation and for operating during and subsequent to postulated accident conditions, including loss of offsite power, provisions for reactor compartment flooding during the post-LOCA period, if required, and the ability of the system to detect and prevent excessive leakage of radioactive material to the ervironment. Include a failure analysis to demonstrate that a single failure will not result in the loss of all or an unacceptable portion of the cooling function (considering failures of active and passive components and diverse sources of electric power for pumps, valves, and control purposes), capability of the system to function during abnormally 
high and low water levels, prevention of long-term corrosion and organic fouling that may degrade system performance, and safety implications related to sharing (for multi-unit facilities). Reference Section 3.6 with respect to the analys is of postulated cracks in moderate-energy piping systems and Sections 2.4.11.5, 2.4.11.6, and 2.4.12 where applicable.

\subsubsection{Cooling System for Reactor Auxiliaries}

Discuss the capability of the reactor system auxiliaries to meet the single-failure criterion when required, the ability to withstand adverse environmental occurrences, requirements for normal operation and for operating during and subsequent to postulated accident conditions, including loss of offsite power, and requirements for leakage detection and containment of leakage. Include a failure analysis to demonstrate that a single failure will not result in the loss of all, or an unacceptable portion of, the cooling function (considering failures of active and passive components, and diverse sources of electric power for pumps, valves, and control purposes), the means for preventing or controlling leakage of activity to the outside environment, leakage detection provisions, prevention of long-term corrosion that may degrade system performance, and safety implications related to sharing (for multi-unit facilities). Reference Section 3.6 with respect to the analysis of postulated cracks in moderate-energy piping systems.

\subsubsection{Demineralized Water Makeup System}

\subsubsection{Potable and Sanitary Water Systems}

A description of the potable and sanitary water systems should be provided. System design criteria should provide for prevention of connections to systems having the potential for containing radioactive material. An evaluation of radiological contamination, including accidental, and safety implications of sharing (for multi-unit facilities) should be described.

\subsubsection{Ultimate Heat Sink}

A description of the ultimate heat sink to be used to dissipate waste heat from the plant during normal, shutdown, and accident conditions should be provided. Additional guidance regarding acceptable features of the ultimate heat sink is given in Regulatory Guide 1.27, "Ultimate Heat Sink for Nuclear Power Plants." Reference Sections 2.3.1.2 and 2.4.11 where applicable.

\subsubsection{Condensate Storage Facilities}

A discussion of the environmental design considerations, requirements for leakage control (including mitigation of environmental effects), limits for radioactivity concentration, code design requirements, and material compatibility and corrosion control should be given. An analysis of storage facility failure and provisions for mitigating environmental effects should 
be provided. The evaluation of radiological considerations should be presented in Chapter 12.

\section{3 Process Auxiliaries}

This section of the SAR should provide discussions of each of the auxiliary systems associated with the reactor process system. Because these auxiliary systems vary in number, type, and nomenclature for various plant designs, the Standard Format does not assign specific subsection numbers to these systems. The applicant should provide separate subsections (numbered 9.3.1 through 9.3.X) for each of the systems. These subsections should provide the following information:

1. Design bases,

2. System description,

3. Safety evaluation,

4. Testing and inspection requirements, and

5: Instrumentation requirements for each system.

The following paragraphs provide examples of systems that should be discussed, as appropriate to the individual plant, and identify some specific information that should be provided in addition to the items identified above. The examples are not intended to be a complete list of systems to be discussed in this section. For example, the boron recovery system and the fajled fuel detection system should both be discussed in this section.

\subsubsection{Compressed Air Systems}

Describe the compressed air systems that provide station air for service and maintenance uses, and include discussion of provisions for meeting the single-failure criterion for safety-related compressed air systems, air cleanliness and quality requirements, and environmental design requirements. The evaluation of the compressed air system should include a failure analysis (including diverse sources of electric power), maintenance of air cleanliness to ensure system reliability, the capability to isolate if required, and safety implications reiated to sharing (for multiunit plants).

\subsubsection{Process Sampling System}

Describe the sampling system for the various plant fluids. The design bases should include consideration of sample size and handling to ensure that a representative sample is obtained; provisions for isolation of the system and the means to limit reactor coolant losses; requirements to minimize, to the extent practical, hazards to plant personnel; and system pressure, temperature, and code requirements. The points from 
which samples will be obtained should be delineated. The evaluation of the sampling system should provide assurance that representative samples will be ottained and that sharing (for multi-unit facilities) will not adversely affect plant safety.

\subsubsection{Equipment and Floor Drainage System}

Describe the drainage systems for collecting the effluent from high activity and low activity liquid drains from various specified equipment items and buildings. Design considerations for precluding backflooding of equipment in safety-related compartments should be discussed. Areas where the drainage system is used to detect leakage from safety systems should be identified. Design considerations for preventing transfer of contaminated fluids to noncontaminated drainage systems should be discussed. An evaluation of radiological considerations for normal operation and postulated spills and accidents, including the effects of sharing (for multi-unit plants), should be presented in Chapters 11 and 12 .

\subsubsection{Chemical and Volume Control System (PWRs) (Including Boron Recovery System)}

9.3.4.1 Design Bases. The design bases for the chemical and volume control system (CVCS) and the boron recovery system (BRS) should include consideration of (1) the capability to vary coolant chemistry for control of reactivity and corrosion and (2) the capability for maintaining the required reactor coolant system inventory and the reactor coolant pump seal water requirements. Items to be considered include the maximum and normal letdown flow rates, charging rates for both normal operation and maximum leakage conditions, boric acid storage requirements for reactivity control, water chemistry requirements, and boric acid and primary water storage requirements in terms of maximum number of startup and shutdown cycles.

9.3.4.2 System Description. A complete description of the system and components, including piping and instrumentation diagrams, should be provided. Design data, seismic category, and quality class should be provided for all components. The principles of system operation, both automatic and manual, should be provided for steady-state, transient, startup, shutdown, and accident conditions. A discussion on reactor coolant water chemistry requirements should be provided. Temperature control provisions for line heat tracing and tank heating, including provision for alarm failures, should be described. Tabulations of system design parameters and component design data should be provided.

9.3.4.3 Safety Evaluation. The safety evaluation should demonstrate that the system is designed to provide for safe operation and shutdown and to prevent or mitigate certain postulated accidents. This includes demonstration that the system boron inventory is adequate for the most stringent cold shutdown requirements, including anticipated operational occurrences. Provisions to prevent loss of solubility of boric acid solutions should also be discussed. This section should also include 
demonstration that the system has the pumping capability to supply reactor coolant makeup for protection against small pipe or component failures. The safety evaluation should demonstrate that the system is designed to limit radioactive releases to the environment to allowable limits for both normal operation and accident conditions. The adequacy of the component and piping seismic design category and quality class should be justified. The results of a failure mode and effects analys is should be presented to demonstrate that the system can meet the single-failure criterion without compromising safe plant shutdown and the ability to prevent or mitigate postulated accidents.

Compliance of the system with applicable General Design Criteria should be demonstrated. The extent to which the recommendations of applicable regulatory guides are followed should be indicated. It should be shown that the essential portions of the system will be protected from failure of non-Seismic Category I equipment and piping and also from flooding, tornadoes, internally and externally generated missiles, and the effects of high- and moderate-energy line failures.

9.3.4.4 Inspection and Testing Requirements. The inspection and testing requirements for the CVCS should be described.

9.3.4.5 Instrumentation Requirements. The system instrumentation and controls should be described. The adequacy of safety-related instrumentation and controls to fulfill their functions should be demonstrated.

\subsubsection{Stardby Liquid Control System (BWRs)}

9.3.5.1 Design Bases. The design bases for the standby liquid control system (SLCS) should include consideration of the capability for reactor shutdown independent of the normal reactivity control system with a reasonable shutdown margin at any time in core life, system redundancy, and ability to periodically verify functional performance capability.

9.3.5.2 System Description. A description of the system and components, complete with piping and instrumentation diagrams, should be provided. Temperature control provisions for line heat tracing and tank heating, including provisions for alarn failures, should be described. Design data, seismic category, and quality class should be provided for all components. The principles of system operation and testing should be provided.

9.3.5.3 Safety Evaluation. The safety evaluation should demonstrate that the system has adequate storage capacity and injection rate to bring the reactor from rated power to cold shutdown at any time in core life (control rods withdrawn in the rated power pattern) with adequate margin for adverse factors, including xenon decay, elimination of steam voids, allowance for imperfect mixing, leakage, and dilution. Provisions to prevent loss of solubility of sodium pentaborate solutions should be discussed. The adequacy of the component and piping seismic design category should be justified. 
The results of a failure mode and effects analysis should be presented to demonstrate that the system can meet the single-failure criterion without compromising the shutdown capability of the system. Compliance of the system with applicable General Design Criteria should be demonstrated. The extent to which the recommendations of applicable regulatory guides are followed should be indicated. It should be shown that the essential portions of the system will be protected from failure of non-seismic equipment and piping and also from flooding, tornadoes, internally and externally generated missiles, and the effects of high- and moderate-energy line failures.

9.3.5.4 Inspection and Testing Requirements. The inspection and testing requirements for the SLCS, including periodic operational testing, should be described.

9.3.5.5 Instrumentation Requirements. The system instrumentation and controls should be described. The adequacy of safety-related instrumentation and controls to fulfill their functions should be demonstrated.

\subsection{Air Conditioning, Heating, Cooling, and Ventilation Systems}

Following are examples of systems that should be discussed, as appropriate to the individual plant. Some specific information that should be provided is also identified. The examples are not intended to be a complete list of systems to be discussed in this section. For example, the ventilation system for both the diesel building and the containment ventilation system should be described in this section.

\subsubsection{Control Room Area Ventilation System}

9.4.1.1 Design Bases. The design bases for the air treatment system for the control room and other auxiliary rooms (e.g., relay rooms and emergency switchgear rooms) considered to be part of the control areas should be provided. Include the design criteria (e.g., single failure), requirements for the manual or automatic actuation of system components or isolation dampers, ambient temperature and humidity requirements, criteria for plant operator comfort and safety, requirements for radiation protection and monitoring of abnormal radiation levels and other airborne contaminants, and environmental design requirements.

9.4.1.2 System Description. A description, including preliminary piping and instrumentation diagrams, of the air treatment systems for the control room should be presented in the PSAR. A detailed updated description and piping and instrumentation diagrams should be provided in the FSAR.

9.4.1.3 Safety Evaluation. A safety evaluation of the control room air treatment system should be provided. The evaluation should include the following subjects. (If these subjects are dealt with elsewhere in the SAR, a summary discussion should be presented here and the sections that include the details should be referenced.) 
1. Detection of adverse or dangerous environmental conditions (smoke, radiation, etc.),

2. Capability to exclude entry of contaminants (zone pressurization and isolation),

3. Capability for the removal of contamination by filiration (also see Section 6.5.1, ESF Filters),

4. Removal of contamination by purging, and

5. Maintenance of acceptable zone temperature and humidity and anticipated degradation of equipment performance if temperature limits are exceeded.

Additional detailed discussion of control room ventilation systems should appear in Section 6.4, "Habitability Systems," and in paragraph 5, "Radiological consequences," of Section 15.X.X.

9.4.1.4 Inspection and Testing Requirements. The inspection and testing requirements for the control room air treatment system should be described.

\subsubsection{Spent Fuel Pool Area Ventilation System}

9.4.2.1 Design Bases. The design bases of the ventilation system for the spent fuel pool area should be provided. Include the requirements for meeting the single-failure criterion, seismic design criteria, requirements for the manual or automatic actuation of system components or isolation dampers, ambient temperature limits, preferred direction of airflow from areas of low potential radioactivity to areas of high potential radioactivity, monitoring normal and abnormal radiation levels within the area, differential pressures to be maintained and measured, and the requirements for the treatment of exhaust air. Details of the means for protection of system vents or louvers from missiles should be provided.

9.4.2.2 System Description. A description, including preliminary piping and instrumentation diagrams, of the spent fuel pool area ventilation system should be presented in the PSAR. In the FSAR, provide a detailed description and piping and instrumentation diagrams.

9.4.2.3 Safety Evaluation. An evaluation of the spent fuel area ventilation system and results from failure mode and effects analysis should be provided. Include a discussion of the ability to (1) detect radiation in the area of the spent fuel pool and (2) filter the contaminants out of the air before exhausting it to the environment or prevent the contaminated air from leaving the spent fuel area.

9.4.2.4 Inspection and Testing Requirements. The inspection and testing requirements for the spent fuel area ventilation system should be described. 


\subsubsection{Auxiliary and Radwaste Area Ventilation System}

9.4.3.1 Design Bases. The design bases for the air handling system for the radwaste area and the areas of the auxiliary building containing safety-related equipment should be presented. Include requirements for meeting the single-failure criterion, seismic design criteria, requirements for the manual or automatic actuation of system components or isofrom areas of low potential radioactivity to areas of high potential radioactivity, differential pressures to be maintained and measured, requirements for the monitoring of normal and abnormal radiation levels, and requirements for the treatment of exhaust air. Details of the means for protection of system vents or louvers from missiles should be provided.

9.4.3.2 System Description. A description, including preliminary piping and instrumentation diagrams, of the air handiing system for the auxiliary and radivaste area should be presented in the PSAR. Detailed updated piping and instrumentation diagrams should be provided in the
FSAR.

9.4.3.3 Safety Evaluation. An evaluation of the auxiliary and radwaste area ventilation system should be presented and should include a system failure analysis (including the effects of inability to maintain preferred airflow patterns). Evaluation of radiological consideration for normal operation should be presented in Chapters 11 and 12 .

9.4.3.4 Inspection and Testing Requirements. The inspection and testing requirements for the auxiliary and radwaste area ventilation sys-
tem should be described.

\subsubsection{Turbine Suilding Area Ventilation System}

9.4.4.1 Design Bases. The design bases for the air handling system for the turbine-generator area in the turbine building should be presented. Include requirements for the manual or automatic actuation of system components or isolation dampers, ambient temperature limits, preferred direction of airflow from areas of low potential radioactivity to areas of higher potential radioactivity, requirements for monitoring of abnormal radiation levels, and requirements for treatment of exhaust air.

9.4.4.2 System Description. A description, including preliminary piping and instrumentation diagrams, of the air handling system for the turbine building should be provided in the PSAR. A detailed updated description and piping and instrumentation diagrams should be provided
in the FSAR.

9.4.4.3 Safety Evaluation. An evaluation of the turbine building air handling system should be presented and should include a system failure analysis (including effects of inability to maintain preferred airflow patterns). Radiological considerations for normal operation should be. evaluated in Chapters 11 and 12. 
9.4.4.4 Inspection and Testing Requirements. The inspection and testing requirements for the turbine building air handling system should be described.

\subsubsection{Engineered-Safety-Feature Ventilation System}

9.4.5.1 Design Bases. The design bases for the air handling system for the areas housing engineered-safety-feature equipment should be presented. Include requirements for meeting the single-failure criterion, requirements for the manual or automatic actuation of system components or isolation dampers, ambient temperature requirements, preferred direction of airflow from areas of low potential radioactivity to areas of higher potential radioactivity, and the requirements for the monitoring of normal and abnormal radiation levels. Details of the means for protection of system vents or louvers from missiles should be provided.

9.4.5.2 Systems Description. A description, including preliminary piping and instrumentation diagrams, of the air handling system for the engineered-safety-feature area should be presented in the PSAR. A detailed updated description and piping and instrumentation diagrams shouid be provided in the FSAR.

9.4.5.3 Safety Evaluation. An evaluation of the engineered-safetyfeature ventilation system should be presented and should include a system failure analysis. An analysis should be provided to demonstrate that a component necessary for safe shutdown or to mitigate the consequences of an accident can perform its safety function when subjected to ambient temperatures and conditions associated with the loss of the engineeredsafety-feature ventilation system during an accident condition coincident with the loss of offsite power. The effect of redundant systems may be included in the evaluation.

9.4.5.4 Inspection and Testing Requirements. The inspection and testing requirements for the engineered-safety-feature ventilation system should be provided.

\subsection{Other Auxiliary Systems}

\subsubsection{Fire Protection System}

\subsubsection{Design Bases.}

1. The PSAR should identify those areas where a fire could affect, either directly or indirectly, Seismic Category I safety-related structures, systems, or components.

2. The concept of defense in depth (using echelons of safety systems to achieve a required high level of safety) is used in the design and operation of nuclear power plants. When applied to the fire protection program, the defense-in-depth principle results in a balance in: 
a. Preventing fires from starting;

b. Detecting fires quickly, suppressing those fires that occur, putting them out quickly, and limiting their damage; and

c. Designing plant safety systems so triat a fire that starts in spite of the fire prevention program and burns for a considerable time in spite of fire protection activities will not prevent essential plant safety functions from being performed.

Although no one of these echelons can be perfect or complete by itself, strengthening any one can compensate in some measure for weaknesses, known or unknown, in the others.

3. The primary objective of the fire protection program is to minimize both the probability and consequences of postulated fires. In spite of steps taken to reduce the probability of fire, fires are expected to occur. Therefore, means are needed to detect and suppress fires with particular emphasis on providing passive and active fire protection of appropriate capability and adequate capacity for the systems necessary to achieve and maintain safe plant shutdown with or without offsite power. For other safety-related systems, the fire protection should ensure that a fire will not cause the loss of function of such systems, even though loss of redundancy within a system may occur as a result of the fire.

Generally, in plant areas where the potential fire damage may jeopardize safe plant shutdown, the primary means of fire protection should consist of fire barriers and fixed automatic fire detection and suppression systems. However, total reliance should not be placed on a single fire suppression system. Appropriate backup fire suppression capability should also be provided throughout the plant to limit the extent of fire damage. Portable equipment consisting of hoses, nozzles, portable extinguishers, complete personnel protective equipment, and air breathing equipment should be provided for use by properly trained firefighting personnel. Access for effective manual application of fire extinguishing agents to combustibles should be provided. The adequacy of fire protection for any particular plant safety system or area should be determined by analys is of the effects of the postulated fire relative to maintaining the ability to safely shut down the plant and minimize radioactive releases to the environment in the event of a fire.

4. Fire protection should start with design and must be carried through all phases of construction and operation. A quality assurance (QA) program is needed to identify and rectify errors in design, construction, and operation and is an essential part of defense in depth.

5. The consequences of inadvertent operation of, or a crack in, a moderate-energy line in the fire suppression system should meet the guidelines specified for moderate-energy systems outside containment. 
6. The FSAR should list any unusually hazardous materials to be used on the site that could present unexpected fire hazards or complicate firefighting activities. Such a material listing would include but not be limited to:
a. Flammable liquids,
b. Strong oxidizing agents,
c. Compressed gases, both flammable and nonflammable,
d. Corrosive materials, both acids and caustics, and
e. Explosives or highly flammable materials.

The listing should indicate the amounts of each material to be used, where in the plant and under what conditions each is to be used, and the expected time duration of use.

\subsubsection{Systems Description}

1. The SAR should discuss and list the features of building and facility arrangements and the structural design features that contribute to fire prevention and fire control. List and describe in the discussion the means of egress, fire barriers, and isolation and containment features provided for flame, heat, hot gases, smoke, and other contaminants. Fire barriers with a minimum fire resistance rating of 3 hours should be used. Interior wall and structural components, thermal insulation materials, radiation shielding materials, and soundproofing should be noncombustible.

The SAR should include drawings and a list of equipment and devices that adequately define the principal and auxiliary fire protection systems.

2. The SAR should state the basic requirements used for the design of the fire water supply and distribution systems. It should also specify any particular seismic requirements imposed on the design of each type of fire protection system used in the plant.

3. The SAR should list the various codes and standards used for design and installation of the plant fire protection system.

4. The SAR should discuss (for multi-unit sites) the special fire hazards created and the protection required for an operating unit during the construction of additional units.

5. The SAR should provide a general description of each fire protection system. It should include preliminary drawings that outline each item of fire protection equipment and the complete fire protection system, showing each in relation to safety-related structures, systems, and components for the entire plant. 
6. The SAR should discuss the protection and extinguishing systems provided to protect the control room and other operating areas containing safety-related equipment, Class IE equipment, and cables.

7. The SAR should describe the design features of detection systems, alarm systems, automatic fire suppression systems, and manual, chemical, and gas systems for fire detection, confinement, control, and extinguishment. Discuss the relationship of the fire protection systems (detection and suppression) to the onsite a.c. and d.c. power sources (emergency power
supplies).

8. The SAR should discuss smoke, heat, and flame control; combustible and explosive gas control; and toxic concaminant control, including the operating functions of the ventilating and exhaust systems during

9. The SAR should discuss the fire annunciator warning system, the alarm detection system in the proposed fire protection systems, and the backup or public fire protection suppression capabilities to be
provided.

10. The SAR should describe electrical cable fire protection and detection and the fire containment, control, and extinguishing systems during the fire for safe of the essential electric circuitry needed Describe the provisions shutdown of the plant and for firefighting. circuitry from the effects of fire-suppressing this essential electrical

Cable and cable tray penetration of fire barriers (vertical and horizontal) should be sealed to give protection at least equivalent to that required of the fire barrier.

Electric cable constructions should, as a minimum, pass the flame test in the current IEEE Std 383, "IEEE Standard of Type Test of Class IE Electrical Cables, Field Splices and Connections for Nuclear Power Generating Stations." (This does not imply that cables passing this test will not require fire protection.)

\subsubsection{Safety Evaluation (Fire Hazards Analysis)}

1. The overall fire protection program should allow the plant to maintain the ability to perform safe shutdown functions and minimize radioactive releases to the environment in the event of a fire. A major element of this program should be the evaluation of potential fire hazards throughout the plant and the effect of postulated fires on safety-related plant
areas.

2. The fire hazards for each area identified in paragraph 1 of Section 9.5.1.l should be evaluated in the SAR. This evaluation should consider (a) fuel loading, considering both fixed and transient combustibles, (b) the expected rate of fire development and maximum intensity, 
as these relate to fire detection response sensitivity, and automatic and manual firefighting activities, and (c) generation of smoke and other combustion products, considering both toxic and corrosive characteristics. Show for each of the postulated events that the combination of fire barriers and accessibility make effective manual firefighting feasible.

3. The SAR should postulate initiation of fire in each area at the location that will produce the most severe fire. An ignition source is to be assumed present. Fire development should consider the potential for involvement of other combustibles, both fixed and transient, in the fire area. Where automatic suppression systems are installed, the effects of the postulated fire should be evaluated with and without actuation of such systems.

4. The SAR should provide a failure mode and effects analysis that demonstrates that operation of the fire protection system in areas containing engineered safety features would not produce an unsafe condition or preclude safe shutdown. The effects of firefighting activities and fire suppression agents on safety systems should be discussed. An evaluation of the effects of failure of any portion of the fire protection system not designed to Seismic Category I requirements should be provided with regard to the possibility of damaging other Seismic Category I equipment. An analysis of the fire detection and protection system with regard to design features to withstand the effects of single failures should be included.

5. The SAR should evaluate the effects of postulated fires on safety-related structures, systems, or components for each area of the plant identified above. The discussion should cover the use of noncombustible and fire-resistant materials.

6. The SAR should provide:

a. A complete set of drawings, including, but not limited to, pertinent details of construction, location of rooms and areas, location of fire detection and suppression systems, and fire water mains and hydrants.

b. A listing by fire area of mechanical and electrical equipment both safety and nonsafety related.

c. A listing by fire area of permanent and reasonably expected transient combustibles.

d. A listing by area of fire detection systems showing type of installation and basis for type selected.

e. A listing by area of both primary and backup fire suppression systems showing type of installation and basis for type selected. 
f. A listing showing the effect of each postulated fire identified in paragraph 1 of Section 9.5.1.1 on capability of safe reactor shutdown and potential release of radioactive material.

9.5.1.4 Inspection and Testing Requirements. The PSAR should list and discuss the installation, testing, and inspection planned during construction of the fire protection systems to demonstrate the integrity of the systems as installed. Describe in the FSAR the periodic operational checks, inspection, and servicing required to maintain this integrity. In the FSAR, discuss the periodic operational testing necessary to maintain a highly reliable alarm detection system.

\subsubsection{Personnel Qualification and Training}

1. The SAR should state the qualification requirements for the fire protection engineer or consultant who is to be responsible for the preparation of the Fire Hazards Analysis and for the design and selection of equipment; inspect and test the complete physical aspects of the system; develop the fire protection program; and assist in the firefighting training for the operating plant. In the FSAR, discuss the initial training and the updating provisions such as fire drills provided for maintaining the competence of the station firefighting and operating crew, including personnel responsible for maintaining and inspecting the fire protection
equipment.

2. Administrative procedures consistent with the need for maintaining the performance of the fire protection system and personnel in nuclear power plants should be provided in the SAR.

Guidance is contained in the following National Fire Protection Association (NFPA) publications:

$$
\begin{aligned}
& \text { NFPA } 4 \text { - Organization for Fire Services } \\
& \text { NFPA } 4 A \text { - Organization of a Fire Department } \\
& \text { NFPA } 6 \text { - Industrial Fire Loss Prevention } \\
& \text { NFPA } 7 \text { - Management of Fire Emergencies } \\
& \text { NFPA } 8 \text { - Management Responsibilities for Effects } \\
& \text { of Fire on Operations } \\
& \text { NFPA } 27 \text { - Private Fire Brigades } \\
& \text { NFPA } 802 \text { - Recommended Fire Protection Practice for } \\
& \text { Nuclear Reactors. }
\end{aligned}
$$

3. The $Q A$ programs of applicants and contractors should ensure that the guidelines for design, procurement, installation, and testing 
and the administrative controls for the fire protection systems for safetyrelated areas are satisfied. The QA program should be under the management control of the $Q A$ organization. This control consists of (a) formulating a fire protection QA program that incorporates suitable requirements and is acceptable to the management responsible for fire protection or verifying that the program incorporates suitable requirements and is acceptable to the management responsible for fire protection and (b) verifying the effectiveness of the QA program for fire protection through review, surveillance, and audits. Performance of other $Q A$ program functions for meeting the fire protection program requirements may be performed by personnel outside the $Q A$ organization. The $Q A$ program for fire protection should be part of the averall plant QA program and should be described in the SAR.

4. The SAR should describe the applicant's Emergency Response Plan with respect to fire protection. The need for good organization, training, and equipping of fire brigades at nuclear power plants requires that effective measures be implemented to ensure proper discharge of these functions. The guidance in Regulatory Guide 1.101, "Emergency Planning for Nuclear Power Plants," should be followed as applicable. Successful firefighting requires both proper equipinent and personnel capable of using it efficiently.

a. A program of periodic maintenance and testing of fire protection systems and equipment, including emergency lighting and communication equipment, will ensure the first of these requirements.

b. Basic training is the other necessary element in effective firefighting operation. Such training can only be accomplished by conducting drills and classroom instruction several times a year so that all members of the fire brigade have had the opportunity to train as a team testing itself in the major areas of the plant.

c. To have proper coverage during all phases of operation, members of each shift crew should be trained in fire protection. Training of the plant fire brigade should be coordinated with the iocal fire department so that responsibilities and duties are delineated in advance. This coordination should be part of the training course and should be included in the training of the local fire department staff. The plant fire brigade should not include any of the plant physical security personnel required to be available to fulfill the response requirements of paragraph $73.55(h)(2)$ of 10 CFR Part 73, "Physical Protection of Plants and Materials." Local fire departments should be provided training in operational precautions when fighting fires on nuclear power plant sites and should be made aware of the need for radiological protection of personnel and the special hazards associated with a nuclear power plant site.

\subsubsection{Communication Systems}

9.5.2.1 Design Bases. The design bases for the communication systems for intra-plant and plant-to-offsite communications should be provided and should include a discussion of the use of diverse system types. 
9.5.2.2 System Description. A description and evaluation of the communication systems should be provided. The FSAR should provide a detailed description and drawings.

\subsubsection{Inspection and Testing Requirements. The inspection and} testing requirements for the communication systems should be provided.

\subsubsection{Lighting Systems}

A description of the normal lighting system for the plant should be provided. A description of the emergency lighting system, including design
criteria and a failure analysis, should also be provided.

\subsubsection{Diesel Generator Fuel 0 i] Storage and Transfer System}

9.5.4.1 Design Bases. The design bases for the fuel oil storage and transfer system for the diesel generator should be provided and should include the requirement for onsite storage capacity, capability to meet design criteria (e.g., single-failure criterion), code design requirements,
and environmental design bases.

A description of the diesel generator fuel oil storage and transfer system, including drawings, should be provided in the PSAR. The FSAR should provide a detailed description and drawings.

An evaluation of the fuel 0 il storage and transfer system should be provided and should include the potential for material corrosion and fuel oil contamination, a failure analys is to demonstrate capability to meet design criteria (e.g., single-failure criterion), ability to withstand environmental design conditions, and the plans by which additional oil may be procured, if required.

\subsubsection{Diesel Generator Cooling Water System}

The design bases for the cooling water system should be provided and should include a discussion of the ability to meet the single-failure criterion. A description of the cooling water system, including drawings,
should be provided.

\subsubsection{Diesel Generator Starting System}

The design bases for the starting system, including required system capacity, should be provided and should include a discussion of the ability to meet the single-failure criterion. A description of the starting system, including drawings, should be provided.

\subsubsection{Diese] Generator Lubrication System}

The design bases for the lubrication system should be provided and should include a discussion of the ability to meet the single-failure 
criterion. A description of the lubrication system, including drawings, should be provided.

\subsubsection{Diesel Generator Combustion Air Intake and Exhaust System}

9.5.8.1 Design Bases. This section should provide the design bases for the diesel generator combustion air intake and exhaust system, including the bases for protection from the effects of natural phenomena, missiles, and contaminating substances as related to the facility site, systems, and equipment and the capability of the system to meet minimum safety requirements assuming a single failure. Seismic and quality group classifications should be provided in Section 3.2 and referenced in this section.

9.5.8.2 System Description. A complete description of the system should be provided, including system drawings detailing component redundancy, where required, and showing the location of system equipment in the facility and the relationship to site systems or components that could affect the system.

9.5.8.3 Safety Evaluation. Analyses should be provided to demonstrate that the minimum quantity and oxygen content requirements for intake combustion air will be met considering such effects as recirculation of diesel combustion products, accidental release of gases stored in the vicinity of the diesel intakes, restriction of inlet airflow, intake of such particulates as airborne dust, and low barometric pressure. The results of failure mode and effects analyses to ensure minimum requirements should be provided. If system degradation could result from the consequences of missiles or failures of high- or moderate-energy piping systems located in the vicinity of the combustion air intake and exhaust system, assurance should be provided that such degradation would not jeopardize the system's minimum safety functional requirements.

9.5.8.4 Inspection and Testing Requirements. Inspection and periodic system testing requirements for the diesel generator combustion air intake and exhaust system should be described. 


\section{STEAM AND POWER CONVERSION SYSTEM}

This chapter of the SAR should provide information concerning the plant steam and power conversion system. For purposes of this chapter, the steam and power conversion system (heat utilization system) should be considered to include the following:

1. The steam system and turbine generator units of an indirectcycle reactor plant, as defined by the secondary coolant system, or

2. The steam system and turbine generator units in a direct-cycle plant, as defined by the system extending beyond the reactor coolant system isolation valves.

There will undoubtedly be many aspects of the steam portion of the plant that have little or no relationship to protection of the public against exposure to radiation. The SAR is, therefore, not expected to deal with this part of the plant to the same depth or detail as those features playing a more significant safety role. Enough information should be provided to allow understanding in broad terms of what the secondary plant (steam and power conversion system) is. but emphasis siould be on those aspects of design and operaticn that do or might affect the reactor and its safety features or contribute toward the control of radioactivity. The capability of the system to function without compromising directly or indirectly the safety of the plant under hoth normal operating or transient situations should be shown by the information provided. Where appropriate, the evaluation of radiological aspects of normal operation of the steam and power conversion system and subsystems should be summarized in this chapter and presented in detail in Chapters 11 and 12.

\subsection{Summary Description}

A summary description indicating principal design features of the steam and power conversion system should be provided. An overall system flow diagram and a summary table of the important design and performance characteristics, including a heat balance at rated power and at stretch power, should be provided. The description should indicate those system design features that are safety related.

\subsection{Turbine-Generator}

\subsubsection{Design Bases}

The design bases for the turbine-generator equipment should be provided and should include the performance requirements under normal, upset, emergency, and faulted conditions; intended mode of operation (base loaded or load following); functional limitations imposed by the design or operational characteristics of the reactor coolant system (rate at which electrical load may be increased or decreased with and without reactor control rod motion or steam bypass); and design codes to be applied. 


\subsubsection{Description}

A description of the turbine-generator equipment, including moisture separation, use of extraction steam for feedwater heating, and control functions that could influence operation of the reactor coolant system, should be provided as well as drawings. The turbine-generator-overspeed control system should be described in detail, including redundancy of controls, type of control utilized, overspeed setpoints, and valve actions required for each setpoint.

\subsubsection{Turbine Disk Integrity}

The failure of a turbine disk or rotor might produce a high-energy missile that could damage a safety-related component. This section should provide information to demonstrate the integrity of turbine disks and rotors.

10.2.3.1 Materials Selection. This section should include materials specifications, fabrication history, and chemical analys is of the disk and rotor forgings. Particular attention should be paid to items affecting fracture toughness and metallurgical stability. The mechanical properties of the disk material such as yield strength and fracture toughness should be listed. The methods of obtaining these properties should be described.

10.2.3.2 Fracture Toughness. The criteria used to ensure protection against brittle failure of low-pressure turbine disks should be described. Include detailed information on ductile-brittle transition temperature (NDT or FATT) and minimum operating temperature. If a fracture mechanics approach is used, the analytical method and the key assumptions made should be described.

10.2.3.3 High-Temperature Properties. Provide the stress-rupture properties of the high-pressure rotor material, and describe the method for obtaining these properties.

10.2.3.4 Turbine Disk Design. Provide the following design information for low-pressure disks and high-pressure rotors:

1. The tangential stress due to centrifugal loads, interference fit, and thermal gradients at the bore region at normal speed and design overspeed.

2. The maximum tangential and radial stresses and their location.

10.2.3.5 Preservice Inspection. Describe the preservice inspection procedures and acceptance criteria to demonstrate the initial integrity of the disks and rotors.

10.2.3.6 Inservice Inspection. The inservice inspection program for the turbine assembly and the inspections and tests of the main steam 
stop and control valves and the reheat stop and intercept valves should be described.

\subsubsection{Evaluation}

An evaluation of the turbine-generator and related steam handling equipment should be provided. This evaluation should include a summary discussion of the anticipated operating concentrations of radioactive contaminants in the system, radiation levels associated with the turbine components and resulting shielding requirements, and the extent of access control necessary based on radiation levels and shielding provided.

Details of the radiological evaluation should be provided in Chapters 11 and 12 .

\subsection{Main Steam Supply System}

\subsubsection{Design Bases}

The design bases for the main steam line piping from the steam generator, in the case of an indirect cycle plant, or from the outboard isolation valve, in the case of a direct cycle plant, should be provided and should include performance requirements, environmental design bases, inservice inspection requirements, and design codes to be applied. Capability of the system to dump steam to the atmosphere, if required, should be discussed. Steam lines to and from feedwater turbines should be included in the descriptions.

\subsubsection{Description}

A description of the main steam line piping, including drawings showing interconnected piping, should be provided.

\subsubsection{Evaluation}

An evaluation of the design of the main steam line piping shouid be provided and should include an analysis of the ability to withstand limiting environmental ard accident conditions and provisions for permitting inservice inspections to be performed. Appropriate references should be made to seisnic classifications in Chapter 3 and to the analysis of postulated high-energy line failure in Section 3.6.

\subsubsection{Inspection and Testing Requirements}

The inspection and testing requirements of the main steam line piping should be described. Describe the proposed requirements for preoperational and inservice inspection of steam line isclation valves or reference other sections of the SAR where these are described. 


\subsubsection{Water Chemistry (PWR)}

The effect of the water chemistry chosen on the radioactive iodine partition coefficients in the steam generator and air ejector should be discussed.

Detailed information on the secondary-side water chemistry, including methods of treatment for corrosion control and proposed specification limits should be provided. Discuss methods for monitoring and controlling water chemistry.

\subsubsection{Steam and Feedwater System Materials}

This section should provide the information indicated below on the materials used for Class 1,2 , and 3 components.

10.3.6.1 Fracture Toughness. Indicate the degree of compliance with the test methods and acceptance criteria of the ASME Code Section III in Articles NB-2300, NC-2300, and ND-2300 for fracture toughness: for ferritic materials used in Class 1,2 , and 3 components.

10.3.6.2 Materials Selection and Fabrication. Information on materials selection and fabrication methods used for Class 1,2 , and 3 components should include the following:

1. For any material not included in Appendix I to Section III of the ASME Code or in Regulatory Guide 1.85, "Materials Code Case Acceptability-ASME Section III Division 1, "provide the data called for under Appendix IV for approval of new materials. The use of such materials should be justified.

2. For austenitic stainless steel components, the degree to which the recommendations of Regulatory Guide 1.44, "Control of the Use of Sensitized Stainless Steel;" Regulatory Guide 1.36, "Nonmetallic Thermal Insulation for Austenitic Stainless Steel;" and Regulatory Guide 1.31, "Control of Ferrite Content in Stainless Steel Weld Metal," are followed should be indicated. Justification for any deviations from the procedures shown in these guides should be provided.

3. Information on the cleaning and handling of all Class 1,2 , and 3 components should be provided. The degree to which the recommendations of Regulatory Guide 1.37, "Qual ity Assurance Requirements for Cleaning of Fluid Systems and Associated Components of Water-Cooled Nuclear Power Plants, "and ANSI N45.2.1-73, "Cleaning of Fluid Systems and Associated Components During Construction Phase of Nuclear Plānts," are followed should be indicated. Justification for any deviations from the position in these documents should be provided.

4. Indicate whether the preheat temperatures used for welding lowalloy steel are in accordance with Regulatory Guide 1.50, "Control of Preheat Temperature for Welding of Low-Alloy Steel." Justification for any deviations from the procedures shown in this guide should be provided. 
For carbon steel materials, indicate whether the preheat temperatures are in accordance with Section III, Article D-1000, of the ASME Boiler and Pressure Vessel Code. The use of alternative procedures should be justified.

5. For all applicable components, the degree to which the recommendations of Regulatory Guide 1.71, "Welder Qualification for Areas of Limited Accessibility," are followed should be indicated. Justification for any deviations from the procedures given in this guide should be provided.

6. Indicate that the nondestructive examination procedures used for the examination of tubular products conform to the requirements of the ASME Boiler and Pressure Vessel Code. Provide justification for deviations from these requirements.

\subsection{Other Features of Steam and Power Conversion System}

This section of the SAR should provide discussions of each of the principal design features and subsystems of the steam and power conversion system. Because these systems vary in number, type, and nomenclature for various plant designs, the Standard Format does not assign specific subsection numbers to these systems. The applicant should provide separate subsections (numbered 10.4.1 through 10.4.X) for each. These subsections should provide the following information:

1. Design bases,

2. System description,

3. Safety evaluation,

4. Tests and inspections, and

5. Instrumentation applications for each subsystem or feature.

The following paragraphs provide examples of subsystems and features that should be discussed, as appropriate to the individual plant, and identify some specific information that should be provided in addition to the items identified above.

\subsubsection{Main Condensers}

The description of the main condensers should include performance requirements, materials of construction, methods used to reduce the probability of corrosion and/or erosion of tubes and components, anticipated inventory of radioactive contaminants during power operation and during shutdown, anticipated air leakage limits, control functions that could influence operation of the primary reactor coolant or secondary systems, potential for hydrogen buildup, and provisions for protection of safetyrelated equipment from flooding as a result of failure of the condenser. 
The description should also include the methods used to detect the ieakage of cooling water into the condensate, the contaminants allowed in the condensate, the procedure to repair condensate leaks, and the length of time the condenser may operate with degraded conditions without affecting the condensate/feedwater quality for safe operation.

\subsubsection{Main Condenser Evacuation System}

The description of the evacuation systems for the main condensers should include performance requirements for startup and normal operation, lanticipated release rates of radioactive materials, evaluation of the capability to limit or control loss of radioactivity to the environment, and control functions that could influence operation of the reactor coolant system. Describe any design features that preclude the existence of explosive mixtures. Details of the radiological evaluation should be provided in Chapter 11.

\subsubsection{Turbine Gland Sealing System}

The discussion of the turbine gland seailing system should include identification of the source of noncontaminated steam, a description of potential radioactivity leakage to the environment in the event of a malfunction, and discussion of the means to be used to monitor system performance. The inspection and testing requirements should be described. The evaluation of the estimate of potential radioactivity leakage to the environment in the event of a malfunction of the turbine gland sealing system should be provided in Chapter 15. Details of the radiological evaluation should be provided in Chapter 11.

\subsubsection{Turbine Bypass System}

The design bases for the turbine bypass system should include performance requirements, capability to meet design criteria, design codes to be applied, and environmental criteria. The evaluation of the turbine bypass system should include a failure analysis to determine the effect of equipment malfunctions on the reactor coolant system.

\subsubsection{Circulating Water System}

The description of the circulating water system shouid include discussion of performance requirements; dependence on the system for cooling during shutdown; anticipated operational occurrences and accidents; control of the circulating water chemistry, corrosion, and organic fouling; environmental influences; and potential interaction of cooling towers, if any, with the plant structure. The potential for flooding safety-related equipment due to the failure of a system component such as an expansion joint should be discussed. References to paragraphs 2.4 .11 .5 and 2.4 .11 .6 should be provided, where applicable. 


\subsubsection{Condensate Cleanup System}

The design bases for the condensate cleanup system should include the fraction of condensate flow to be treated, impurity levels to be maintained, and design codes to be applied. The evaluation of the condensate cleanup system should include an analysis of demineralizer capacity and anticipated impurity levels, an analys is of the contribution of impurity levels from the secondary system to reactor coolant system activity levels, and performance monitoring. Provisions for the control of chloride ion and other contaminants should be described.

\subsubsection{Condensate and Feedwater Systems}

The design bases for the condensate and feedwater systems should include design codes to be applied, criteria for isolation from the steam generator or reactor coolant system, supply of condensate available for emergency purposes, inservice inspection requirements, and environmental design requirements. The evaluation of the condensate and feedwater systems should include an analysis of component failure, effects of equipment malfunction on the reactor coolant system, and an analys is of isolation provisions to preclude release of radioactivity to the environment in the event of a pipe leak or break.

Provide the following intormation with reference to fluid flow instabilities, e.g., water hammer, for steam generators using top feed:

1. A description of normal operating transients that could cause the water level in the steam generator to drop below the sparger or cause the nozzles to uncover and al low steam to enter the sparger and feedwater piping.

2. A summary of the criteria for routing or isometric drawings showing the routing of the feedwater piping system from the steam generators to the restraint that is closest, on the upstream side, to the feedwater isolation valve that is outside containment.

3. A description of the piping system analyses, including any forcing functions, or the result of test programs performed to verify that uncovering of feedwater lines could not occur or that such uncovering would not result in unacceptable damage to the system. A summary of relevant water hammer experience is provided in NUREG-0291, "An Evaluation of PWR Steam Generator Water Hammer."

\subsubsection{Steam Generator Blowdown System (PWR)}

10.4.8.1 Design Bases. This section should provide the design bases for the steam generator blowdown system (SGBS) in terms of its ability to maintain optimum secondary-side water chemistry in recirculating steam generators of PWRs during normal operation, including anticipated opera: tional occurrences (main condenser inleakage and primary-to-secondary leakage). The design bases should include consideration of expected and 
design flows for all modes of operation (process and process bypass), process design parameters and equipment design capacities, expected and design temperatures for temperature-sensitive treatment processes (demineralization and reverse osmosis), and process instrumentation and controls for maintaining operations within established parameter ranges.

Seismic and quality group classifications of the SGBS should be provided in Section 3.2 and referenced in this section.

10.4.8.2 System Description and Operation. A detailed description of the SGBS, including component description, piping and instrumentation diagrams, process flow diagrams, and equipment general arrangement drawings (reference may be made to pertinent information in Section 11.2), should be provided. Discuss the operating procedures and the processing to be provided for all anticipated modes of operation, including system or process bypass, significant primary-to-secondary leakage, and main condenser inleakage.

Discuss the instrumentation and controls provided to protect temperature-sensitive elements (demineralizer resins or reverse osmosis membranes) and to control flashing, liquid levels, and process flow through system components. The radioactive waste treatment and process and effivent radiological monitoring aspects of the SGBS should be described in Sections 11.2, 11.3, 11.4, and 11.5.

10.4.8.3 Safety Evaluation. The interfaces between the SGBS and other plant systems should be discussed. Unusual design conditions that could lead to safety problems should be identified and evaluated. Provide a failure mode and effects analys is of any interactions that may incapacitate safety-related equipment. Provide coolant chemistry specifications to demonstrate compatibility with primary-to-secondary system pressure boundary material. The bases for the selected chemistry limits should be included. (Information provided in Section 5.4 .2 may be referenced.)

10.4.8.4 Tests and Inspections. The inspection and periodic testing requirements for the SGBS should be described.

\subsubsection{Auxiliary Feedwater System (PWR)}

10.4.9.1 Design Bases. This section should provide the design bases for the auxiliary feedwater system in terms of the safety-related functional performance requirements of the system, including the required pumping capacities of the pumps, diversity of power supplied to the system pumps and system control valves, capabilities of the pumps (head/flow) with respect to supply requirements of the steam generator, and the auxiliary feedwater supply capacity requirements for makeup during maximum hot standby conditions and for cold shutdown of the facility following a reactor trip or accident condition; requirement for the system's ability to withstand adverse environmental occurrences and the effects of pipe breaks; requirement of the system to perform its safety-related function in the 
event of a single failure coincident with pipe breaks, environmental occurrences, and the loss of offsite power and/or the standby a.c. power system. The means by which the system is protected from the effects of hydraulic instability (water hammer) or the design considerations precluding the occurrence of hydraulic instability should be provided.

Seismic and quality group classification should be provided in Section 3.2 and referenced in this section.

10.4.9.2 System Description. A detailed description of the auxiliary feedwater system should be provided, including piping and instrumentation diagrams, system drawings, and the location of components in the station complex. The description and drawings should also include subsystems, system interactions, components utilized, piping connection points, instrumentation and controls utilized, and system operations, i.e., system function during normal operations and the minimum functional conditions of the system in the event of pipe breaks, loss of main feedwater system, or loss of offsite power. The information should also state the maximum length of time the plant could do without normal feedwater and the minimum auxiliary feedwater flow rate required after this time period (i.e., pumps started and control valves open) for these conditions.

10.4.9.3 Safety Evaluation. An evaluation of the capability of the auxiliary feedwater system should include (either in this section or by reference) the means by which protection from postulated failures of high- and moderate-energy systems is accomplished for the system and auxiliary supporting systems and the means by which the system is capable of withstanding the effects of site-related natural phenomena. Failure mode and effects analyses should be provided that ensure minimum safety requirements are met assuming a postulated pipe failure concurrent with a single active component failure in any system required to ensure performance of the auxiliary feedwater system. An analys is should demonstrate the capability of the system to preclude hydraulic instabilities (characterized as water hammer) from occurring for all modes of operation.

An analysis or analyses to demonstrate the system's capability to perform its safety function when subjected to a combination of environmental occurrences, environmental conditions, pipe treak, and loss of power during normal and accident conditions should be performed. In addition, an analysis should be performed to demonstrate the system's capability to perform its safety function utilizing diverse power sources to ensure system operability without reliance on a.c. power.

10.4.9.4 Inspection and Testing Requirements. The inspection and periodic testing requirements for the auxiliary feedwater system should be described.

10.4.9.5 Instrumentation Requirements. The system instrumentation and controis should be described. The adequacy of safety-related instrumentation and controls to fulfill their functions should be demonstrated. 


\section{RADIOACTIVE WASTE MANAGEMENT}

This chapter should describe:

1. The capabilities of the plant to control, collect, handle, process, store, and dispose of liquid, gaseous, and solid wastes that may contain radioactive materials, and

2. The instrumentation used to monitor the release of radioactive wastes.

The information should cover normal operation, including anticipated operational occurrences (refueling, purging, equipment downtime, maifitenance, etc.). The proposed radioactive waste (radwaste) treatment systems should have the capability to meet the requirements of 10 CFR Parts 20 and 50 and the recommendations of appropriate regulatory guides concerning system design, control and monitoring of releases, and maintaining releases of radioactive materials at the "as low as is reasonably achievable" level in accordance with Appendix I to 10 CFR Part 50.

\subsection{Source Terms}

The PSAR should indicate the sources of radioactivity that serve as design bases for the various radioactive waste treatment systems for normal operation, including anticipated operational occurrences, as well as for design conditions. The parameters used to determine the specific activity of each radioisotope in the primary and secondary (PWR) coolant should be described and all assumptions justified.

The PSAR should provide the concentrations of fission, activation, and corrosion products used in the source term calculations and their bases. The activation of water and constituents normally found in the reactor coolant system should also be taken into account. The source of each isotope (e.g., C-14, Ar-41) should be identified and the concentration of each isotope indicated. Provide the basis for the values used. Previous pertinent operating experience should be cited.

Mathematical models and parameters used to calculate source terms for normal operation, including anticipated operational occurrences, should be provided.

For the purpose of evaluating the adequacy of various ventilation systems, provide in the PSAR estimates of the leakage rate from the reactor coolant system and other fluid systems containing radioactivity into individual cubicles and areas that may require access by operating personnel. Tabulate the sources of leakage. Estimates of the releases of radioactive gases and radioiodines from each leakage source and their subsequent transport and release path should be provided. The basis for the values used should be indicated. Cite previous pertinent experience from operating reactors. Discuss leakage measurements and special design features to 
reduce leakage. The principal discussions of coolant leakage in other sections of the SAR should be referenced.

The PSAR should identify all sources of releases of radioactive materia) that are not normally considered part of the radioactive waste management systems, e.g., the steam generator blowdown system, building ventilation exhaust systems, containment purging, and the turbine gland seal system. Estimates of the release of radioactive materials (by radionuclide) from each source identified and the subsequent transport mechanism and release path should be provided. Identify planned operations, including anticipated operational occurrences, that may result in release of radioactive materials to the environment. Consider leakage rates and concentrations of radioactive materials for both expected and design conditions. The bases for all values used should be provided. Describe changes from previous designs that may affect the release of radioactive materials to the environment.

The FSAR should provide additional information required to update the PSAR to the final design conditions.

\subsection{Liquid Waste Management Systems}

This section should describe the capabilities of the plant to control, collect, process, handle, store, and dispose of liquid radioactive waste generated as the result of normal operation, including anticipated operational occurrences. Process and effluent radiological monitoring and sampling systems should be described in Section 11.5 .

\subsubsection{Design Bases}

The PSAR should provide the design objectives and design criteria for the liquid radioactive waste handling and treatment systems in terms of expected annual quantities of radioactive material (by radionuclide) released, averaged over the life of the plant, and the expected doses to individuals at or beyond the site boundary. An evaluation should be included to show that the proposed systems are capable of controlling releases of radioactive materials within the numerical design objectives of Appendix I to 10 CFR Part 50 . The evaluation should also show that the proposed systems contain all items of reasonably demonstrated technology that, when added to the system and in order of diminishing costbenefit return, can for a favorable cost-benefit ratio effect reductions in dose to the population reasonably expected to be within 50 miles of the reactor. All assumptions should be provided and the calculational methods should be shown. An evaluation should be provided to show that the proposed systems have sufficient capacity, redundancy, and flexibility to meet the concentration limits of 10 CFR Part 20 during periods of equipment downtime and during operation at design basis fuel leakage (i.e., leakage from fuel producing 1 percent of the reactor power for a PWR or fuel having a noble gas release rate of $100 \mu \mathrm{Ci} / \mathrm{sec}$ per wht after a 30 minute decay for a BWR). 
A tabulation showing the liquid radwaste system components and their design parameters, e.g., flow, temperature, pressure, and materials of construction, should be provided. An evaluation indicating the capabilities of the system to process surge waste flows associated with anticipated operational occurrences such as anticipated waste flows from backto-back refueling and equipment downtime should be included.

The seismic design criteria and analytical procedures for structures housing the liquid ractwaste components should be provided along with the quality group classification for the liquid radwaste components and piping. Seismic and quality group classifications provided in Section 3.2 may be incorporated by reference. The PSAR should describe how the requirements of General Design Criteria 60 and 64 of Appendix A to 10 CFR Part 50 will be implemented.

Design features incorporated to reduce maintenance, equipment downtime, liquid leakage, or gaseous releases of radioactive materials to the building atmosphere or to facilitate cleaning or otherwise improve radwaste operations should be described.

The design provisions incorporated to control the release of radioactive materials due to overflows from all liquid tanks outside containment that could potentially contain radioactive materials should be described. Discuss the effectiveness of both the physical and the monitoring precautions taken, e.g., dikes, level gauges, and automatic diversion of wastes from tanks exceeding a predetermined level. The potential for operator error or equipment malfunctions (single failures) to result in uncontrolled releases to the environment should be discussed. Describe the design provisions and controls provided to preclude inadvertent or uncontrolled releases of radioactivity to the environs. Process and effluent radiological monitoring systems should be described in Section 11.5.

The FSAR should provide any additional information required to update the PSAR to the final design conditions.

\subsubsection{System Description}

The PSAR should include a description of each liquid waste subsystem and the process flow diagrams indicating processing equipment, normal process routes, equipment capacities, and redundancy in equipment. For multi-unit stations, those subsystems that are shared should be indicated. All equipment and components that will normally be shared between subsystems should be identified. Indicate the processing to be provided for all liquid radwastes, including turbine building floor drains and steam generator blowdown liquids (PWR).

For each subsystem, tabulate or show on the flow diagrams the maximum and expected inputs in terms of flow (gal/day per reactor) and radioactivity (fraction of primary coolant activity) for normal operation, including anticipated operational occurrences. The bases for the values used should be provided. 
The segregation of liquid waste streams based on conductivity, radioactivity, and chemical composition, as appropriate, should be described. Indicate all potential bypass routes, the conditions governing their use, and their anticipated frequency of bypass due to equipment downtime. The piping and instrumentation diagrams (P\&IDs) should indicate system interconnections and seismic and quality group interfaces.

The location of secondary flow paths for each system should be indicated. The normal operation of each system and differences in system operation during anticipated operational occurrences such as startups, shutdowns, and refueling should be described.

The FSAR shouid provide any additional information required to update the PSAR to the final design conditions.

\subsubsection{Radioactive Releases}

The PSAR should provide the criteria for determining whether processed liquid wastes will be recycled for reuse or further treatment or discharged to the environment. Discuss the influence the plant water balance (requirements) and the expected tritium concentrations in process streams will have on the release parameters assumed.

The parameters and assumptions used to calculate releases or radioactive materials in liquid effluents and their bases should be provided. Provide the expected releases of radioactive materials (by radionuclides) in liquid effluents resulting from normal operation, including anticipated operational occurrences, and from design bases fuel leakage in $\mathrm{Ci} / \mathrm{yr}$ per reactor.

Tabulate the releases by radionuclide for each subsystem and for the total system, and indicate the effluent concentrations. The calculated effluents should be compared with the concentration limits of 10 CFR Part 20, Appendix B, Table II, Column 2; the doses due to the effluents should be compared with the numerical design objectives of Appendix I to 10 CFR Part 50 and the dose limits of 10 CFR Part 20 . Identify all release points for liquid wastes and the dilution factors considered in the evaluation.

The FSAR should provide any additional information required to update the PSAR to the final design conditions.

\subsection{Gaseous Waste Management Systems}

This section should describe the capabilities of the plant to control, collect, process, handle, store, and dispose of gaseous radioactive waste generated as the result of normal operation and anticipated operational occurrences. Process and effluent radiological monitoring systems should be described in Section 11.5. 
In this section, the term "gaseous waste systems" is applied to all plant systems that have a potential to release radioactive materials in gaseous effluent to the environment, including building ventilation systems. Gaseous wastes include noble gases, halogens, tritium, argon-41, carbon-14, and radioactive material in particulate form.

\subsubsection{Design Bases}

The PSAR should provide the design objectives and design criteria for the gaseous radioactive waste handling and treatment systems in terms of expected annual quantities of radioactive material (by radionuclide) released, averaged over the life of the plant, and expected doses to individuals at or beyond the site boundary. An evaluation should be provided to show that the proposed systems are capable of controlling releases of radioactive materials within the numerical design objectives of Appendix I to 10 CFR Part 50. The evaluation should also show that the proposed systems contain all items of reasonably demonstrated technology that, when added to the system and in order of diminishing cost-benefit return, can for a favorable cost-benefit ratio effect reductions in dose to the population reasonably expected to be within 50 miles of the reactor. All assumptions should be provided and the calculational methods should be shown. An evaluation should be provided to show that the proposed systems have sufficient capacity, redundancy, and flexibility to meet the concentration limits of 10 CFR Part 20 when operating at design basis fuel leakage (i.e., leakage from fuel producing 1 percent of the reactor power for a PWR or fuel having a noble gas release rate of $100 \mu \mathrm{Ci} / \mathrm{sec}$ per wt after a 30-minute decay for a BWR).

The gaseous radwaste system components and their design parameters, e.g., flow, temperature, pressure, and materials of construction, should be listed. Provide an evaluation indicating the capabilities of the system to process surges in waste fiows associated with anticipated operational occurrences such as cold startups, shutdowns, purging of containment, back-to-back refueling, and equipment downtime.

The seismic design criteria and analytical procedures for equipment support elements and structures housing the gaseous waste treatment system should be provided along with the quality group classification for the gaseous waste treatment components and piping. The PSAR should describe how the requirements of General Design Criteria 50 and 64 of Appendix A to 10 CFR Part 50 will be implemented.

Design features incorporated to reduce maintenance, equipment downtime, leakage, and gaseous releases of radioactive materials to the building atmosphere or to facilitate cleaning or otherwise improve radwaste operations should be described.

The design provisions incorporated to control the release of radioactive materials in gaseous effluents as the result of equipment malfunction or operator error should be described. Discuss the effectiveness of monitoring precautions taken, i.e.s automatic termination of waste 
release from waste gas storage tanks when the release exceeds a predetermined level. The potential for an operator error or equipment malfunction (single failures) that may result in uncontrolled releases of radioactivity to the environment should be discussed. Process and effluent radiological monitoring systems should be described in Section 11.5.

The design objectives of the plant ventilation systems for normal and emergency operation, including anticipated operational occurrences, should be described with respect to meeting the requirements of $10 \mathrm{CFR}$ Parts 20 and 50.

For systems where the potential for an explosion exists, any equipment that is not designed to withstand the pressure peak of the explosion should be identified and justification provided. Process instrumentation (including gas analyzers) and design features provided to prevent explasions should be described along with provisions to ensure that seals will not be permanently lost following an explosion.

The FSAR should provide any additioral information required to update the PSAR to the final design conditions.

\subsubsection{System Description}

The PSAR should include a description of each gaseous waste subsystem and the process flow diagrams indicating processing equipment, normal flow paths through the system, equipment capacities, and redundancy in equipment. For multi-unit stations, those subsystems that are shared should be indicated. All equipment and components that will normally be shared between subsystems should be identified. For each subsystem, tabulate or show on the flow diagrams the maximum and expected inputs in terms of flow and radioactivity content for normal operation, including anticipated operational occurrences. The bases for the values used should be provided. Indicate the composition of carrier and blanket gases, and describe the segregation of streams containing hydrogen, if appropriate.

The piping and instrumentation diagrams should indicate system interconnections and seismic and quality group interfaces. Instrumentation and controls that govern the operation should be described. Indicate all potential bypasses of normal process routes, the conditions governing their use, and the anticipated frequency of bypass due to equipment downtime. Provide the location of liquid seals, show them on the P\&IDs, and describe how blown seals will be automatically reestablished. The location of vents and secondary flow paths for each system should be indicated. Describe both the normal operation of each system and the differences in system operation during anticipated operational occurrences such as startups, shutdowns, refueling, and purging of containment.

The ventilation system for each building that can be expected to contain radioactive materials should be described. Include building volumes, expected flow rates from buildings and equipment cubicles, filter characteristics, and the design criteria on which these are based. Describe 
both the normal operation of each ventilation system and the differences in operation during anticipated operational occurrences such as startup, shutdown, and refueling. Chapter 9 should be referenced, as appropriate. The FSAR should provide a tabulation showing the calculated concentrations of airborne radioactive material (by radionuclide) expected during normal and anticipated operational occurrences for equipment cubicles, corridors, and areas normally occupied by operating personne?.

The subsystems in the steam and power conversion systems that are potential sources of gaseous radioactive effluents should be described. Examples of such systems are the turbine gland sealing systems and the main condenser vacuum system. Provide the flow rates and concentrations of radioactive materials (by radionuclide) through these systems during normal operations and anticipated operational occurrences. The bases for the values used should be provided. Tabulate the expected frequency and quantity of steam released during steam dumps to the atmosphere (PWR) or pressure relief valve venting to the suppression pool (BWR). The bases for the values used should be provided. Other sections of the SAR should be referenced, as appropriate.

The FSAR should provide any additional information required to update the PSAR to the final design conditions.

\subsubsection{Radioactive Releases}

The PSAR should provide the criteria to be used for releasing gaseous wastes and the acceptable release rates.

The parameters and assumptions used in calculating releases of radioactive materials in gaseous effluents and their bases should be provided. Provide the expected releases of radioactive materials (by radionuclides) in gaseous effluents resulting from normal operation, including anticipated operational occurrences, in $\mathrm{Ci} / \mathrm{yr}$ per reactor.

Tabulate the peleases by radionuclide for each subsystem and for the total system, and indicate the effluent concentrations. The calculated effluents should be compared with the concentration limits of 10 CFR Part 20, Appendix B, Table II, Column 1 ; the doses due to the effluents should be compared with the numerical design objectives of Appendix I to 10 CFR Part 50 and the dose limits of 10 CFR Part 20. The dilution factors considered in the evaluation should be indicated.

Identify all release points of gaseous waste to the environment on process flow diagrams, general arrangement drawings, or a site plot plan.

For release points, give:

1. Height of release,

2. Inside dimensions of release point exit, 
3. Effluent temperature, and

4. Effluent exit velocity.

The FSAR should provide any additional information required to update the PSAR to the final design conditions.

\subsection{Solid Waste Management System}

This section should describe the capabilities of the plant to control, coilect, handle, process, package, and temporarily store prior to shipment wet and dry solid radioactive waste generated as a result of normal operation, including anticipated operational occurrences. In this section, the term "solid waste management system" means a permanently installed system. Process and effluent radiological monitoring systems should be described in Section 11.5.

\subsubsection{Design Bases}

The PSAR should provide the design objectives and design criteria for the solid radioactive waste handling and treatment system in terms of the types of wastes, the maximum and expected volumes to be handled, and the isotopic and curie content. The seismic design criteria and analytical procedures for structures housing the solid radwaste system should be provided along with the quality group classification for the solid radwaste components and piping. Seismic and quality group classifications provided in Section 3.2 may be incorporated by reference. Indicate how the requirements of 10 CFR Parts 20,50, and 71 , and applicable DOT regulations will be implemented.

The FSAR should provide any additional information required to update the PSAR to the final design conditions.

\section{I1. 4.2 System Description}

The PSAR should describe the wet solid waste subsysiem to be used for processing ion exchange resins, filter sludges, evaporator bottoms, and miscellaneous liquids. List the system components (evaporator concentrates, sludges tanks, phase separator tanks, etc.). Their design capacity and materials of construction should be indicated. In the PSAR, tabulate the maximum and expected waste inputs, their physical form (resin, sludge, etc.), sources of waste, volume per batch, and isotopic composition. The bases for the values used should be provided. Describe the method to be used for solidifying each waste type, the type of container in which the wastes will be packaged, and the means to be used to ensure the absence of free liquid in the waste containers, including in the FSAR the process

control program to ensure a solid matrix.

Process flow diagrams indicating the normal process route, flow rates, equipment holdup times, expected isotopic content of each flow, and equipment capacities should be provided. Describe the instrumentation and controls 
used for process control. Provide the piping and instrumentation diagrams that show system interconnections and seismic and quality group interfaces. Describe the design provisions incorporated to control the release of radioactive materials due to overflows from tanks containing liquids, sludges, and spent resins. Identify a 11 tanks or equipment that use compressed gases for any function and provide information as to the gas flow rate volume per operation, expected number of operations per year, expected radionuclide concentration of offgases, treatment provided, and interfaces with ventilation exhaust systems. Discuss the effectiveness of the physical and monitoring precautions taken (e.g., retention basins, curbing, and level gauges). The potential for operator errors or equipment malfunctions (single failures) that may result in uncontrolled releases of radioactive material should be discussed.

Describe the dry solid waste subsystem to be used for processing dry filter media (ventilation filters); contaminated clothing, equipment, tools, and glassware; and miscellaneous radioactive wastes that are not amenable to solidification prior to packaging. Tabulate the maximum and expected waste inputs in terms of type (filters, tools, etc.), sources of waste, volume, and isotopic and curie content. The bases for the values used should be provided. Describe the method of packaging and equipment to be used. The provisions to be used to control airborne radioactivity due to dust during compaction and baling operations should be described. Discuss the methods of handling and packaging large waste materials and equipment that has been activated during reactor operation (e.g., core components).

Describe the containers to be used for packaging wastes and indicate their compliance with applicable Federal regulations. Provisions for sealing, decontaminating, and moving the containers to storage and to shipping areas should be discussed along with the potential for radioactive spills due to dropping containers from cranes, monorails, etc. Describe provisions for collecting and processing decontamination i iquids and spillage. The provisions for waste storage prior to shipping, including the storage capacity and the expected onsite storage time should be described. Layout drawings of the packaging, storage, and shipping areas should be provided.

The maximum and expected annual volumes and the curie and isotopic content of wastes to be shipped offsite for each waste category should be indicated.

The FSAR should provide any additional information required to update the PSAR to the final design conditions.

\subsection{Process and Effluent Radiological Monitoring and Sampling Systems}

This section should describe the systems that monitor and sample the process and effluent streams in order to control releases of radioactive materials generated as the result of normal operations, including 
anticipated operational occurrences, and during postulated accidents. The process sampling system should be described in Section 9.3.2.

\subsubsection{Design Bases}

The PSAR should inciude the design objectives and design criteria for the process and effluent radiological monitoring systems and the sampling systems in relation to the requirements of 10 CFR Parts 20 and 50 . Indicate whether, and if so how, the guidance of Regulatory Guide 1.21, "Measuring, Evaluating, and Reporting Radioactivity in Solid Wastes and Releases of Radioactive Materials in Liquid and Gaseous Effluencs from Light-WaterCooled Nuclear Power Plants," will be followed; if it will not be followed, the specific alternative approaches to be used should be described. For the effluent monitoring system, distinguish between the design objectives for normal operations, including anticipated operational occurrences, and the design objectives for monitoring postulated accidents.

The FSAR should provide any additional information required to update the PSAR to the final design conditions.

\subsubsection{System Description}

Provide system descriptions for radiation detectors and samplers used to monitor and control releases of radioactive materials generated as the result of normal operations, including anticipated operational occurrences, and during postulated accidents.

For continuous process and effluent radiation monitors, provide the following information:

1. Location of monitors,

2. Type of monitor, sensitivity, ${ }^{\star}$ and measurement made (e.g., gross, $\beta-\gamma$, or isotopic analysis),

3. Instrumentation, redundancy, independence, and diversity of the components supplied,

4. Range of radioactivity concentrations to be monitored and bases for range provided,

5. Types and locations of annunciators, alarms, and automatic controls and actions initiated by each, *

6. Provisions for emergency power supplies, chosen, * and

7. Setpoints for alarms and controls and bases for values

FSAR only. 
8. Description of provisions for radiological monitoring instrument calibration, maintenance, inspection, decontamination, and replacement.*

For each location subject to routine sampling, indicate whether, and if so how, the guidance of Regulatory Guide 1.21 will be followed; if it will not be followed, the specific alternative approaches to be used should be described. The following information should be provided:

1. Basis for selecting the location,

2. Expected flow, comprsition, and concentrations, trations),

3. Quantity to be measured (e.g., gross, $\beta-\gamma$, or isotopic concen-

4. Sampling frequency, type of sample nozzle or other sample equipment, and procedures used to obtain representative samples, ${ }^{\star}$ and

5. Analytical procedure and sensitivity. *

\subsubsection{Effluent Monitoring and Sampling}

Indicate how the requirements of General Design Criterion 64 will be implemented with respect to effluent discharge paths for radioactivity that may be released from normal operations, including anticipated operational occurrences, and from postulated accidents.

\subsubsection{Process Monitoring and Sampling}

Indicate how the requirements of General Design Criterion 60 will be implemented with respect to the automatic closure of isolation valves in gaseous and liquid effluent discharge paths. Indicate how the requirements of General Design Criterion 63 will be implemented with respect to the monitoring of radiation levels in radioactive waste process systems.

FSAR only. 